MARIA FERNANDA DE MATOS MALUF

O perfil da sexualidade em mulheres com câncer de mama

SÃo PAULO

2008 
MARIA FERNANDA DE MATOS MALUF

O perfil da sexualidade em mulheres com câncer de mama

Dissertação apresentada à Faculdade de Medicina da Universidade de São Paulo, para a obtenção do título de Mestre em Ciências

Área de concentração: Obstetrícia e Ginecologia Orientador: Profa . Dra . Elsa Aida Gay Pereyra 


\section{DEDICATÓRIA}

A meus pais pelo incentivo e por todo amor.

A meu namorado, seus pais e irmãs por todo amor, carinho e incentivo.

In memorian de meus avós, meus tios e meus amigos que se foram.

In memorian de M. I.S., que desde o inicio da descoberta de sua doença enfrentou-a corajosamente, continuando a viver com intensidade sua vida, sem temer a morte.

O câncer de mama a levou, mas os ensinamentos de vida que me proporcionou foram o bem maior que alcancei nesta pesquisa.

A todas as mulheres. 


\section{AGRADECIMENTOS}

Primeiramente, gostaria de agradecer a minha orientadora, $\operatorname{Prof}^{a} \operatorname{Dr}^{\mathrm{a}}$ Elsa Aida Gay Pereyra pela atenção e profissionalismo que me dispensou durante estes anos.

A meu co-orientador, Prof. Dr. Alfredo Carlos Simões Dornellas de Barros pelo carinho, apoio e orientação que possibilitou a realização desta pesquisa no Núcleo de Filantropia em Mastologia do Hospital Sírio Libanês e pelo reconhecimento de meu trabalho junto a seus Residentes, através do exercício da Docência.

A meu co-orientador, Prof. Dr. Marco de Tubino Scanavino, pelo carinho, apoio, parceria e orientação frente às questões psicológicas e psiquiátricas envolvidas nesta pesquisa, e por todas as oportunidades oferecidas ao longo desses anos no Projeto Sexualidade Humana (Prosex Ipq FMUSP), com o exercício da Docência junto aos alunos da Graduação na Disciplina Optativa de Sexualidade Humana e seus Transtornos.

À Prof ${ }^{a}$ Dra $^{a}$ Carmita Helena Najjar Abdo, que apoiou esta pesquisa desde seus primórdios no Curso de Especialização em Sexualidade Humana FMUSP, e pela oportunidade dada em compor a equipe do Prosex IPq HC FMUSP.

À Dra Cleusa Kazue Sakamoto, por sua excelente orientação em minha banca de qualificação, por sua amizade e por seus ensinamentos durante minha formação como Psicóloga e após, nas Iniciações Científicas. 
Ao Prof. Dr. Roberto Hegg e Dr Ciro Vieira pelos direcionamentos pontuais realizados em minha banca de qualificação.

À Prof ${ }^{a} \operatorname{Dr}^{a}$ Angela Maggio da Fonseca, pela preciosa assistência, incentivo constante, atenção e disponibilidade durante o processo de confecção desta Dissertação; também pelo seu carinho e atenção desde o momento em que iniciei meus trabalhos e estudos em Mastologia na Clínica Ginecológica, na época apenas para coletar dados referentes à minha Especialização.

À Prof ${ }^{a}$ Dr $^{a}$ Julieta Quayle, que viabilizou a condução administrativa do projeto de pesquisa junto à Diretoria do Departamento de Psicologia.

Ao Dr. Lincon Jo Mori, amigo e Mestre, sempre solícito e disponível, que desde o início de meus estudos sobre sexualidade e mastectomia radical, sempre acreditou na importância do aprofundamento dos conhecimentos nesta área, para a promoção da saúde integral da mulher.

Ao Consultor Estatístico Fabrício Saad Duarte, que com seu profissionalismo e excelente suporte e orientação estatísticas tornou viável o desenho metodológico e a execução desta pesquisa com excelência.

A todas as pacientes e seus maridos pela disposição em participar desta pesquisa, compartilhando suas experiências de vida para o crescimento do conhecimento a cerca da sexualidade em mulheres brasileiras com câncer de mama, submetidas à mastectomia radical.

Ao CNPQ pela concessão da bolsa de pesquisa que viabilizou esta pesquisa.

Por último, mas não menos importante, a toda equipe da Clínica Ginecológica da FMUSP e do Serviço de Biblioteca e Documentação da FMUSP pelo prestimoso auxílio, carinho, apoio e credibilidade. 
Esta Dissertação está de acordo com as seguintes normas, em vigor no momento desta publicação:

Referências: Adaptado de International Committee of Medical Journals Editors (Vancourver). Universidade de São Paulo. Faculdade de Medicina. Serviço de Biblioteca e Documentação. Guia de apresentação de dissertações, teses e monografias. Elaborado por Anneliese Carneiro da Cunha, Maria Júlia de A. L. Freddi, Maria F Crestana, Marinalva de Souza Aragão, Suely Campos Cardoso, Valéria Vilhena. $2^{\mathrm{a} e d . ~ S a ̃ o ~ P a u l o: ~ S e r v i c ̧ o ~ d e ~ B i b l i o t e c a ~ e ~}$ Documentação; 2005.

Abreviaturas dos títulos dos periódicos de acordo com List of the Journls Indexed in Index Medicus. 


\section{SUMÁRIO}

Lista de abreviaturas

Lista de tabelas

Lista de gráficos

Lista de figuras

Lista de quadros

RESUMO

ABSTRACT

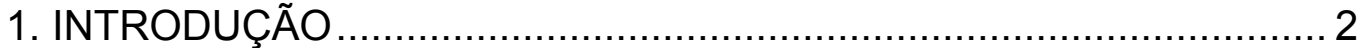

2. OBJETIVOS

\section{REVISÃO DA LITERATURA}

3.0 A sexualidade feminina e a formação do eu-pele feminino . 7

3.1 A sexualidade feminina no climatério 15

3.2 As disfunções sexuais femininas 23

3.3.A mastectomia radical e a sexualidade feminina 29

3.3.1. O câncer de mama 30

3.3.2. O tratamento cirúrgico do câncer de mama................... 33

3.3.3 As cirurgias de reconstrução mamária ........................... 36

3.3.4 Conseqüências do câncer de mama na sexualidade feminina 37

3.3.5 Efeitos da quimioterapia sobre a sexualidade feminina ....57

3.4 processo de luto no câncer de mama. 63 
3.5. O impacto psicológico do câncer de mama................................. 70

3.6 O câncer de mama e o relacionamento conjugal ......................... 73

4. CASUÍSTICA E MÉTODO

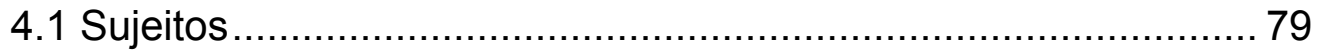

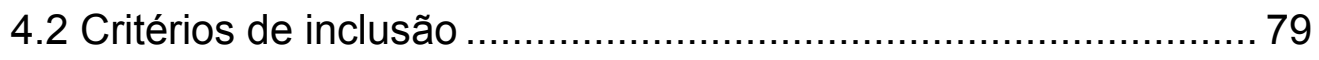

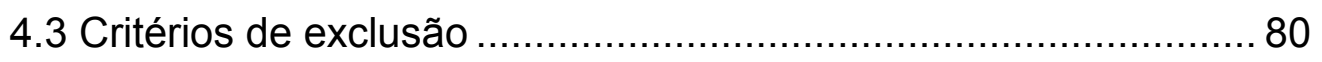

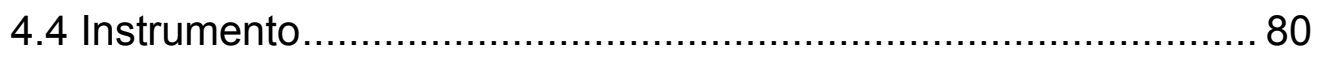

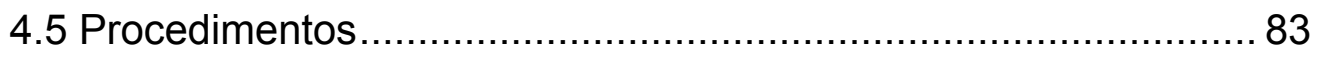

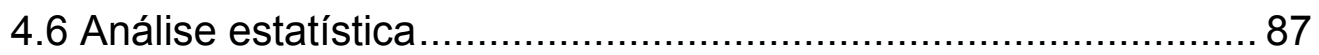

5. RESULTADOS

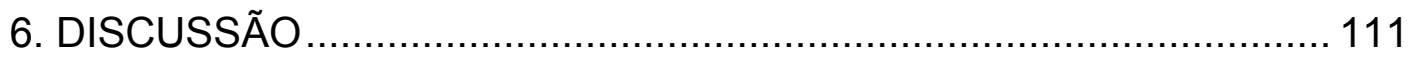

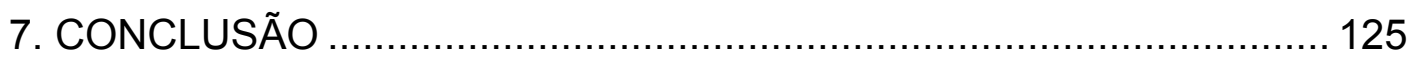

\section{ANEXOS}

Anexo A: Salvador Dali. Space Eve (1972) ………………………….......122

Anexo B: Salvador Dali. Estudos anatômicos (1937) .....................................128

Anexo C: Disfunções sexuais femininas segundo DSM IV TR (APA, 2002)..129

Anexo D: Diagnóstico para disfunções sexuais devido à condição médica geral 130

Anexo E: Grupos de transtorno sexuais segundo o DSM IV TR e a CID 10.131

Anexo F: Declaração do Núcleo de Mastologia do Hospital Sírio Libanês.....132

Anexo G: Pacientes selecionadas pertencentes a amostra final com filtro, segundo diagnóstico em prontuário ……………………………133

Anexo H: Questionário de função sexual de Watts (WSFQ) ..........................135

Anexo I: WSFQ Grupo Cirúrgico - fase diagnóstica ………………………...138

Anexo J: WSFQ Grupo Cirúrgico - fase pós-diagnóstica................................112 
Anexo L:WSFQ Grupo Controle - fase diagnóstica

Anexo M: WSFQ Grupo Controle - fase pós-diagnóstica ...........................150

Anexo N: Registro da Pesquisa no Ministério da Saúde ..............................154

Anexo O: Aprovação Comissão de Ética e Pesquisa .....................................155

Anexo P: Termo de Consentimento Livre e Esclarecido - grupo cirúrgico .....156

Anexo Q: Termo de Consentimento Livre e Esclarecido - grupo controle .....158

9. REFERÊNCIAS

\section{APÊNDICES}

Apêndice 1:Classificação das neoplasias mamárias segundo a CID 10 (1995)

Apêndice 2: Estadiamento TMN do câncer de mama

Apêndice 3: TMN: classificação clínica

Apêndice 4: pTMN: classificação patológica

Apêndice 5:Categorias de avaliação Bi-Rads (2003) 


\section{LISTA DE ABREVIATURAS}

$\begin{array}{ll}\text { APA } & \text { Associação Psiquiátrica Americana } \\ \text { CID 10 } & \text { Classificação Internacional das Doenças }-10^{\mathrm{a}} \mathrm{ed} . \\ \text { DSM IV TR } & \text { Manual Estatístico de Doenças Mentais }-4^{\mathrm{a} e d .} \text { revisada } \\ \text { FSH } & \text { Honmônio folículo estimulante } \\ \text { MR } & \text { Mastectomia radical sem reconstrução } \\ \text { MRR } & \text { Mastectomia radical com reconstrução } \\ \text { OMS } & \text { Organização Mundial da Saúde } \\ \text { SUS } & \text { Sistema Único de Sáude } \\ \text { T0 } & \text { Avaliação inicial das pacientes (diagnóstico) } \\ \text { T3 } & 3 \text { meses de seguimento } \\ \text { T6 } & 6 \text { meses de seguimento } \\ \text { T9 } & 9 \text { meses de seguimento } \\ \text { T12 } & 12 \text { meses de seguimento } \\ \text { WFSQ } & \text { Watts Sexual Function Questionnaire }\end{array}$




\section{LISTA DE FIGURAS}

Figura 1: Sistema de representação da transição menopáusica proposto pela Oficina das Etapas Reprodutivas de Idade

Figura 2: Ciclo de reposta sexual feminino 27

Figura 3: Câncer de mama: terapêutica 36 


\section{LISTA DE TABELAS}

Tabela 1: Resultados do Watts Sexual Function Questionnaire

Tabela 2: Perfil sócio demográfico das entrevistadas 90

Tabela 3a: Exames de seguimento 91

Tabela 3b: Exames de seguimento realizados. 91

Tabela 4. Análise exploratória das questões quantitativas em T12. 92

Tabela 5: Cálculo do Delta Escore (t12 - t0) para comparação grupo controle $\mathrm{x}$ mastectomia radical. 98

Tabela 6: Avaliação de depressão 106 


\section{LISTA DE GRÁFICOS}

Gráfico 1:Comparação da evolução dos casos novos de câncer de mama para cada 100 mil mulheres. 31

Gráfico 2: Comparação da evolução da estimativa de novos casos de câncer de mama por região geográfica 32

Gráfico 3: Escore médio em desejo, excitação, orgasmo e resolução mastectomia radical $(\mathrm{MR})-(\mathrm{t} 0 \times \mathrm{t} 3 \times \mathrm{t} 6 \times \mathrm{t} 9 \times \mathrm{t} 12)$ 96

Gráfico 4: Escore médio em desejo, excitação, orgasmo e resolução grupo controle $(\mathrm{GC})-(\mathrm{t} 0 \times \mathrm{t} 3 \times \mathrm{t} 6 \times \mathrm{t} 9 \times \mathrm{t} 12)$ 96 
Quadro 1: Desejo.

Quadro 2: Excitação 101

Quadro 3: Orgasmo 101

Quadro 4: Resolução 101 


\section{RESUMO}

MALUF MFM. O perfil da sexualidade em mulheres com câncer de mama [Dissertação]. São Paulo: Faculdade de Medicina, Universidade de São Paulo; 2008. 190p.

INTRODUÇÃO: O câncer de mama é a neoplasia maligna que mais atinge o sexo feminino, sendo responsável por cerca de $20 \%$ dos óbitos por câncer entre as mulheres. Os tratamentos utilizados promovem, de modo geral, alterações na auto-imagem, na imagem corporal, no auto-conceito e na função sexual feminina. Assim, objetiva-se avaliar a presença ou não de disfunções sexuais em mulheres com câncer de mama tratadas cirurgicamente.

MÉTODOS: foram avaliadas pelo período de um ano, 52 mulheres entre 50 e 60 anos de idade, divididas em dois grupos: controle, composto por 37 mulheres com tumores benignos de mama e 15 submetidas à mastectomia radical, utilizando o Watts Sexual Function Questionnaire (WSFQ), que avalia os quatro componentes da experiência sexual, incluindo as percepções sobre desejo sexual, interesse, orgasmo e satisfação, específico para avaliar a sexualidade em sujeitos com patologias clínicas, previamente aplicado na população brasileira. A este questionário foram acrescidas questões qualitativas visando a avaliação e observação das reações das pacientes frente ao diagnóstico cirúrgico e as possíveis alterações advindas da mastectomia radical na auto-estima, no humor, na capacidade de planejar o futuro e na manutenção do relacionamento afetivo-sexual. Testes estatísticos para medidas repetidas, análise de correlação entre variáveis e análise exploratória de dados multidimencionais estão entre as técnicas estatísticas utilizadas para avaliar o conjunto de dados.

RESULTADOS: As principais variações detectadas ao longo do tempo, foram o desejo sexual, no grupo controle e na excitação no grupo cirúrgico. Avaliando-se o impacto do tempo observou-se uma piora na fase do desejo das pacientes pertencentes ao grupo controle comparado ao grupo de mastectomia radical. Dentre as pacientes submetidas à mastectomia, 37,5\% das que realizaram reconstrução mamária tem melhor auto-imagem e exercem sua sexualidade adequadamente. A realização do processo de elaboração do luto foi observada durante as diversas etapas do tratamento do câncer de mama. Observou-se amplitude de variações nos sentimentos / atitudes que a doença causa em cada paciente, não sendo possível uma padronização do comportamento e complementando de forma decisiva na avaliação objetiva realizada através da escoragem WSFQ.

CONCLUSÃO: Pacientes submetidas à mastectomia radical apresentaram indícios de transtorno de excitação, quando comparadas à mulheres com tumores benignos de mama nas quais observa-se falta de desejo sexual.

DESCRITORES: neoplasia mamária, mastectomia radical, sexualidade feminina, disfunções sexuais 


\section{SUMMARY}

MALUF MFM. The sexual profile of women with breast cancer [Dissertation]. São Paulo: "Faculdade de Medicina, Universidade de São Paulo"; 2008. 190p.

INTRODUCTION: breast cancer is the malign neoplasia what most gets female sex, being responsible for about $20 \%$ from cancer's death among women. The treatments used to promote alterations on self-image, on body image body, into the self-concept and on the female sexual function. So, we aim to access the presence or not sexual dysfunctions in women with breast cancer submitted to surgery treatment.

METHODS: were evaluated by a period of one year, 52 women among 50 and 60 years old, divided in two groups: control, compounded by 37 women with benign breast tumors and 15 submitted to radical mastectomy, using the Watts Sexual Function Questionnaire (WSFQ), that assesses the four components from sexual experience, including the perceptions of sexual desire, interest, orgasm and satisfaction, specific to evaluate sexuality in subjects with clinics pathologies previously applied on Brazilian population. For this questionnaire have been added qualitative questions aimed the appraisal and observation from patients reactions to surgical diagnosis and the possible occurring alterations of radical mastectomy in self-steam, in humor, in the capacity of planning future and at the maintenance of the affective-sexual relationships. Statistic tests about repetitive measures, analysis between correlation variables and analysis of multidimencional exploratory data are among the statistics techniques used to evaluate the data set.

RESULTS: the main variations detected in a long of the time, was the sexual desire in control group and in excitation in surgical group. Evaluating the impact of the time observed, considering comparatively both groups, there was a worsening in phase of desire in control group when compared to radical mastectomy group. Among the patients submitted to the mastectomy, $37.5 \%$ of that carried out mammary reconstruction has better self -image and exercise its sexuality adequately. The achievement of the trial of elaboration of the mourning process was observed during the diverse phases of the breast cancer treatment. It was seen amplitude of variations in feelings / attitudes that illness causes in each patient, not being possible a stardandization of the behavior and complementary of decisive form in the objective evaluation carried out through the WSFQ score

CONCLUSION: Patients submitted to radical mastectomy presented indications of perturbation of excitement, when compared to women with benign breast tumors when were observed lack of sexual deseire.

DESCRIPTOR: breast neoplasm, radical mastectomy, female sexuality, sexual dysfunction 


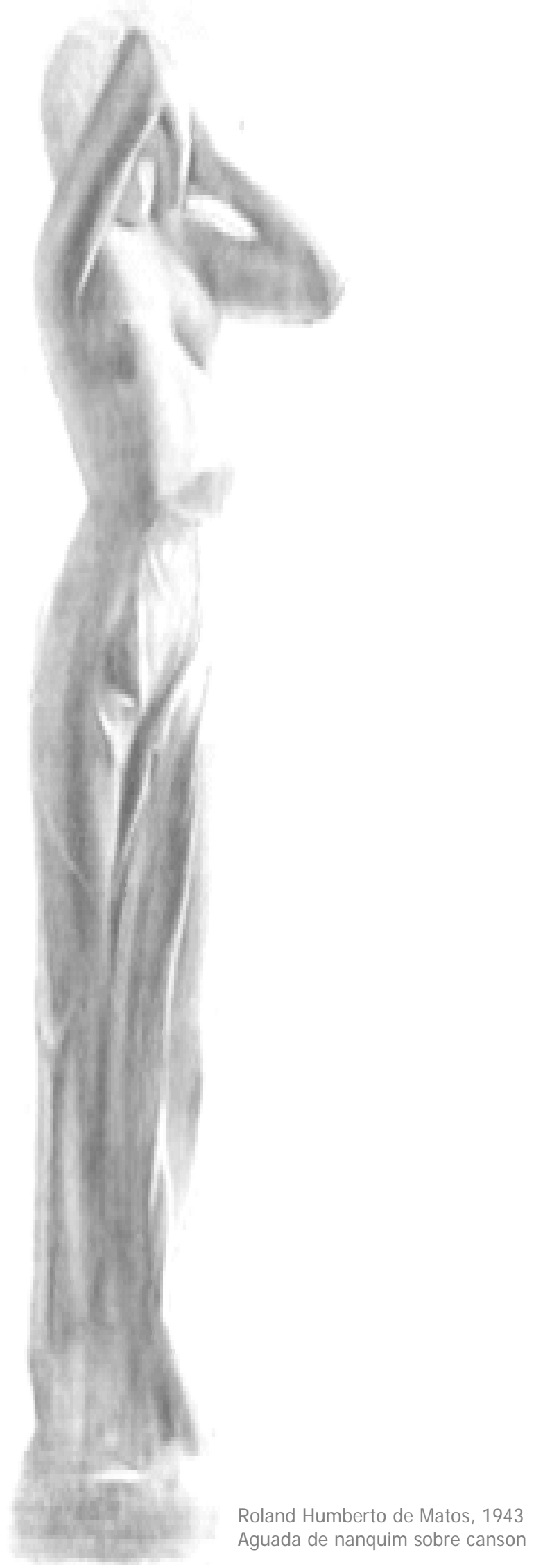


1. INTRODUÇÃO 
A sexualidade é inata a todos os seres do reino animal, porém no ser humano está ligada não só à reprodução como também à obtenção de prazer.

Em cada época, as normas sociais ditam diferentes padrões para o protótipo da mulher sensual e atraente.

Visando atingir estas "metas sociais", o corpo feminino se tornou bem delineado, definido cujas formas são valorizadas, através das vestimentas: justas e/ou curtas, com decotes, fendas, feitas com tecidos de última geração que modelam este corpo "esculpido" e extremamente sexualizado.

A erotização do corpo feminino, pode ser bem percebida no campo das artes como na escultura e na pintura. Nesta última, é rica e incessantemente retratada por toda a obra de Salvador Dali que não só pintou o nu sensual da mulher, como também o erotizou. Porém, contrastando com o belo e harmônico (anexo A), Dali dividiu e mutilou o corpo feminino em seus Estudos Anatômicos de 1937 (anexo B) (Descharnes, 1997).

Tal como na obra de Dali (1937), quando a mulher se submete à mastectomia para tratamento de um carcinoma, este corpo "perfeito" sofre um "corte" em sua harmonia, tornando-se "imperfeito". Esta "imperfeição" pode causar diversos problemas, incluindo aqueles relacionados à sexualidade, sendo que estes podem ou não estar ligados diretamente à cirurgia realizada (Miller e Graham, 1975; Lim et al, 1995). No caso de mulheres submetidas à quimioterapia existe risco ainda maior de virem a apresentar alguma disfunção sexual após o tratamento (Thors et al., 2001). 
Após a mastectomia radical há opção de se realizar ou não a reconstrução mamária. Na primeira, existe diminuição dos efeitos negativos do câncer de mama no que se refere ao bem-estar sexual e psicossocial, principalmente quando realizada imediatamente à cirurgia (Rowland et al., 2000, Al-Ghazal et al, 2000a; Cohen et al, 2000), devido ao decréscimo dos fatores mórbidos (Al-Ghazal et al., 2001b; Ganz et al., 2000; Schover, 1991; Dorval et al, 1998) ou de "proteção psicológica" (Schover, 1994; Fallowfield, 1990).

Por outro lado, as mulheres para as quais a reconstrução não é indicada ou que optam por não fazê-la, apresentam grande morbidade psicossocial, ou seja, fatores relacionados à ansiedade, a depressão, a autoimagem, a sexualidade e a auto-estima (Al-Ghazal et al., 2001 a; Pelusi, 2006)

Em relação à vivência da sexualidade após a mastectomia radical, havendo a reconstrução, o impacto sobre a vida sexual da mulher é menor, devido a sua influência sobre à auto-imagem, o auto-conceito e sobre os processos psíquicos a estes relacionados como o luto e a depressão (Maluf, 2005, 2006).

Tendo em vista as controvérsias ainda existentes na literatura, decidiuse aprofundar o estudo deste tema visando a melhor compreensão da influência da mastectomia radical sobre a sexualidade feminina, sobre a ressignificação da identidade feminina, sobre o processo de luto no câncer de mama, seu impacto psicológico nas cirurgias radicais e sua influência no relacionamento conjugal. 
2. OBJETIVOS 
Objetivos:

$\checkmark$ Investigar e compreender o significado do momento diagnóstico e da mastectomia radical para a mulher com câncer de mama e sua relação com a sexualidade

$\checkmark$ Caracterizar, comparar e compreender o processo de elaboração do luto nas pacientes submetidas à mastectomia radical e sua relação com a sexualidade

$\checkmark$ Identificar a existência de possíveis alterações na vivência da sexualidade do casal em conseqüência do tratamento cirúrgico de suas parceiras Identificar e comparar a existência de mudanças na vivência da sexualidade nas mulheres submetidas à mastectomia radical e as implicações para a identidade feminina. 
3. REVISÃO DE LITERATURA

Roland Humberto de Matos, 1943

Aguada de nanquim sobre canson 


\subsection{A sexualidade feminina e a formação do "eu-pele" feminino}

A sexualidade é inata a todos os seres do reino animal, porém no ser humano encontra-se ligada não só à reprodução como também à obtenção de prazer.

Comparando-se a psicologia entre homens e mulheres, nota-se que, em média, as mulheres associam à sexualidade a ternura, aos sentimentos e aos afetos, havendo coerência maior entre os sentimentos sexuais e toda a vida emocional, talvez devido a motivos biológicos (Horney, 1991).

Para Hélène Deutsch (1960), a sexualidade feminina está relacionada às funções reprodutivas, sendo uma inseparável da outra. Assim,

a relação entre a sexualidade e a tendência maternal é de natureza psicológica complicada, e esta complexidade parece indicar uma determinação a mais, além da puramente hormonal (p. 40).

De acordo com Lima (1984), até as seis primeiras semanas de vida, os embriões são neutros do ponto de vista sexual, em virtude da indiferenciação das gônadas que nesta etapa são duas pregas gonadais

A partir deste momento, ocorre a primeira etapa da diferenciação gonadal em razão da presença ou não do cromossomo $Y$ na estrutura cromossômica do embrião. Na presença deste cromossomo, há a multiplicação dos cordões sexuais que irão se propagar na porção interna ou medular da gônada, constituindo os cordões seminíferos que originarão os canais seminíferos. Caso contrário, ocorre atrofia medular e o desenvolvimento cortical originando os ovários. A partir desta parede, 
deslocam-se para o interior, grupos de células que constituirão os folículos primordiais.

Após a diferenciação gonadal, os hormônios passam a influir na diferenciação sexual: o hormônio antimülleriano (produzido desde a oitava semana até o nascimento, pelas células de Sertoli, que ficam no interior dos canais seminíferos) e o hormônio androgênico, testosterona (produzido na nona semana de gestação pelas células de Leydig, localizadas entre os canais seminíferos).

Havendo a estimulação hormonal, ocorre a inibição das estruturas femininas e desenvolvimento dos genitais masculinos. Em sua ausência há o crescimento das estruturas genitais femininas (Lima, 1984).

O desenvolvimento biológico da mulher é marcado por várias etapas visíveis que denotam a mudança do corpo infantil ao corpo feminino adulto, sensual e harmônico em suas formas e contornos. A primeira mudança ocorre com o aparecimento das mamas, que precede a menarca, marco da entrada na vida adulta e fértil (Potts e Short, 2002).

A mama, além de ter sua função e simbologia ligada à maternidade e a segurança está associada às imagens de intimidade, oferenda, dádiva e refúgio (Chevalier e Gheerbrant, 1996). Ao longo da vida da mulher, a mama sempre esteve associada, em nossa cultura e também em outras, à identidade corporal feminina e aos sentimentos de auto-estima, como órgão de "contato e atração", sendo também símbolo extremamente narcisista (Basegio, 1999). 
Durante o desenvolvimento psicossexual, tanto a menina quanto o menino passam por fases que abrangem desde a completa dependência da mãe cuidadora e provedora de suas necessidades (fase oral) até uma fase de maior independência ao final da fase fálica, marcada pelo declínio do Complexo de Édipo.

Essas fases são denominadas, segundo a teoria psicanalítica de Sigmund Freud, de "fases da organização da libido". A libido, é conceitualizada por ele como "uma força quantitativamente variável que permite medir os processos e as transformações no domínio da excitação sexual", Freud (1996 a, d) sendo base da pulsão sexual. Sua natureza é essencialmente sexual, sendo irredutível a outras formas de energia mental não-especificadas (Garcia-Roza, 1998). A "libido é invariável e necessariamente de natureza masculina*, ocorra ela em homens ou em mulheres e independentemente de ser seu objeto homem ou mulher" (Freud, 1996 a, p. 226).

As fases de organização da libido são determinadas ou pela predominância de uma zona erógena ou por um modo de relação de objeto (Garcia-Roza,1998).

A primeira fase do desenvolvimento sexual pré-genital é oral. Nela o prazer está ligado à ingestão de alimentos e à excitação da mucosa dos lábios e da cavidade bucal. É também marcada pela completa dependência do bebê à mãe ou cuidador. Nesta etapa do desenvolvimento, as trocas

\footnotetext{
* O sentido do termo "masculino" quando Freud se refere à natureza da libido, é de atividade e passividade, pois um instinto é sempre ativo ou passivo mesmo que o objeto desejado seja passivo.
} 
ocorridas entre mãe e filho são de suma importância para as futuras relações.

Durante a mamada, a criança tem contato com a pele do seio ${ }^{\dagger}$ da mãe, sentindo sua temperatura, seu toque. O sugar o seio materno é o ponto de partida de toda a vida sexual, sendo este o primeiro objeto do instinto sexual (Freud, 1996 a; Simanke, 1994).

A segunda é a anal-sádica, que ocorre entre os dois e os quatro anos de idade, aproximadamente, na qual a libido encontra-se organizada sob a região anal numa relação de "passividade" e "atividade", construída através da experiência de retenção e expulsão das fezes.

Na fase fálica há predomínio dos órgãos genitais, em que a oposição entre os sexos é caracterizada pela castração. No menino, esta fase encontra-se ligada ao interesse narcísico que ele têm pelo próprio pênis em contraposição à descoberta de sua ausência nas meninas. Para elas essa constatação determina o surgimento da inveja do pênis com o conseqüente ressentimento para com a mãe por "não lhe ter dado um pênis", o que será compensado com o desejo de ter um filho.

Este período é marcado pelo Complexo de Édipo, no qual a criança se encontra ligada ao genitor do sexo oposto, sendo seu relacionamento com o genitor do próprio sexo mais hostil. No caso da menina, seu primeiro objeto de amor foi à mãe e neste momento é o pai (Freud, 1996b).

\footnotetext{
† entenda-se "seio" como sinônimo de "mama", por se tratar de uma expressão comum às teorias psicanalíticas e psicológicas.
} 
O declínio do Complexo de Édipo ocorre em função da ameaça de castração: o menino percebe, ao observar os genitais das mulheres, que são desprovidas de um pênis e pensa que isto ocorreu por causa de uma punição e por associação, teme ser castrado pela figura paterna (Freud, 1996 c, e).

Na menina ocorre o contrário: ela entra no Complexo de Édipo através da castração, imaginando que em alguma época anterior possuía um pênis e que foi perdido por castração. Para ela, a castração é fato consumado, ao passo que o menino teme a possibilidade de sua ocorrência. O declínio do Complexo de Édipo para a menina é marcado pela angústia de violação, onde há a valorização da imagem fálica do outro: o pênis (Freud, 1996 c, e. Nagera, 1983).

O Complexo de Castração pode apresentar-se sob diversas formas, ser reconduzido a formulações simultaneamente diferentes e complementares, entre sujeito e outrem; perder e receber: "eu sou castrado (sexualmente privado de); eu serei castrado; eu receberei (desejo de receber) um pênis; outra pessoa é castrada, deve ser (será) castrada; outra pessoa receberá um pênis (tem um pênis)" (Laplanche, 1992, p.76).

De acordo com Freud:

O temor da castração não é, naturalmente, o único motivo para repressão: na verdade, não sucede nas mulheres, pois, embora tenham elas um complexo de castração, não podem ter medo de serem castradas. Em seu sexo, o que sucede é o temor à perda do amor, e que é, evidentemente, um prolongamento posterior da angústia da criança quando constata a ausência da mãe (Freud 1996 b, p. 256). 
Através do Complexo de Castração a menina é posta à frente da diferença anatômica entre os sexos e se percebe como não provedora de um pênis. Por outro lado, nota que sua mãe tem seios e seu pai não. Olha para si e pergunta à mãe porquê não os tem. Assim, a menina percebe que existe algo de fálico no corpo feminino: os seios, que passará a dar importância com o passar do tempo, valorizando assim seu sexo específico (Potts, 2001; Dolto, 1996 a, b; Deutsch, 1960).

Deste modo, a mulher aceita e toma consciência de seu corpo fálico plástico, sentindo-se desejável, atraindo olhares do sexo oposto e conseqüentemente, começa a perceber que sua sexualidade está ligada a algo maior, valorizado culturalmente, que é a capacidade de gerar e de nutrir uma nova vida.

Assim, a mulher interioriza as imagens do que é ser e pertencer ao sexo feminino, por meio da construção de sua auto-imagem e de sua imagem corporal.

A imagem corporal é uma representação mental do "self" físico, que inclui atitudes e percepções sobre a aparência física, o estado de saúde, habilidades e sexualidade, sentir-se sexualmente atraente (Taylor et al., 2002, Schover et al., 1995; Hopwood, 2000). É componente integral do autoconceito que é a percepção total do indivíduo seguro de si, que acredita em quem é, na forma como se olha, e como se sente em relação a si mesmo. Como componente de um "self" físico, pessoal, social e ético-moral, o autoconceito influencia o modo como o indivíduo percebe e interage com o mundo (Mock, 2003). 
Entender a imagem corporal como componente do autoconceito (Le Mone, 1991) auxilia no entendimento do papel dos seios como símbolos de feminilidade, de atração sexual e criação (maternidade).

Quando acontece algo que modifica o corpo feminino, podem aparecer os sentimentos de inadequação, de não ser mais atraente ou de vergonha, que complicam a vivência da sexualidade com plenitude, ao potencializar atitude de inibição e apatia (Carrasco, 2001).

Neste contexto, a mastectomia radical promove uma agressão à pele, a unidade corporal e psíquica da mulher, promovida principalmente pela perda da integridade corporal (Simanke, 1994).

A pele tem como funções, conter e reter em seu interior o "bom" e o "pleno" como o aleitamento e cuidados, sendo uma interface que marca o limite com o "de fora", mantendo-o externo; é a barreira que protege contra as agressões provindas do meio; é um lugar e meio primário de comunicação com os outros, de estabelecimento de relações significativas, que, ao ser agredida e retirada, permite que os conteúdos internos, físicos e psicológicos, sejam exteriorizados (Anzieu, 1989).

Ao mutilar-se o corpo, mutila-se a pele. As sensações são retiradas ou diminuídas. Segundo Anzieu (1989), as mutilações da pele são tentativas dramáticas de manter os limites do corpo e do Eu, restabelecendo o sentimento de coesão, de estar intacto.

Para Foltz (1987) e Daune (1995), a perda de uma parte significantemente relacionada à identidade feminina, como as mamas, resulta em alterações negativas na imagem corporal e no autoconceito. $O$ 
grau dessas alterações pode estar supostamente relacionado com o grau de mudança física e com o significado pessoal daquela parte. A reconstrução mamária pode resultar na melhora da imagem corporal e do autoconceito (Mock, 2003).

A retirada da mama fere e mutila o "eu-pele" feminino, gerando a perda da coesão psíquico-corporal adquirida em etapas anteriores do desenvolvimento, alterando a imagem corporal construída ao longo do tempo. Conseqüentemente, a mulher revive a angústia de castração primária, ou seja, a angústia de perceber-se sem o que é fálico nas mulheres: as mamas.

A perda da mama pode, assim, ser equiparada a castração, sendo um golpe à sexualidade, aos sentimentos de maternidade e feminilidade (Taylor, 1985, Deutsch, 1960).

A amputação das mamas causa estranheza em função da agressão ao "eu-pele". O "eu-pele" é a representação de que se serve o Eu da criança, durante as fases precoces de seu desenvolvimento, para representar a si mesmo como Eu que contém os conteúdos psíquicos, a partir de sua experiência de superfície do corpo. Ou seja, o momento em que o Eu psíquico se diferencia do Eu corporal no plano operativo e permanece confundido com ele no plano figurativo (Anzieu, 1989).

Causa também, algumas vezes, o decréscimo ou perda das sensações na área da cicatriz, o que se constitui em problema para várias mulheres (Wilmoth, 2003). A perda da sensação gerada pela estimulação do mamilo (cicatriz) está ligada à extirpação da pele que recobre as mamas, já que os 
prazeres da pele encontram-se integrados como preliminar da atividade sexual adulta (Anzieu, 1989), quer seja pela estimulação da área por carícias orais, quer pelo toque.

\subsection{A sexualidade feminina no climatério}

O climatério é período do ciclo biológico da mulher situado entre a menacme (vida reprodutiva) e a senilidade (fase não reprodutiva) (PintoNeto, 2003; Sampaio et al, 1999; Fernandes, 1999).

Durante o climatério ocorre a menopausa, isto é, a parada permanente da menstruação, em decorrência da perda definitiva da atividade folicular ovariana, ocorre na maioria dos paises industrializados, em torno dos 50 anos (48 - 52 anos). Para tal, deve ter ocorrido período de pelo menos doze meses de ausência de fluxo, para que seja considerada como última menstruação, ou seja, seu diagnóstico é retrospectivo (OMS, 1981).

É uma endocrinopatia de consumo de natureza genética, gerado pela deficiência de hormônios esteróides ovarianos em decorrência da falência funcional das gônadas por exaustão folicular e resistência dos folículos remanescentes à ação das gonadotrofinas, especialmente ao hormônio folículo estimulante (FSH) (Rennó Júnior et al, 2004; Fernandes et al.,1999).

O déficit hormonal secundário à falência ovariana geralmente é acompanhado por sintomatologia clínica, alterações do ciclo menstrual e 
fenômenos atróficos (Fernandes et al, 1999; Rennó Junior et al, 2004; Carrasco, 2002).

Em 2001, a Sociedade Americana de Medicina Reprodutiva, o Instituto Nacional de Idade, o Instituto Nacional da Saúde da Criança e do Desenvolvimento Humano e a Sociedade Norte-Americana de Menopausa co-patrocinaram em conjunto, as Oficinas das Etapas Reprodutivas de Idade (STRAW) na tentativa de desenvolver uma estrutura que pudesse ser a base do entendimento da menopausa e da pós-menopausa (Soules et al, 2001).

O sistema de estágios ideais deveria ter as seguintes características:

$\checkmark$ critério objetivo, mais que sintomatologias subjetivas, que definissem cada estágio;

$\checkmark$ uso de fidedignidade, reprodutibilidade e avaliação barata por período;

$\checkmark$ habilidade de representar prospectivamente pacientes individualmente;

$\checkmark$ ser claro, não sobreposto e com estágios mutuamente exclusivos.

Para o sistema de estágios foram considerados diversos componentes em potencial: ciclo menstrual, fatores endócrinos e bioquímicos, fertilidade, sinais e sintomas em outros órgãos do sistema e anatomia uterina/ovariana. A âncora para o sistema de estágios é o final do período menstrual (FMP). Cinco estágios ocorrem anteriormente à FMP (figura 1); a variação da idade e duração de cada estágio é modificável. O sistema de estágios foi desenvolvido no workshop em sete estágios: cinco precedem e dois seguem ao final do período menstrual. Assim: 
Estágios: -5 a -3 , abrange o período reprodutivo

Estágios: -2 e -1, transição menopáusica

Estágios 1 e 2, pós-menopausa.

Figura 1: Sistema de representação da transição menopáusica proposto pela Oficina das Etapas da Reprodutiva de Idade (STRAW)

Final do período menstrual

(FPM)

0

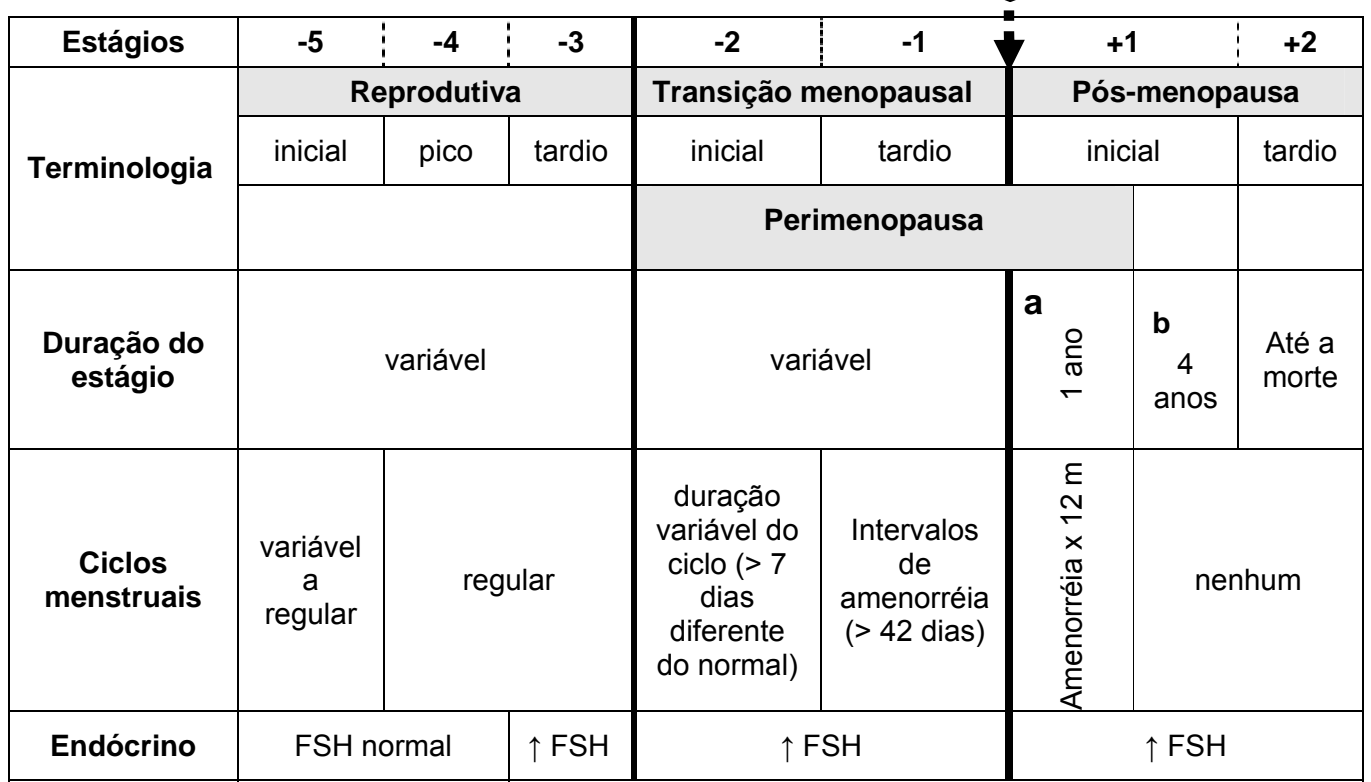

FONTE: Soules et al. (2001)

Estudos clínicos de mulheres na menopausa mostram que 90\% delas apresentam irregularidades menstruais durante os primeiros anos de perimenopausa, e que somente 10 a $12 \%$ apresentam amenorréia direta (Backmann et al., 2004; Gupta et al, 2006)

A dispareunia e a diminuição do desejo são duas das disfunções sexuais que acometem todas as mulheres sexualmente ativas, mas que 
podem ser intensificadas em virtude do climatério, devido às alterações orgânicas presentes.

Dentre as causas orgânicas que promovem disfunções sexuais nesta etapa da vida da mulher, destacam-se as seguintes alterações (Mooradiana e Greiff, 1990; Amin et al, 1990; Kovalevsky, 2005):

a) Genitália: redução do tamanho vaginal, afinamento das paredes, lubrificação deficiente, decréscimo no fluxo sangüíneo, redução dos lábios maiores, afinamento dos lábios menores, aumento da exposição do clitóris, decréscimo da sensibilidade, vaginites.

b) Mama: atrofia, decréscimo do ingurgitamento durante a excitação, mudanças sensoriais nos mamilos e auréola.

c) Redução no tônus perineaes.

d) Alterações hormonais: decréscimo nos níveis plasmáticos de estrogênios e androstenediona e aumento nos níveis plasmáticos de testosterona e dos hormônios folículo estimulantes, luteinizante.

e) Coexistência de doenças como: diabetes mellitus, insuficiência cardíaca congênita, angina, artrite, demência, câncer, cirurgias ginecológicas.

f) Alterações neuro-psicológicas

O estado hipoestrogênico da menopausa promove significantes mudanças físicas (Phillips, 2000) e alterações no humor ou diminuição na sensação de bem-estar, promovendo impacto negativo sobre a sexualidade (Cawood e Bancroft, 1996; Young McCaughan, 1996; Fenlon, 1995). A diminuição do desejo, da excitação e da freqüência do intercurso sexual e o 
aumento da dispareunia estão associados à menopausa (Backmann e Leiblum, 2004; Phillips, 2000), embora estes achados não sejam universais (Cawood e Bancroft, 1996; Rogers e Krisjanson, 2001).

Dentre os fatores psicológicos associados pode-se destacar o aumento na prevalência de ansiedade e depressão, a ausência de parceiro sexual, a existência de atitudes negativas em relação ao exercício da sexualidade em mulheres mais velhas, a perda de privacidade no que concerne ao viver com os filhos ou à institucionalização e a devoção religiosa.

As mudanças relacionadas à idade no nível dos esteróides sexuais e as inúmeras alterações neuroendócrinas são os determinantes bioquímicos mais importantes da maturação sexual e senescência (Mooradian e Greiff, 1990).

A organicicidade hormonal ligada ao hipoestrogenismo é importante causa indireta da perda do interesse sexual nas mulheres na pósmenopausa por resultar na síndrome de deficiência estrogênica urogenital feminina.

Esta síndrome é caracterizada por alterações atróficas na genitália feminina, ou seja, na ausência de estrogênio a mucosa da vagina atrofia e se torna mais delgada, havendo perda ou diminuição acentuada na lubrificação vaginal.

Mulheres na pós-menopausa que não fazem reposição estrogênica e aquelas que não têm relações sexuais regulares podem apresentar certo grau de atrofia do tecido vaginal, resultando em desconforto e dor durante a relação. A fricção do pênis na mucosa apertada e ressecada freqüentemente 
produz irritação dolorosa, erosões e às vezes, lesões abertas dos tecidos vaginais. Lesões vaginais traumáticas são comuns em mulheres que têm coitos vigorosos, especialmente quando não é utilizado nenhum lubrificante. Estas lesões podem ser graves o suficiente para impedir relações sexuais e levar a perda do desejo (Kaplan, 1999).

Para tanto mulheres na pós-menopausa com câncer de mama, o ressecamento vaginal é forte fator preditivo de disfunção sexual (Ganz et al, 1999, 2000).

O tratamento eficaz para aliviar a dispareunia e restaurar a fisiologia vaginal ao seu estado pré-menopausa é a reposição estrogênica por via oral ou transdérmica, porém esta não deve ser realizada em mulheres com história pessoal ou familiar de câncer de mama, útero e ovários (Lobo, 1993; Kaplan, 1999).

Greer (1994) considera que mulheres de meia idade não têm direito ao exercício de sua sexualidade a não ser que tenham um parceiro interessado nelas e que quanto mais velha a mulher for ficando, piores são suas chances de conseguir um novo parceiro, principalmente se nunca fez sexo.

A menopausa naturalmente ocorrendo, freqüentemente coincide com o diagnóstico de câncer de mama (Ganz et al, 1998). De todas as mulheres diagnosticadas com câncer de mama, entre 20 e $30 \%$ estão na prémenopausa no momento do diagnóstico (Fenlon, 1995), a maioria daquelas estão na fase transitória ou na perimenopausa (Knobf, 1998).

Ganz et al. (2003) avaliaram prospectivamente, durante seis anos, a qualidade de vida e a saúde reprodutiva de mulheres entre 25 e 51 anos de 
idade, tratadas cirurgicamente de câncer de mama. Destas 44,2\% foram submetidas a mastectomia e $55,8 \%$ a tumorectomia, sendo que $23,3 \%$ das pacientes realizaram a reconstrução mamária. O tratamento quimioterápico foi significativamente mais utilizado em pacientes jovens (86\%). Não houve relação positiva significativa entre a idade avançada e o uso de tamoxifeno. Terapias quimio e hormonioterápicas foram realizadas em aproximadamente um quarto das mulheres, havendo $18 \%$ de uso corrente de tamoxifeno.

Durante o diagnóstico de câncer de mama, a maioria das mulheres estava menstruando (pré ou perimenopausa). Em média de seis anos mais tarde: a maioria das mulheres com idade $\geq 40$ anos no diagnóstico estava na pós-menopausa.

Houve decréscimos significativos na vitalidade (energia), com piores escores dentre as pacientes mais jovens. Nestas, o funcionamento social e emocional também foi mais baixo, com piora na saúde mental.

Comparando-se a saúde mental das pacientes com a transição menopáusica por faixa etária no diagnóstico, os piores níveis foram observados naquelas na faixa etária dos 24 aos 34 anos que entraram na menopausa após o tratamento não houve diferenças estatisticamente significantes associadas ao tratamento físico ou bem estar emocional, ou funcionamento sexual.

Sentimentos de maior vulnerabilidade, de haver maior comorbidade e de ter entrado da menopausa após o tratamento do câncer de mama, estavam significantemente associadas a pobre percepção da saúde. 
De Lorenzi e Saciloto em 2006 realizaram estudo transversal com 206 mulheres na pós-menopausa entre 45 e 60 anos. Cerca de 60,6\% das pacientes sexualmente ativas (85\%) relatavam diminuição da atividade sexual após a menopausa, atribuindo esta ocorrência a impotência sexual do parceiro $(41,7 \%)$. Aproximadamente $25,7 \%$ negaram satisfação durante o intercuso sexual

As mulheres "infantis" ou que não resolveram seu Complexo de Édipo, ao entrarem na menopausa, sofrem com pesar a perda da fecundidade, achando que não são mais válidas como mulheres. Esse sofrimento é uma angústia real de castração se, até esse momento, sua existência vazia é representada pela maternidade e pelas tarefas domésticas, isto é, uma fertilidade simbólica (Dolto, 1996a).

Já para aquelas mulheres nas quais a menopausa se instala de maneira tranqüila, se abre um período de florescimento da vida psicossocial, um período de grande estabilidade fisiológica e afetiva, o acesso e a um certo "saber" de experiência feito e de lúcida condescendência. Por outro lado, a velhice neurótica é simbolizada pelas velhas bruxas mal-amadas e incapazes de amar (Dolto, 1996a).

Desta forma, a existência de uma relação de maior afetividade, cumplicidade e compreensão entre o casal onde se abordem as dificuldades, impedindo assim que o processo de incompreensão se instale e torne-se crônico, é de suma importância na vivência da sexualidade (Carrasco, 2000). 


\subsection{As disfunções sexuais femininas}

A sexualidade e a função sexual foram diferenciadas por Bruner et al. (1998), pelo menos em termos de instrumento de avaliação, refletindo a perspectiva biopsicossocial que inclui a anatomia sexual e fisiológica, funcionamento da função sexual e imagem corporal. A função sexual, é o único foco de muitos instrumentos de avaliação, mas é somente uma dimensão da sexualidade. A função sexual tem foco mais estreito e geralmente inclui aspectos do ciclo de resposta sexual, isto é, desejo, interesse, orgasmo ou atividade e satisfação.

Já as disfunções sexuais são determinadas por distúrbio no processo que caracteriza o ciclo de resposta sexual ou por dor associada ao intercurso sexual (APA, 2002).

As desordens no ciclo de resposta sexual podem ocorrer em uma ou em mais de uma fase, a saber: desejo, excitação, orgasmo e resolução (Kaplan, 1999).

Estima-se, que o número de mulheres com disfunções sexuais varie entre 19 a 50\% da população de pacientes não hospitalizados, aumentando de 68 a $75 \%$ quando os problemas ou descontentamento sexuais estão presentes (Phillips, 2000).

Visando facilitar o diagnóstico dos transtornos sexuais, há dois manuais classificatórios, comumente utilizados: o DSM IV-TR (Manual de Diagnóstico e Estatística de Doenças Mentais, 4ª edição, texto revisado), editado pela Associação Psiquiátrica Americana (2002) e a CID-10 
(Classificação Internacional de Doenças Mentais, $10^{\text {a }}$ edição), publicado pela Organização Mundial de Saúde, em 1995.

A diferença mais marcante entre ambos está na necessidade de que uma perturbação (no caso a disfunção sexual), cause acentuado sofrimento ou dificuldade interpessoal. Deve-se determinar também a natureza do início do problema, pois pode existir desde o início da vida sexual (primário) ou ter sido adquirida (secundário) a partir de um momento (evento) determinado, após período de funcionamento adequado, por exemplo, após o tratamento para o câncer (APA, 2002).

Deve-se observar se o transtorno é situacional, quando circunscrito a contextos específicos ou se é geral, quando aparece em todas as situações de vida, podendo assim caracterizar, por exemplo, depressão. É de suma importância a investigação da dimensão etiológica para que se possa compreender se a disfunção é causada por fatores psicológicos ou combinados. Neste último caso, a aparição de um transtorno é gerada pela ação conjunta de fatores psicológicos e o aparecimento de alguma enfermidade ou consumo de alguma substância.

O diagnóstico deve ser realizado por meio de entrevista onde será coletado todo o histórico de vida do indivíduo, focando-se sua história sexual, além dos exames físicos e psiquiátricos cuidadosos (Abdo, 2000).

Para o DSM IV-TR (APA, 2002), o diagnóstico é realizado quando os três critérios abaixo estão concomitantemente presentes (anexo C):

Critério A: a característica do transtorno sexual.

Critério B: causar sofrimento ou dificuldade interpessoal. 
Critério C: não poder ser melhor explicado por outra desordem do Eixo I (exceto outra disfunção sexual), e não é causada exclusivamente ao efeito fisiológico direto de uma substância (por exemplo, abuso de drogas, medicações) ou condição médica geral (APA, 2002).

No caso de pacientes com câncer, de modo geral, sem disfunções sexuais prévias, o diagnóstico de disfunções sexuais está relacionado com a condição médica geral.

Segundo o DSM IV-TR (APA, 2002), os tratamentos para o câncer como cirúrgico, radiação e a quimioterapia possuem efeitos colaterais que, por sua vez, são causadores de disfunções sexuais.

Desta forma, ao diagnosticar-se a presença de disfunções sexuais em pacientes com câncer de mama, deve-se levar em consideração (APA, 2002):

Critério A: disfunção sexual clinicamente significante que resulte em acentuado sofrimento ou dificuldade interpessoal, predominante no quadro clínico.

Critério B: há evidência pela história, exame físico ou achados laboratoriais que a disfunção sexual é plenamente explicada pelo efeito direto de uma condição médica geral.

Critério C: o distúrbio não pode ser melhor explicado por outro transtorno mental, por exemplo, transtorno depressivo maior.

A classificação das disfunções sexuais inclui o nome da condição médica geral do Eixo I seguido pelo código da condição médica geral do Eixo III (anexo D): 
Já a CID 10 (OMS, 1996) classifica as disfunções sexuais femininas em ausência ou perda do desejo sexual (F52.0), no qual o problema principal e não secundário a outras dificuldades sexuais como a dispareunia (frigidez, transtorno hipoativo de desejo sexual).

Quando houver outras disfunções sexuais não devidas a transtorno ou à doença orgânica, estas serão classificadas sob o código F 52.8. Nos casos de disfunção sexual não devida a transtorno ou à doença orgânica, não especificada, estas são classificadas como F52.9.

Visando melhor diferenciação entre a nomenclatura adotada por ambos manuais diagnósticos, lista-se no anexo $\mathrm{E}$ a classificação dos transtornos sexuais femininos.

Em 2001, Basson sugeriu o novo ciclo de resposta sexual feminino baseado não numa linearidade, isto é, desejo, excitação, orgasmo, resolução, mas em uma resposta cíclica na qual mesmo sem ter um desejo que se manifeste voluntariamente pela mulher, ao ser estimulada pelo parceiro, ela se engaja na atividade sexual e o ciclo de resposta sexual inicia-se. Este ciclo foi revisto pela autora em 2005 onde ela inseriu a motivação como um fator importante para que a atividade sexual ocorra (figura 2). 
Figura 2: Ciclo de resposta sexual feminino

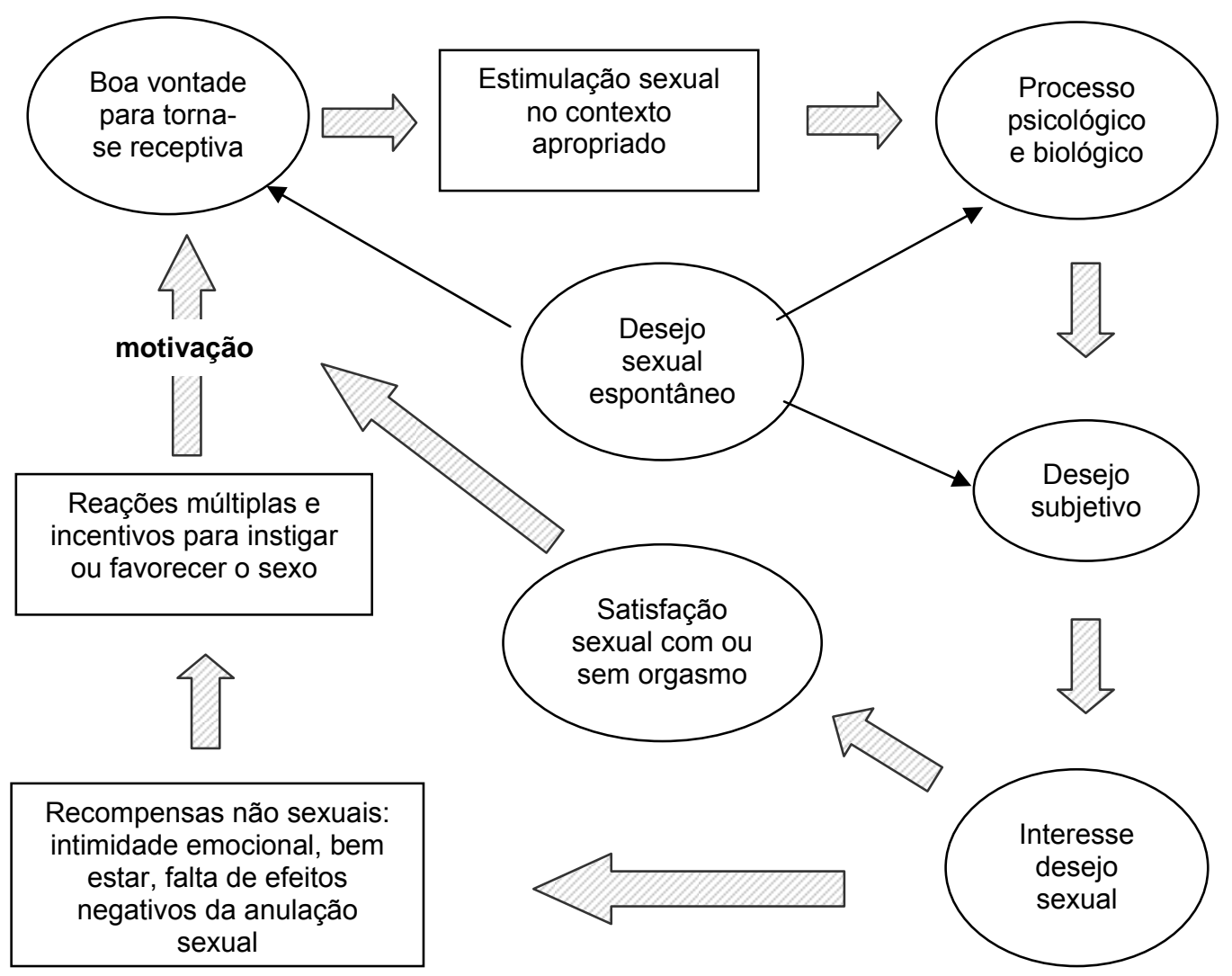

FONTE: Basson R. CMAJ. 2005;172:1327-1333.

Apesar da leitura realizada por Basson $(2001,2005)$ aplicar-se mais às mulheres, os manuais diagnósticos utilizam-se do modelo linear proposto por Master e Johnson na década de 70 e readequado por Helen Kaplan (1979).

Em geral, o comportamento sexual é adversamente afetado pela depressão e ansiedade associadas ao diagnóstico de câncer. No câncer de mama, em função do desfiguramento e da baixa auto-estima, estima-se que aproximadamente $90 \%$ das pacientes apresentem alguma forma de disfunção sexual (Mooradian e Greiff, 1990).

Os tratamentos adjuvantes à mastectomia como a quimioterapia, podem gerar algumas disfunções sexuais, além de problemas orgânicos 
como náusea, vômito e alopécia, que afetam a sexualidade das pacientes (Kaplan, 1992).

Pesquisas sugerem que $50 \%$ das pacientes com câncer de mama apresentam disfunções sexuais a longo prazo (Ganz, 1998), como a perda do desejo sexual e a dispareunia, relacionadas ao tratamento quimio e radioterápico (Mc Kee e Schover e 2001).

O sentimento de mutilação $(18,52 \%)$ relacionado às alterações na imagem corporal em conseqüência da mastectomia radical, é queixa manifesta por $90 \%$ das mulheres, sendo esta uma das principais causas de disfunções sexuais entre estas mulheres, devido a sua inabilidade em relaxar e desfrutar a relação em conseqüência da alteração da imagem corporal. Para estas, a atividade sexual apresenta queda de 62,96\%, com conseqüente diminuição da satisfação sexual após mastectomia radical, para $70,73 \%$ das mulheres (Buković et al, 2005). 


\subsection{Mastectomia radical e sexualidade feminina}

\subsubsection{O câncer de mama}

Câncer é o crescimento anormal do tecido celular capaz de invadir outros órgãos localmente ou à distância (metástases) sendo, em sua maioria, oriundo de alterações no DNA (Falzoni, 2000).

Estudos realizados a partir de 1955 mostraram conclusivamente que a história da vida emocional, muitas vezes, desempenha importante papel na determinação da resistência do indivíduo em contrair câncer e na evolução da doença após seu surgimento (Leshan, 1992).

Para Schávelzon (1992), apud Melo Filho (1992), o câncer é uma modificação do organismo como um todo e não apenas como uma invasão, agressão ou irritação externa. Sendo assim, em certo momento da vida do indivíduo existe um não reconhecimento dos elementos orgânicos e psicológicos que o integram, isto é, há alteração na leitura do sistema imune do indivíduo que pode ocorrer em função de inúmeros fatores como, por exemplo, a presença de elementos carcinogenéticos no meio externo, oncogenes e/ou protocogenes, ação virótica, falha imunológica, problemas emocionais, traumas psicológicos, entre outros.

Todo fator carcinogênico externo provocará ou ajudará o nascimento, formação ou deformação de células normais, que enquanto forem 
reconhecidas como não pertencentes ao organismo, serão destruídas e eliminadas. Porém, em um dado momento, esse processo de não reconhecimento se altera e o indivíduo passa a aceitar ou reconhecer como integrante de seu organismo essa célula diferente ou tumoral. Desta forma, esta célula integra-se ao organismo, não sendo combatida por ele, podendo assim crescer e reproduzir-se, cumprindo sua função (Falzoni, 2000).

A maioria dos carcinomas da mama se origina das células que revestem o curto segmento do dúctulo terminal da árvore mamária, na transição entre a porção ductular e acinar (Souza et al, 2000; Falzoni, 2000).

O câncer de mama é a neoplasia maligna que mais atinge o sexo feminino, sendo responsável por cerca de $20 \%$ dos óbitos por cânceres entre as mulheres (Frost, 2000; Souza et al, 2000).

No Brasil, estima-se o surgimento de 49.400 novos casos de câncer de mama $(51,66 \%)$ em 2008, com risco estimado de 51 casos para cada 100 mil mulheres (INCA, 2008).

Ao observarem-se às estimativas dos anos anteriores (gráfico 1), notase aumento de 8.190 casos novos, com risco estimado de 42 casos a cada 100 mil mulheres, quando se compara o ano de 2003 a 2008 (risco estimado de 12 e 51 casos, respectivamente). 
Gráfico 1: Comparação da evolução dos casos novos de câncer de mama para cada 100 mil mulheres

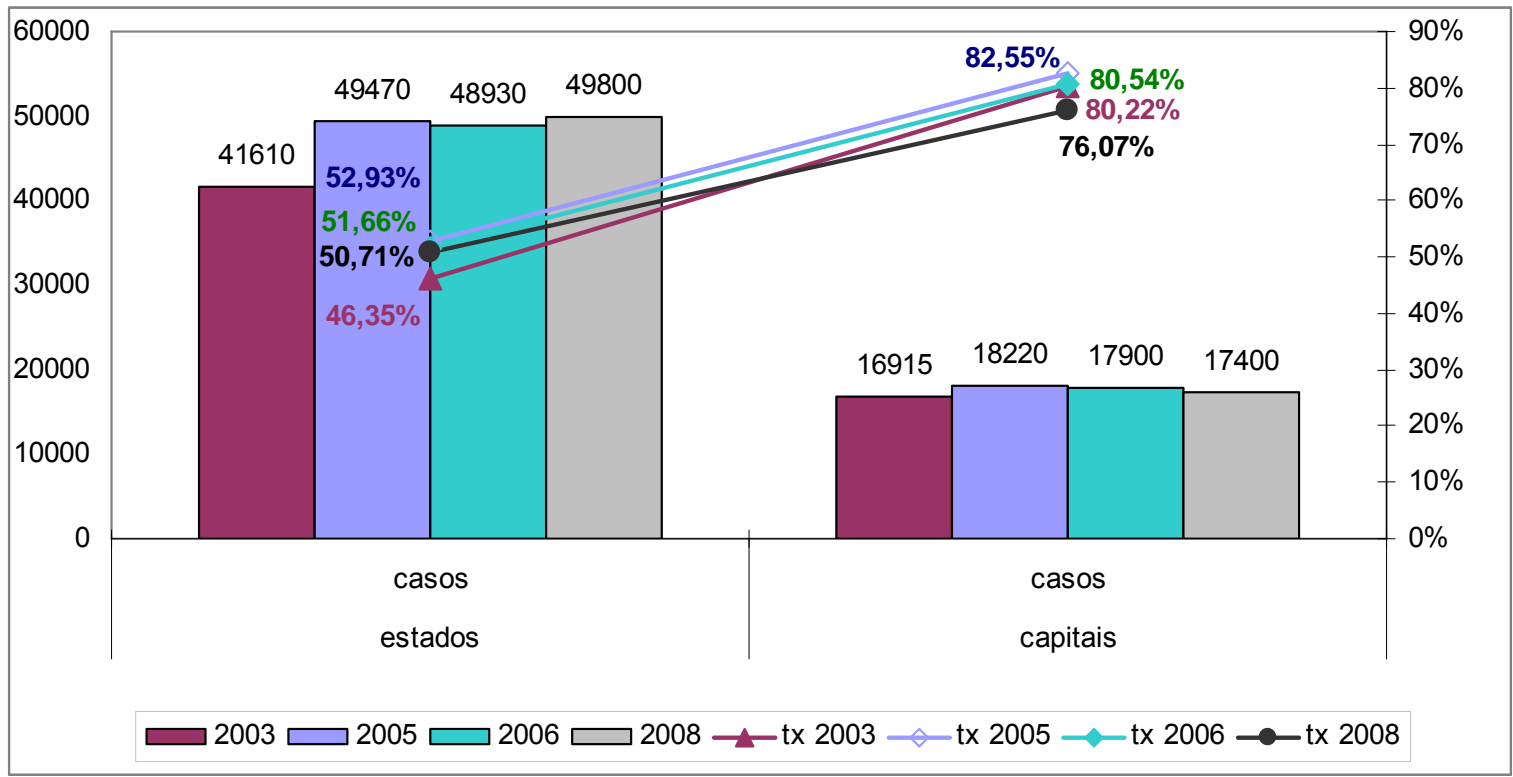

FONTE: INCA $(2003,2005,2006,2008)$

Entre as regiões brasileiras, a região Sudeste concentra $70,50 \%$ dos novos casos de câncer de mama atingindo sozinha 28.640 pessoas acometidas seguida pelas demais regiões, as quais totalizam 20.290 casos novos de câncer (gráfico 2), com risco estimado de 73 casos novos por 100 mil, (INCA, 2008). 
Gráfico 2: Comparação da evolução da estimativa de novos casos de câncer de mama por região geográfica

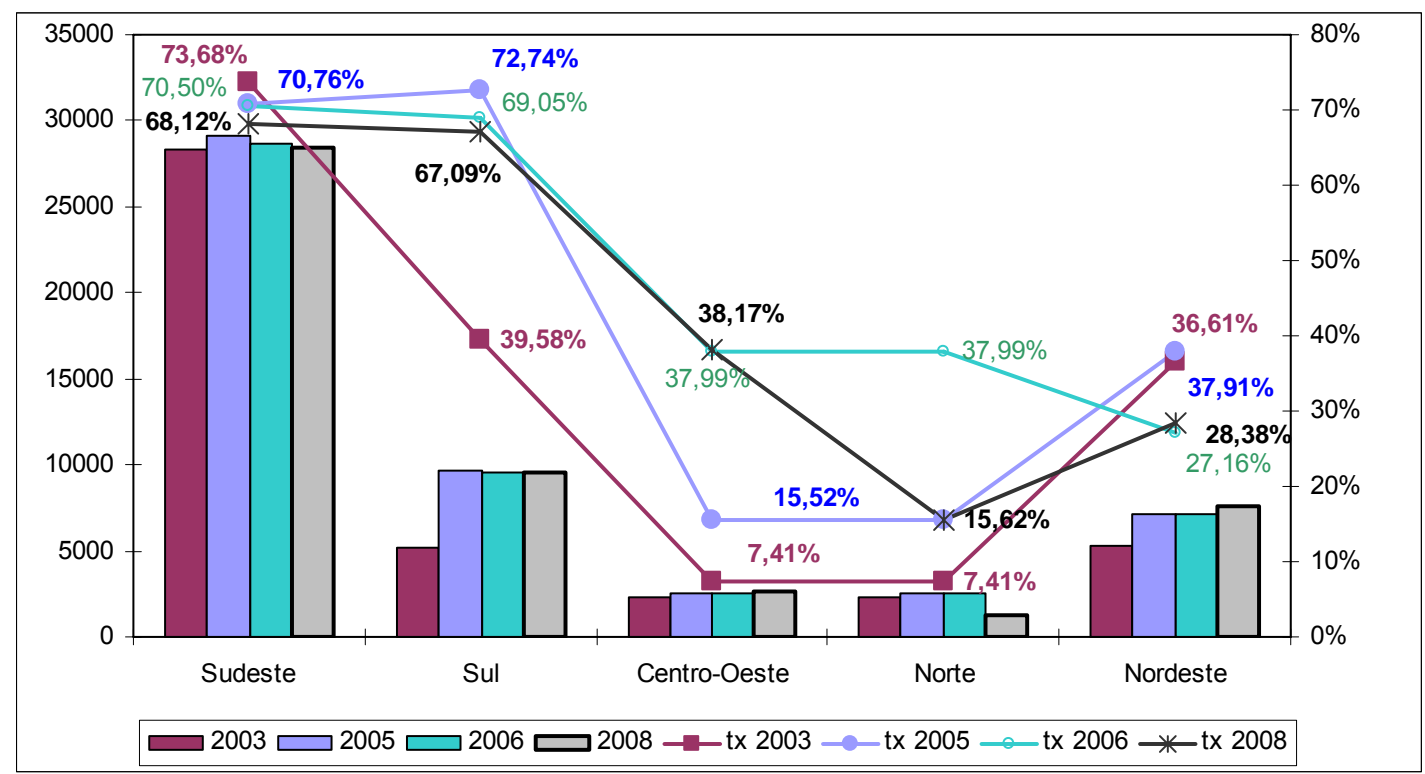

FONTE: INCA $(2003,2005,2006,2008)$

Estas estimativas mostram quão importante é incentivar a mulher a realizar o auto-exame mensal das mamas, através do qual é possível a detecção precoce do câncer que deve ser mais bem investigada através de exames físicos, de imagem (mamografia, ultra-som e ressonância magnética) e de confirmação histológica (Silva et al, 2001; Greene, 2002).

De acordo com a sub-localização anatômica, os tumores da mama, são classificados de acordo com a CID O (OMS, 1996) (apêndice 1).

No momento diagnóstico e após o tratamento, por exemplo, após ciclos de quimioterapia prévia, são realizados estadiamentos clínicos do tumor. (apêndices 1, 2, 3). 


\subsubsection{O tratamento cirúrgico do câncer de mama}

Após o diagnóstico da doença, existem algumas possibilidades de tratamento tais como a quimioterapia neo-adjuvante seguida de cirurgia ou o

procedimento cirúrgico "per si". Estes procedimentos abrangem desde a retirada única do tumor, preservando-se assim a mama, até a mastectomia radical, na qual a mama é extirpada uni ou bilateralmente, havendo também ressecção dos músculos peitorais (maior e menor) e a completa dissecção axilar (Halsted, 1982, Donegan e Spratt, 1995; Basegio, 1999; Silva et al, 2001).

Após o tratamento cirúrgico, as pacientes são submetidas à quimioterapia adjuvante e radioterapia adjuvante ou hormonioterapia. Em alguns casos, há indicação de tratamentos neo-adjuvantes, como a quimioterapia que tem como finalidade a redução da massa tumoral, propiciando uma cirurgia tecnicamente mais adequada, além de fornecer dados quanto à sensibilidade do tumor aos fármacos utilizados em tumores localmente avançados (Souza et al, 2000a).

Já a quimioterapia adjuvante é indicada para todas as pacientes com metástase axilar e para aquelas com tumor maior que $2 \mathrm{~cm}$, mesmo sem axila comprometida. Em alguns casos, dependendo dos fatores prognósticos são indicados para pacientes com tumores entre 1 e $2 \mathrm{~cm}$ de diâmetro, em função do achado axilar. 
O tratamento quimioterápico tem como efeito colateral a alopécia, além de mudanças corpóreas e não fisiológicas que incluem, mal estar geral (inclusive na possibilidade de diminuição da imunidade e infecções oportunistas), náuseas e vômitos importantes (10\%), queda na função cognitiva, como alterações na memória entre outras. É também fator crucial preditivo de disfunções sexuais em mulheres com câncer de mama em função da diminuição da função ovariana, principalmente em pacientes na pré-menopausa, podendo desenvolver diminuição da lubrificação vaginal, atrofia vaginal, fogachos (15\%), amenorréia (Kaplan, 1992; 1999).

As manifestações clínicas desta função dependerão do grau de destruição folicular dentro dos ovários por exemplo, em decorrência da utilização de ciclofosfamida, que tem potencial de prejuízo irrevogável importante sobre a função ovariana da mulher (Rogers et al, 2002; Ganz et al, 1998; Schover, 1994; Barni et al, 1997). A extensão e permanência destes danos dependem da idade, dose administrada e duração da quimioterapia (Kaplan, 1992; Reichman et al, 1994).

De modo geral, todos os tratamentos utilizados para o câncer como o cirúrgico, quimioterapia, radioterapia e a hormonioterapia tem impacto negativo no funcionamento sexual e sobre a fertilidade. Os fatores contribuintes para os problemas psicossexuais são decorrentes dos efeitos do tratamento utilizado e do processo da doença (Sundquist, 2003). 


\section{Efeitos do tratamento}

$\checkmark$ Fadiga, náusea, perda do cabelo

$\checkmark$ Perda da libido

$\checkmark$ Perda da fertilidade, indução a menopausa

$\checkmark$ Linfoedema

$\checkmark$ Ganho ou perda de peso

$\checkmark$ Redução / falta de lubrificação vaginal

$\checkmark$ Redução / falta de resposta orgásmica

$\checkmark$ Perda / alterações em partes do corpo, órgãos sexuais

$\checkmark$ Incontinência urinária

\section{Efeitos do processo da doença}

$\checkmark$ Perda muscular

$\checkmark$ Anemia, palidez

$\checkmark$ Ansiedade, depressão, perda da libido

$\checkmark$ Dor, fadiga

$\checkmark$ Prejuízo neurológico

$\checkmark$ Perda das sensações.

Portanto, o tratamento do câncer de mama engloba um conjunto de procedimentos que abrangem controles locorregionais e sistêmicos, tratamentos cirúrgicos, seguidos ou não por radioterapia, tratamentos quimio e/ou hormonioterápicos, visando terapêutica ideal com o conseqüente sucesso terapêutico (figura 3): 
Figura 3: Câncer de mama: terapêutica

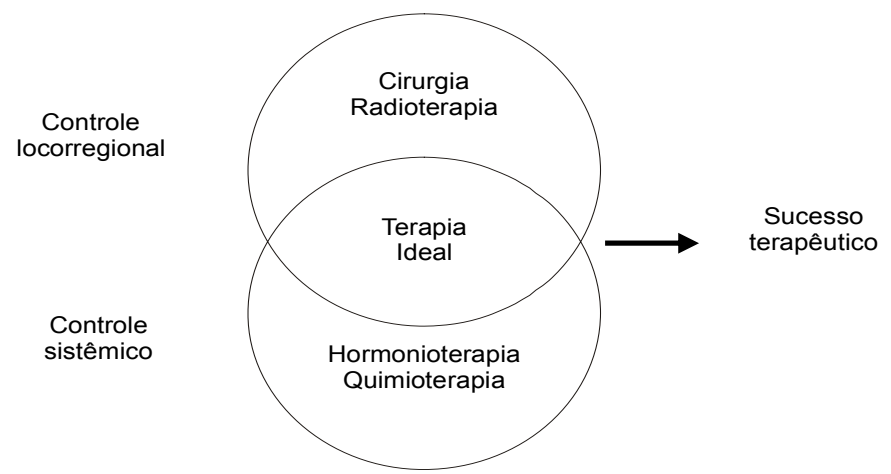

Fonte: Souza et al. (2000)

\subsubsection{As cirurgias de reconstrução mamária}

Quando a mastectomia é escolhida ou é a única opção terapêutica indicada, ou quando há significativo desfiguramento resultante de cirurgia conservadora, a mulher deve decidir se: opta pela reconstrução cirúrgica de suas mamas, se usa uma prótese temporária ou permanente, ou se não tomar nenhuma ação. Optando pela reconstrução, ela deve decidir se esta será imediata ou tardia, isto é, se ocorrerá no mesmo tempo cirúrgico da mastectomia ou a posteriori (Resnick, 2002).

As pesquisas mostram que a reconstrução executada simultaneamente à mastectomia é opção segura para mulheres com câncer de mama (Malata, 2000), além de proporcionar à mulher menor angústia psicológica relacionada a perda da (s) mama (s) e melhor qualidade de vida (Al-Ghazal 
et al., 2000a; Goin e Goin, 1981). As vantagens cirúrgicas da reconstrução imediata da mama incluem o fato dos tecidos do peito estarem intactos de radioterapia ou cicatrizes, e por ser único procedimento ao qual a paciente se submete (Resnick, 2002).

\subsubsection{Conseqüências do câncer de mama na sexualidade feminina}

Quando se pesquisa, na literatura, sobre os efeitos da mastectomia radical na sexualidade feminina, encontra-se que esta forma de intervenção é, na maioria das vezes, comparada à mastectomia simples, à mastectomia parcial, ou seja, a procedimentos menores que a mastectomia total e que podem ou não estar acompanhados de dissecção axilar (Schover, 1994; Schover et al., 1995; Yurek et al., 2000; Fung et al., 2001; Nissen et al., 2001; Parvanova et al, 2001; Veronesei et al, 2002).

O efeito do tipo de cirurgia no ajustamento psicológico aparece mediado pelo sentimento de desfiguramento e pelas mudanças nos padrões afetivo-sexuais nos relacionamentos dos casais.

Mulheres submetidas às cirurgias conservadoras, ao contrário das submetidas à cirurgias radicais, apresentam sentimentos positivos em relação a seu corpo, principalmente quanto a sua nudez. Após a 
mastectomia radical modificada, por volta de $25 \%$ das mulheres apresentam importante ansiedade ou humor depressivo (Schover, 1991).

Wapnir et al. (1999) avaliaram 30 pacientes submetidas à mastectomia e 30 à tumorectomia com dissecção axilar, sendo que $96,6 \%$ destas últimas tiveram as mamas irradiadas. Entre as pacientes mastectomizadas, apenas quatro foram irradiadas. Em relação à quimioterapia esta foi realizada em 17/30 pacientes tumorectomizadas e em 19/30 mastectomizadas.

A tumorectomia não estava associada a diferenças estatisticamente significantes nos índices de qualidade de vida nas questões da versão modificada do Medical Outcomes Study (SF-36), exceto na vitalidade. Diferenças significantes foram encontradas neste grupo em relação ao vestir-se, à nudez e no impulso sexual, quando comparadas às pacientes submetidas à mastectomia.

As cirurgias radicais usualmente produzem pior ajustamento psicológico, as pacientes referem maior declínio em suas relações afetivosexuais, do que as pacientes submetidas à mastectomia simples ou modificada que por sua vez referem maior declínio do que as pacientes submetidas à tumorectomia (Taylor, 1985).

Em 1985, Taylor et al. compararam 9 pacientes submetidas à Halsted, a 31 submetidas às técnicas modificadas e 26 a tumorectomia, concluindo que quanto mais radical a cirurgia, pior o ajustamento psicológico, sendo os principais colaboradores para isso, o senso de desfiguramento produzido pela cirurgia e os efeitos do funcionamento afetivo-sexual sobre o relacionamento conjugal, havendo maior perturbação sexual nas mulheres 
submetidas à mastectomia radical. A correlação entre o tipo de cirurgia e o ajustamento, demonstrou ser estatisticamente significante.

Assim, quando a mulher é submetida à mastectomia, como forma de tratamento para o câncer de mama, este corpo "perfeito" sofre um "corte" em sua harmonia, tornando-se "imperfeito". Esta "imperfeição" pode causar diversos problemas, incluindo aqueles ligados à sexualidade, sendo que estes podem ou não estar correlacionados diretamente à cirurgia feita (Miller e Graham, 1975; Lim et al, 1995).

Em relação à sexualidade das pacientes submetidas à cirurgias conservadoras, McPhail e Wilson (2000) observaram que não houveram diferenças relacionadas ao interesse sexual anterior ao diagnóstico e tratamento $(71 \%)$ havendo, porém, diminuição deste interesse em $29 \%$ das mulheres e maior inibição sexual em $25 \%$ delas.

Mudanças negativas no relacionamento sexual foram percebidas por $17.9 \%$ das mulheres, no período entre o diagnóstico e o tratamento. $\mathrm{O}$ completo cessar da atividade sexual ocorreu em $7 \%$ das pacientes.

Boff (1999) constatou que existem mudanças significativas em vários comportamentos relacionados à sexualidade nas pacientes submetidas à mastectomia, tais como: dificuldade em agir sedutoramente, dificuldade em despir-se na frente do marido; não visualização e toque da cicatriz cirúrgica pelo marido e, algumas vezes, diminuição da atividade genital representando uma mescla de auto-estima e imagem corporal abalada.

Isto se deve aos sentimentos de menos valia, causados e aflorados pela mutilação, que estas pacientes passam a ter quando se comparam a 
mulheres saudáveis neste caso, com as mamas preservadas (Maluf, 2005, 2006d).

Após submeter-se à mastectomia, existe a opção da realização ou não da reconstrução mamária concomitantemente a cirurgia ou em outro momento.

A realização da reconstrução no mesmo tempo cirúrgico da mastectomia oferece grandes vantagens como a preservação do revestimento cutâneo da mama posicionado em relação ao tórax e a boa qualidade do tecido, evitando assim intensas fibroses e a retração da cicatriz resultante da mastectomia, além do benefício psicológico para a paciente (Góes, 1995), através da diminuição dos efeitos negativos do câncer de mama no que tange ao bem estar sexual e psicossocial destas mulheres (Ganz et al., 2000).

Em estudo realizado por Al-Ghazal et al. (2000a), as pacientes foram submetidas à diferentes tipos de reconstrução mamária (38 com reconstrução imediata; 83 com reconstrução tardia) e acompanhadas para se avaliar ansiedade, depressão, imagem-corporal, auto-estima, sexualidade e satisfação.

Das pacientes submetidas à reconstrução imediata (95\%), o nível de satisfação encontrado foi "muito" ou "moderado" (94\%). Já as pacientes de reconstrução tardia (76\%), preferiam a reconstrução imediata, sendo o índice de satisfação de $73 \%$.

Com relação à sexualidade, apenas $8 \%$ do grupo de reconstrução imediata comparada com $32 \%$ do grupo de reconstrução tardia sentiram 
óbvio prejuízo em sua atração sexual. As mulheres do grupo de reconstrução imediata (63\%) sentiam-se sexualmente atraentes, o que foi significantemente melhor do que o grupo de reconstrução tardia (17\%), no qual $51 \%$ das pacientes sentiam-se pouco menos atraentes, quando comparadas ao grupo de reconstrução imediata (29\%).

Os resultados mostram as vantagens da reconstrução imediata sobre a tardia não referem apenas a melhores resultados cosméticos e a relação custo benefício, mas também as vantagens na qualidade de vida e melhora do bem-estar psicológico: baixo índice de depressão e ansiedade, altos índices de auto-estima e boa imagem corporal

Pesquisas mostram que as pacientes submetidas à mastectomia sem reconstrução são acometidas por maior morbidade psicossocial, ou seja, fatores relacionados à ansiedade, depressão, auto-imagem, sexualidade e auto-estima. Por outro lado, havendo a reconstrução, a cirurgia tem efeito menos impactante sobre a vida sexual da mulher que se sente desejável quando anseia ter relações sexuais e quanto as suas práticas sexuais ou ao quanto ela desfruta destas relações, contribuindo, portanto, para diminuição dos fatores mórbidos (Al-Ghazal et. al., 2000 a, b; Ganz et. al., 2000, Schover, 1991) ou sendo um fator de "proteção psicológica" para mulheres jovens (Schover, 1994).

Rowland et al. (2000), recrutaram 1.119 mulheres submetidas à tumorectomia, 327 à mastectomia com reconstrução e 511 à mastectomia sem reconstrução. O grupo de tumorectomia mostrou menos problemas relacionados à imagem corporal e sentimentos de serem sexualmente 
atraentes do que ambos os grupos de mastectomia, sendo estes dados estatisticamente significantes. Porém o benefício da reconstrução para a imagem corporal das mulheres submetidas à mastectomia foi menor do que o esperado.

Menos que $30 \%$ das mulheres submetidas à cirurgia conservadora, perceberam que o câncer teve impacto negativo em sua vida sexual, mais que $40 \%$ submetidas à mastectomia (com, 45,4\% e sem reconstrução, $41,3 \%)$ referiram impacto negativo.

Wilmoth e Townsend (1995), avaliaram 45 mulheres submetidas à tumorectomia, 74 à mastectomia sem reconstrução e 45 à mastectomia com reconstrução e mostraram que não existem diferenças significativas na sexualidade entre os três grupos, medidas através do WSFQ (Watts Sexual Function Questionnaire) e do Sexual Behavior Questionnaire. Foi observado que as pacientes submetidas à mastectomia com reconstrução não tiveram os efeitos positivos esperados sobre o comportamento sexual, especialmente se foram submetidas à quimioterapia adjuvante.

A quimioterapia adjuvante teve efeitos significantemente negativos sobre o comportamento sexual das pacientes estudadas, conforme observado por Kaplan (1992).

Em outro estudo realizado por Al-Ghazal et al. (2000b) com 577 mulheres submetidas à tumorectomia (44\%), a mastectomia (35\%) e a mastectomia com reconstrução (21\%) observaram diferenças estatísticas significantes entre os três grupos, favorecendo o grupo submetido à tumorectomia seguido pelo grupo de mastectomia com reconstrução, quanto 
a satisfação e morbidade psicossocial (ansiedade, depressão, imagem corporal, sexualidade e auto-estima). Grande morbidade foi observada no grupo das mastectomizadas.

Quanto à sexualidade, 39\% das mastectomizadas demonstraram óbvio prejuízo quanto a se sentir sexualmente atraente, o que já não ocorria no grupo submetido a tumorectomia (44\%). Já no grupo de mastectomia com reconstrução, $44 \%$ das pacientes percebiam-se pouco menos atraentes sexualmente.

Estes resultados reafirmam que a reconstrução mamária oferece a possibilidade de benefícios psicológicos para as pacientes com câncer de mama operável, da mesma forma como pacientes que fizeram reconstrução relatam menos sofrimento psicológico do que aquelas submetidas à mastectomia simples sem reconstrução.

Harcourt et al. (2003), compararam 56 mulheres submetidas à mastectomia sem reconstrução, com 37 que realizaram reconstrução imediata, com 10 que reconstruíram as mamas tardiamente, em 6 e 12 meses de pós-operatório.

Altos níveis de ansiedade foram observados pré-cirurgicamente em todos os grupos, não importando o tipo de procedimento cirúrgico adotado. Níveis mais altos de sofrimento, baixo funcionamento psicológico e pior imagem corporal neste estágio, foram reportados por mulheres no grupo de reconstrução tardia. A preocupação com a auto-imagem referida por este grupo melhorou significantemente ao longo do estudo, sugerindo que a 
cirurgia foi bem sucedida em aliviar o sofrimento pré-cirúrgico sobre sua aparência.

Em relação à sexualidade, aquelas submetidas à mastectomia sem reconstrução reportaram escores significantemente baixos na dimensão do funcionamento sexual. Tendiam a dar avaliações de satisfação mais altas do que aquelas submetidas à reconstrução, que basearam suas respostas nos sentimentos sobre sua aparência. O grupo de mastectomia provavelmente avaliou sua satisfação de encontro à prioridade da remoção do câncer.

No estudo conduzido por Cyran et al. (2001), 102 pacientes submetidas à mastectomia e 96 à tumorectomia, demonstrou que mulheres submetidas à mastectomia tendiam a preocupar-se mais com a recidiva da doença, o pode explicar a opção inicial de realizar a mastectomia como tratamento, mas também sugere a mastectomia pode não reduzir adequadamente suas preocupações. No caso de pacientes submetidas à tumorectomia, no entanto, o medo de recidiva pode ser atribuído pelo aumento da escolaridade e aconselhamento médico.

Mock (1993), comparou a auto-imagem de 62 mulheres submetidas à mastectomia, 47 a mastectomia com reconstrução tardia, 58 a mastectomia com reconstrução imediata e 90 a cirurgia conservadora, encontrando diferenças significativas na imagem corporal em função do tipo de cirurgia realizada: àquelas submetidas à cirurgia conservadora referiram grande satisfação com seus corpos do que mulheres tratadas com mastectomia ou mastectomia com reconstrução imediata. Este achado vem de encontro aos resultados encontrados por Margolis (1990). 
O aumento do uso das cirurgias conservadoras pode diminuir os efeitos negativos do carcinoma de mama sobre a qualidade de vida de pacientes com idade inferior a 50 anos. Para eles, estas cirurgias parecem ter efeito protetor contra o sofrimento, quando comparado a mastectomia radical. Este estudo foi concluído oito anos após o tratamento inicial de câncer de mama (Dorval et al., 1998).

A prevalência das disfunções sexuais em pacientes com câncer de mama, varia entre $21 \%$ e $39 \%$, podendo estar associadas ao medo da mutilação e a rejeição sexual. No caso de mulheres que tenham auto-estima ou imagem corporal intimamente relacionadas as mamas como fonte de atração, estão mais sujeitas a "riscos", após a mastectomia, relacionados à imagem corporal e à sexualidade, do que aquelas que não tem essa preocupação (Kaiser, 1992).

Nissin et al. (2001) realizou estudo prospectivo de 24 meses de pósoperatório com 55 mulheres submetidas à mastectomia, 40 a mastectomia com reconstrução e 103 a cirurgia conservadora, concluíram que mulheres submetidas à cirurgia conservadora ou reconstrução pós-mastectomia não mostraram nenhuma vantagem com relação àquelas submetidas à mastectomia, nas escalas de qualidade de vida: pacientes que realizaram reconstrução apresentaram grave distúrbio do humor e pobre bem-estar quando comparadas àquelas submetidas à mastectomia sem reconstrução. Mulheres submetidas à reconstrução falam sobre os efeitos negativos da mastectomia em sua vida sexual. 
Hartcher et al. (2001), avaliaram 143 mulheres com alto risco de desenvolver câncer de mama, para as quais foi oferecida a possibilidade de se fazer mastectomia bilateral profilática. Estas pacientes podiam declinar ou aceitar tal tratamento. A decisão sobre submeter-se ou não à mastectomia, foi adida por 11 pacientes, excluídas do estudo.

As pacientes foram avaliadas visando-se à investigação do impacto psicossocial causado pela mastectomia bilateral profilática. Os resultados mostraram que pacientes não cirúrgicas apresentaram altos escores para ansiedade que não declinaram conforme o tempo, tendendo a utilizar-se de mecanismos de deslocamento para enfrentar a situação, ao invés de focarem o problema, mecanismo este utilizado freqüentemente pelas pacientes cirúrgicas.

Foi averiguada a questão do desconforto e do prazer sexual. Com relação à primeira, houve mudanças discretas durante o tempo dentro ou entre os grupos. Não houve alterações significantes relacionadas a decréscimo no prazer sexual em ambos os grupos (escala de 0 a 18, sendo 18 o escore de máximo prazer sexual).

Margolis et al. (1990) indicaram que pacientes submetidas à mastectomia radical apresentam decréscimo na qualidade (76\%) e na freqüência das relações sexuais. Em relação à imagem corporal, sentem-se, de modo geral, menos atraentes $(78 \%)$, sexualmente menos desejáveis (73\%), menos atraentes quando despidas (100\%), envergonhadas com suas mamas (57\%) e percebem que a estimulação nas mamas tende a ser menos importante na relação (86\%). A diminuição do prazer sexual foi atribuído 
diretamente a imagem corporal desfavorável secundária à mastectomia, o que vem de acordo aos achados de Yilmazer et al. (1994), cujas pacientes submetidas à mastectomia radical foram impactadas negativamente em sua imagem corporal, identificando e associando a perda das mamas com a perda da feminilidade $(72,5 \%)$, sentindo-se pois incompletas $(82,5 \%)$ como resultado da distorção em sua aparência.

Ganz et al. (1998), ao avaliarem 444 mulheres submetidas à cirurgia conservadora, 269 à mastectomia radical e 151 à mastectomia radical com reconstrução, verificaram que $65,5 \%$ das pacientes submetidas à cirurgia conservadora estavam sexualmente ativas no momento do diagnóstico de câncer de mama. Para aquelas que eram inativas, em mais da metade (55\%) a inatividade devia-se a não existência de um parceiro e por uma variedade de razões, sendo a mais comum à perda de interesse do parceiro ou por algum problema físico do mesmo que impedia a relação sexual. Aproximadamente $91 \%$ das mulheres sexualmente ativas tinham o mesmo parceiro. Neste estudo, foram encontradas algumas diferenças na imagem corporal entre os três grupos, mas esta não se traduziu em fortes efeitos sobre a função sexual.

Em 1999, Ganz et al. avaliaram duas amostras independentes sendo a primeira constituída por 472 pacientes (249 submetidas à cirurgia conservadora, 99 à mastectomia radical com reconstrução e 124 à mastectomia radical) e a segunda por 662 pacientes (395 submetidas à cirurgia conservadora, 132 mastectomia radical com reconstrução e 135 mastectomia radical sem reconstrução), totalizando 1134 pacientes. 
A qualidade do relacionamento com o parceiro foi um dos fatores preditivos de satisfação sexual em ambas as amostras e a presença de problemas sexuais no parceiro também contribuía para a satisfação das pacientes.

Cohen et al. (2000), avaliaram 123 mulheres submetidas à cirurgia conservadora e 60 à mastectomia radical, por 60 meses e observaram que as primeiras apresentavam aumento de distúrbios psicológicos (dor, sofrimento) durante o tempo, ao passo nas demais houve diminuição dos níveis de estresse psicológico durante o tempo.

As curvas do estudo se cruzavam aproximadamente em 20 meses de pós-operatório, sugerindo que as mulheres submetidas à cirurgia conservadora apresentavam menores níveis de sofrimento psicológico durante os 20 primeiros meses de pós-operatório mas grandes níveis de sofrimento mais tarde.

Em estudo realizado por Fung et al. (2000) com 14 submetidas à cirurgia conservadora, 17 à mastectomia, 17 à mastectomia com reconstrução, não foram encontradas diferenças estatísticas significantes nos três grupos em relação a vida sexual e bem-estar psicológico. Porém houve diferenças significativas no que concerne a melhor auto-imagem no grupo de cirurgia conservadora comparado ao grupo de mastectomia: $86 \%$ das pacientes estavam satisfeitas com o tipo de cirurgia escolhida e todas as pacientes estavam satisfeitas com o tratamento que receberam de modo geral, apesar do tipo de cirurgia realizado. 
Para Fallowfield e Hall (1991), os distúrbios psicossociais e sexuais são seqüelas comuns ao diagnóstico e tratamento do câncer de mama, residindo à morbidade psicológica no fato que a amputação das mamas produzirem profundo efeito negativo nos sentimentos de feminilidade, auto-estima e imagem-corporal, sendo isto mais marcado em culturas que promovem as mamas como símbolo da feminilidade.

Ganz et al. (1992), avaliaram a qualidade de vida, nível de performance e ajustamento psicológico de 57 mulheres submetidas à mastectomia e 52 submetidas à cirurgia conservadora por um ano de seguimento. Não foram encontradas diferenças significantes na qualidade de vida, transtornos do humor, nível de performance ou ajustamento global entre os grupos estudados. Como prognosticado, pacientes mastectomizadas reportaram maiores dificuldades relacionadas ao vestuário e a imagem corporal, porém estes dados aparentemente não afetaram a avaliação do humor e da qualidade de vida. Os autores concluíram que pacientes submetidas à cirurgia conservadora não obttiveram melhor qualidade de vida ou de humor que pacientes mastectomizadas, no entanto apresentam menos problemas relacionados ao vestuário e à imagem corporal. Porém estas pacientes requerem intervenção psicossocial mais intensa no pós-operatório devido à adição da primeira carga de radioterapia.

Jahkola (1998), avaliou 56 pacientes submetidas à mastectomia e 90 à cirurgia conservadora encontrou diferença estatísticamente significante em ambos os grupos com relação à satisfação sexual, resultado cosmético e 
satisfação com a vida social. Para isso foi considerada uma escala de valores de 0 (pior) a 10 (melhor).

Os escores foram significantemente maiores no grupo submetido à cirurgia conservadora do que na mastectomia, indicando melhor qualidade de vida.

Lim et al. (1995), avaliaram 24 mulheres casadas, sendo 21 submetidas à mastectomia radical e três à cirurgia conservadora. Dentre as pacientes mastectomizadas, observou-se redução na freqüência do intercurso sexual em $45 \%$ e decréscimo do desejo em $30 \%$, sendo estas percentagens estatisticamente significantes.

Nas três pacientes submetidas à cirurgia conservadora, não se notaram decréscimos na satisfação com a vida sexual. Destas, duas apresentaram queda do desejo para intercurso sexual e em uma não houve diminuição da satisfação na vida sexual.

As mudanças nos hábitos sexuais ocorreram exclusivamente no grupo submetido à mastectomia, sendo gerado pelas alterações na imagem corporal e auto-imagem sexual.

Meyerowitz et al. (1999), dividiram 440 mulheres submetidas a tumorectomia, 155 a mastectomia com reconstrução e 268 sem reconstrução em dois grupos de acordo com a existência ou não de atividade sexual, isto é, sexualmente ativas ou inativas.

As mulheres sexualmente inativas, o eram devido à ausência de parceria $(57 \%)$, falta de interesse $(23 \%)$, parceiro com problemas físicos (16\%) ou falta de interesse do parceiro (10\%). Já nas sexualmente ativas 
(56\%) mantinham relações pelo menos uma vez por semana enquanto $12 \%$ tinham atividade sexual menos que uma vez por mês. A iniciativa para a relação sexual era tomada em $57 \%$ pelo parceiro.

Mulheres sexualmente ativas antes do diagnóstico e não mais no momento da pesquisa, eram mais propensas a experimentar impacto negativo do câncer, enquanto que as mulheres que não tinham atividade sexual eram menos propensas a referir sobre o impacto do câncer de mama em sua vida sexual.

Para um terço das mulheres, o câncer de mama teve impacto negativo sobre a vida sexual. Estas que reportaram impacto negativo geral, foram aquelas que tiveram alterações hormonais, problemas de relacionamento com seus parceiros e dificuldades devido ao ressecamento vaginal. A grande maioria das pacientes identificou mudanças negativas em pelo menos algumas áreas da sexualidade, como se observa na tabela 1.

Tabela 1: resultados do Watts Sexual Function Questionnaire

\begin{tabular}{lcc}
\hline Pacientes sexualmente ativas $(\mathrm{n}=268)$ & DP \\
\hline Escore total & 55.1 & 9.52 \\
Sub-escala: desejo & 18.1 & 93.61 \\
Sub-escala: interesse & 12.4 & 4.15 \\
Sub-escala: orgasmo & 12.9 & 3.33 \\
Sub-escala: satisfação & 11.8 & 2.06 \\
\hline
\end{tabular}

NOTA: DP: desvio padrão $-p>.01$ 
Em 2004, Maluf estudou 19 pacientes submetidas à mastectomia radical (média etária de 49,2 anos) visando a observação da presença ou não de disfunções sexuais relacionadas à mastectomia radical. As pacientes foram divididas em dois grupos de acordo com a realização ou não de reconstrução mamária.

Todas as pacientes responderam em uma única aplicação, ao Watts Sexual Function Questionnaire - WSFQ (Watts, 1982) em torno do terceiro mês de pós-operatório, o qual foi traduzido e adaptado à realidade brasileira, sendo acrescidas questões qualitativas que visavam aprofundar 0 conhecimento sobre os sentimentos e pensamentos das pacientes ao saber que seriam submetidas à mastectomia radical.

Os resultados do WSFQ demonstraram a presença de indícios de disfunção orgásmica nas pacientes submetidas à mastectomia radical sem reconstrução quando comparadas àquelas submetidas à mastectomia radical com reconstrução.

Estas mulheres conseguiam se engajar na atividade sexual e manter seu nível de excitação, tendo-se mantido o interesse do parceiro por elas. Porém no desenvolver da relação, as mesmas não chegam, ao orgasmo, possivelmente devido às alterações existentes em relação a sua autoestima, no ver-se e no tocar-se.

Poulsen et al. (1997), observaram que pacientes submetidas à mastectomia apresentavam baixos escores de auto-imagem do que pacientes submetidas à cirurgia conservadora, o que não foi traduzido em problemas sexuais. 
Schain (1994), comparando pacientes submetidas à mastectomia e àquelas submetidas à tumorectomia e a radioterapia verificou diferenças estatisticamente significantes no seguimento de seis meses, no que concerne aos problemas na relação sexual em $19 \%$ do grupo de mastectomizadas quando comparadas a $5 \%$ daquelas submetidas à tumorectomia e a radioterapia. Em 12 meses, $16 \%$ das pacientes de mastectomia comparadas a $15 \%$ submetidas à tumorectomia, referiram sentir-se moderadamente a severamente perturbadas com as dificuldades sexuais. Após 24 meses do início da pesquisa, 13\% das mulheres que perderam a mama, comparadas a $12 \%$ das pacientes de cirurgia conservadora, referiram este nível de preocupação

Shimozuma et al. (1999), concluíram que a auto-imagem é fator importante para as pacientes após a cirurgia. Desta forma, 66,7\% das pacientes mastectomizadas sentiam-se desconfortáveis com as mudanças corporais, contra $41,3 \%$ das pacientes submetidas à cirurgia conservadora em um mês. Em 12 meses esta percentagem era de 54,8\% e 38\%, respectivamente. A dificuldade de mostrar o corpo foi referida por $57,8 \%$ das mastectomizadas e por $34,7 \%$ das pacientes submetidas à cirurgia conservadora em um mês e por $43,7 \%$ e $23,9 \%$ respectivamente, em um ano. Assim, um ano após a cirurgia, a maioria das mulheres mostrou níveis estáveis ou melhores de funcionamento físico e psicológico, com poucos casos de deterioração significativa.

Yurek et al. (2003), compararam três grupos cirúrgicos para determinação das diferenças individuais na sexualidade no pós-operatório e 
o estresse causado pela mudança corporal. Estes grupos foram compostos por 78 pacientes submetidas à tumorectomia, 29 à mastectomia radical com reconstrução, 79 à mastectomia radical modificada e quatro à mastectomia bilateral.

Com relação ao funcionamento sexual, não houve diferenças significativas entre os grupos. Já em relação à aproximação ou afastamento do comportamento / atividade sexual, houve diferença significativa, indicando que a freqüência do comportamento sexual era significantemente mais baixa em mulheres que receberam reconstrução do que naquelas submetidas à tumorectomia ou à mastectomia radical modificada.

Em relação à reposta sexual, as mulheres tratadas com cirurgia conservadora relataram maior interesse durante a atividade sexual do que aquelas submetidas à mastectomia radical modificada.

Taylor et al. (2002) verificaram em 91 mulheres com câncer de mama, que a atração sexual está marginalmente associada ao estágio da doença, quimioterapia e local resultante, não estando associada ao tipo ou tempo de e cirurgia, radioterapia, estado civil ou educação. Não foram encontradas diferenças entre os grupos cirúrgicos cujas pacientes que receberam quimioterapia, mas sim entre aquelas que não receberam este tratamento, como as pacientes mastectomizadas, que relatam maior preocupação com a atração sexual. Este resultado vem de encontro ao que autores como Ganz et al. (1992, 1998), Schain et al., (1994) e Mock (1993) referiram de que cirurgias conservadoras estão menos propensas a resultar em distúrbios da imagem-corporal do que a mastectomia. 
Urbanek et al. (1992, 1994 a), observaram problemas relacionados à auto-imagem, em 154 mulheres com tumores malignos, tais como não conseguir se ver nua na frente de outras mulheres e nem na frente dos parceiros. Sentimentos adversos eram mais freqüentes durante a primeira semana de pós-operatório, havendo uma pior adaptação nas mulheres entre os 40 e os 44 anos: mudanças nas relações emocionais entre o casal eram mais favoráveis que na vida sexual.

Urbanek et al. (1994b), conduziram questões relacionadas a mudanças no estado geral do intercurso sexual após o tratamento de carcinoma em comparação com o ano precedente ao estabelecimento do diagnóstico, em 151 pacientes.

O intervalo de tempo utilizado foi: abaixo de um ano, entre um e dois anos e mais de dois anos de pós-cirúrgico. Deterioração mais freqüente da função sexual foi observada em pacientes após longo intervalo seguinte à operação. Foi encontrada proporção significativamente alta de mulheres com sintomatologia neurótica acentuada no grupo com leve disfunção sexual.

Veronesi et al. (2002, 1986), conduziram estudo randomizado comparativo entre cirurgias conservadoras (quadrantectomia) e mastectomia radical, em 20 anos de seguimento.

As 352 pacientes submetidas a quadrantectomia tiveram alta taxa de recorrência do tumor comparadas ao grupo de mastectomia. Destas 30 pacientes com recorrência tumoral na mesma mama, 29 foram submetidas à mastectomia radical e uma foi submetida a nova ressecção local. 
Das pacientes que iniciaram o estudo, 152 faleceram no grupo de mastectomia radical e 156 no grupo de cirurgia conservadora. Destas, 57\% morreram de câncer de mama (86 no grupo de mastectomia radical e 91 no grupo de cirurgia conservadora), $14 \%$ de outro câncer primário e $24 \%$ de doenças não-neoplásicas.

Analisando-se os dados obtidos, os autores acreditam que o uso de técnicas conservadoras está associado à alta qualidade de vida, sendo razão importante para a detecção precoce do câncer de mama.

Mulheres submetidas à cirurgia conservadora têm auto-imagem mais favorável do que aquelas submetidas à mastectomia (Irwig e Bennetts, 1997).

Em estudo recente conduzido por Bukóvic et al. (2005) com 108 pacientes em estágio avançado de câncer de mama, tratadas com mastectomia radical modificada associada a quimio ou radioterapia adjuvante e 98 em estágios iniciais da doença, tratadas com cirurgia conservadora: tumorectomia e radioterapia observaram-se em ambos os grupos, um significativo número de pacientes satisfeitas com sua vida sexual antes do tratamento $(70,37 \%$ e $73,47 \%$, respectivamente), índice este radicalmente reduzido após o tratamento (56,48\% e 50\% respectivamente).

No grupo em estadio avançado, $58,33 \%$ das pacientes perceberam diferença em sua imagem corporal, em contraste a $44,90 \%$ do grupo em estadio inicial, havendo proporção similar de pacientes que se sentiam mutiladas $(18,52 \%$ vs $8,16 \%)$. 
Os resultados obtidos neste estudo, confirmam e estendem as pesquisas prévias sobre o prejuízo no funcionamento sexual entre as sobreviventes de câncer de mama.

\subsubsection{Os efeitos da quimioterapia, hormonioterapia e radioterapia sobre} a sexualidade feminina

O sofrimento em curto prazo, causado pelos efeitos da quimioterapia adjuvante, como fadiga, alopécia, constipação, náusea, estomatites e ganho de peso, podem contribuir para alterar o funcionamento sexual, em virtude da diminuição da libido feminina e da capacidade da mulher para se engajar na atividade sexual (Rogers et al., 2002).

O uso da quimioterapia pode resultar na perda temporária ou permanente da função ovariana, relacionada à destruição dos folículos ou fibrose dos ovários (Rogers, 2002; Horden, 2000).

Mulheres com mais de 35 anos estão mais propensas à menopausa permanente (entre $61 \%$ e $97 \%$ ) do que as mais jovens (22\% a $61 \%$ ) que possuem número maior de oócitos na reserva, o que diminui a probabilidade de apresentarem qualquer dano permanente ao ovário após a quimioterapia (Horden, 2000; Schover, 1994; Rogers, 2002; Kaplan, 1992).

Quando a menopausa é induzida pela quimioterapia, há tendência de agravamento dos sintomas da menopausa (Barret-Connor, 1998), tais como 
mais oscilações do humor, alta incidência de ondas de calor, aumento na probabilidade de depressão, secura e atrofia vaginal e vulvar. A mucosa vaginal torna-se frágil e fina, ficando irritada durante o intercurso sexual (Horden, 2000).

Devido às propriedades imunossupressoras da maioria dos agentes quimioterápicos, algumas mulheres podem ter episódios de Candida albicans, herpes genital, gonorréia ou verrugas genitais associadas à quimioterapia. Desta forma, a prática de sexo com proteção deve ser adotada pelo casal (Horden, 2000).

Pozo et al. (1992), verificaram os efeitos da quimioterapia em dois momentos do pós-operatório em 48 pacientes mastectomizadas e 15 tumorectomizadas: em três meses, estava relacionada inversamente a satisfação simultânea de vida, positivamente contribuindo para pensamentos intrusos, positivamente nas avaliações simultâneas de dor que interferem nas atividades diárias, e inversamente nas auto-avaliações simultâneas de adaptação; aos seis meses foi relacionada positivamente nas avaliações simultâneas de dor que interferem nas atividades diárias e a intrusão de pensamento, referidos na avaliação no $12^{\circ}$ mês.

Análises comparativas entre os dois grupos de pacientes mostraram resultados significantes: em seis meses de seguimento as pacientes submetidas à tumorectomia referiram maior satisfação em sua vida sexual do que as mastectomizadas. Resultado semelhante surgiu no $12^{\circ}$ mês de seguimento. 
Em 1997, Barni et al. avaliaram 21 mulheres submetidas à quadrantectomia e 29 à mastectomia. Destas pacientes, 30\% apresentaram disfunções sexuais após o tratamento cirúrgico, com piora em torno de $27 \%$. Os problemas sexuais surgiram principalmente após a quimioterapia (36\%), após a cirurgia (12\%) ou após a radioterapia (6\%).

Problemas sexuais, tais como disfunções, costumam aparecer como conseqüência do hormônio e da quimioterapia (Thors et al., 2001) e incluem a perda da libido, a infertilidade e a menopausa prematura (Maguire, 1999).

Quando as disfunções sexuais ocorrem, pode haver certa dificuldade de aceitação por parte dos parceiros. A dificuldade na adaptação as mudanças nas relações conjugais e/ou sexuais são preditivas de depressão no parceiro (Maguire, 1999).

Schover et al. (1995) observaram a presença de disfunções sexuais em 27 mulheres submetidas à mastectomia parcial e 146 a mastectomia com reconstrução imediata.

Da amostra estudada, 43 mulheres receberam tratamento quimioterápico (significantemente mais jovens do que as demais), se observado maior preocupação destas com a recorrência do câncer, menor freqüência e desejo sexual, dispareunia e vagina mais ressecada, habilidade para alcançar o orgasmo durante o intercurso sexual tente a ser reduzida, no entanto a habilidade de ter orgasmos por carícias não-coitais não diferiu das demais mulheres. A satisfação sexual destas mulheres é expressivamente menor, além de apresentarem pior imagem-corporal. 
Broeckel et al. (2002), compararam 58 mulheres com câncer de mama a 21 mulheres sem câncer. Dentre as pacientes com câncer de mama, 47\% foram submetidas à mastectomia, 50\% a tumorectomia e 3\% à mastectomia e tumorectomia. Estas pacientes receberam quimioterapia adjuvante e $71 \%$ receberam também radioterapia adjuvante e 48\% hormonioterapia (tamoxifeno).

Pacientes com câncer de mama apresentaram menor função sexual e também significante piora em relação à fadiga, depressão, ondas de calor e ressecamento vaginal quando comparadas ao grupo sem câncer, sendo este último fator que contribui para fraco funcionamento sexual, em longo prazo, em pacientes com câncer de mama, interferindo potencialmente no desejo sexual e pode contribuir para uma dispareunia.

Wilmoth (2001), examinou as conseqüências do câncer de mama na função sexual de 11 mulheres submetidas à mastectomia e 7 à tumorectomia, sendo que $94 \%$ das pacientes receberam somente quimioterapia adjuvante ou em combinação com hormônio ou radioterapia.

Foram observadas alterações relacionadas à aparência que produziram mudanças tanto emocionais quanto práticas, tais como: vestirse, estar nua na frente de alguém e a alopécia. $O$ término da menstruação foi associado ao envelhecer.

Várias participantes referiram diminuição do desejo sexual, sendo esta experiência incômoda, especialmente para as que previamente tinham experimentado muito desejo sexual e para aquelas que haviam construído muito de sua identidade ao redor de sua capacidade de funcionamento 
sexual. As pacientes tinham problemas relacionados ao ressecamento vaginal, dor, perda de sensibilidade nas mamas, decréscimo na sensação orgásmica e aumento no tempo até alcançar o orgasmo. Houve também mudanças nas posições durante as relações, em função da cirurgia, assim como mudanças no lado da cama para dormir. Várias mulheres se sentiam diminuídas em seus conceitos enquanto mulher, indicando alguma reflexão interna sobre a experiência sofrida, para se redefinirem.

Os relacionamentos eram importantes (tanto os familiares quanto os amigos) porque tanto o apoio como a falta de apoio de alguém significativo afetou a capacidade das pacientes em lidar com o tratamento e os efeitos colaterais relacionados a este.

Young McGaughan (1996), descreveu o funcionamento sexual de mulheres com câncer de mama tratadas com hormônio ou quimioterapia comparando-as a mulheres tratadas sem uso de fármacos. Destas pacientes, 63 foram submetidas à mastectomia radical modificada e quatro a cirurgia conservadora.

Controlando-se a hormonioterapia, a quimioterapia produz efeitos significantemente negativos sobre à auto-imagem, afeto (humor), sintomas psicológicos e funcionamento sexual global. No entanto, não há efeitos significantes da endocrinoterapia em nenhum dos itens da escala DSFI, quando a quimioterapia é controlada.

Em relação à presença ou não dos sintomas da menopausa, diferenças estatisticamente significantes foram encontradas quando se comparou a presença ou não de tratamento quimioterápico. As pacientes que receberam 
quimioterapia demonstram sintomas de menopausa e os sintomas de disfunção sexual foram mais freqüentes. A imagem corporal e o funcionamento sexual global também foram impactados negativamente, quando comparadas àquelas que não receberam quimioterapia. Em relação à satisfação sexual, os escores foram similares em ambos os grupos, porém as pacientes que receberam quimioterápicos referiram maior ressecamento vaginal e dispareunia.

De modo geral, a literatura compara a mastectomia radical (Halsted ou modificada) a um procedimento conservador e/ou a mastectomia radical com reconstrução com cirurgias conservadoras ou, no cruzamento entre estes três procedimentos.

Independentemente do tipo de comparação realizada, a conclusão geral mostrada nestes estudos é de que as cirurgias conservadoras como a tumorectomia, apresentam menor morbidade para as pacientes, aliadas ao fato de serem melhores e para a preservação da função sexual (Schover, 1991) seguida pela mastectomia com reconstrução (Al-Ghazal et al, 2000 a, b). Pior morbidade, incluindo-se nesta os efeitos sobre a sexualidade é observada nas pacientes submetidas à mastectomia radical à Halsted (Taylor, 1985).

A função sexual é importante aspecto da qualidade de vida que deve ser abordada com o paciente juntamente a discussões sobre a doença, tratamento e outros sintomas ou problemas, mesmo que isto seja feito em outro momento. Deve ser feita à ligação entre a sexualidade, a saúde e a questão sexual, que são debatidos, enfatizando-se a importância de manter 
a atividade sexual durante o tratamento e recuperação. No tratamento do câncer, pode ser importante a designação de algum membro especialista em sexualidade para este papel (McKee e Schover, 2001).

\subsection{O processo de luto no câncer de mama}

O tratamento do câncer de mama é longo e abrange não só intervenções cirúrgicas, como também procedimentos neo e adjuvantes, além do constante seguimento nos anos subseqüentes.

Durante todas estas etapas e principalmente na fase diagnóstica, a mulher é acometida por inúmeras experiências internas, que abrangem desde o choque e negação da doença até uma fase em que ela aceita que tem câncer, procurando pois, um tratamento (Maluf, 2006d; Oktay, 1998). Este processo vem acompanhado por senso de alienação, decréscimo da auto-estima, desesperança, depressão, hostilidade e culpa (Rabinowitz, 2002) e muito sofrimento (Meechan et al, 2003).

De modo geral, doente de câncer é tratado como quem está para morrer brevemente. Querem saber "quanto tempo" o enfermo ainda tem de vida (assim como o próprio paciente) e algumas vezes se padecem da situação ao invés de apoiar o indivíduo e motivá-lo a seguir em frente, o que ajudaria, e muito, a diminuir a incidência de depressão. $O$ portador de 
câncer, como a maioria dos doentes, percebe no olhar do outro que este se apieda de sua situação, pois estes sentimentos, por mais que se tente disfarçar, transparecem.

Nos dias atuais, o câncer continua a carregar o estigma que possuía, o que pode ser claramente observado no dia a dia, quando vê-se pessoas que não mencionam a palavra câncer por acharem que podem atrair a doença para si ou a chamam de "aquela doença", ou de "aquilo". O estigma também é percebido em relação ao doente de câncer: "coitado, está com câncer" ou "coitado, ele era uma boa pessoa e morreu de câncer" (Maluf et al, 2006c).

O diagnóstico é o momento em que a existência é posta à prova, pois pode se findar a qualquer instante: é a percepção e a tomada de consciência da existência real da morte. A proximidade da morte e sua relação com a mesma, fazem com que a mulher pense e repense sobre questões existenciais, sobre planos futuros, tanto na esfera profissional como e principalmente na familiar, em questões relacionadas aos filhos, marido e ao planejamento desta família (ter ou não outros filhos).

Após esta primeira reação, a mulher vivencia várias fases de conflito interno que oscilam desde a negação da doença, onde a paciente (e familiares), frente ao choque causado pela notícia, não acredita que tenha câncer, até a procura de diversos profissionais na esperança de que algum deles lhe dê um diagnóstico contrário aos achados. Depois disso, a fase final de aceitação, quando há a aceitação do diagnóstico de câncer de mama e a procura pelo tratamento (Maluf, 2005). 
Esses conflitos são demonstrações das alterações psicológicas pelas quais passa a mulher portadora de câncer de mama e seus familiares e que não terminam com a cirurgia, mas que vão além, com os tratamentos adjuvantes como a quimioterapia, radioterapia e hormonioterapia. Porém, estas alterações podem ser agravadas se houver: história prévia de tratamento psiquiátrico, desordens afetivas durante o tratamento primário, labilidade emocional, a existência de pobre suporte social e a falta de uma ocupação (Fallowfield, 1990).

Durante as etapas de aceitação da doença, é de suma importância que a paciente receba suporte emocional por parte de seus familiares e amigos (Rodrigues, 1998), porém algumas vezes isto se torna difícil em virtude dos fortes laços afetivos que unem estas pessoas e pelo desconhecimento da evolução e tratamento da doença. Isto é, se estas pessoas não conseguirem encarar a realidade da doença (o que é, suas características, tratamento, possibilidade de cura, entre outros) provavelmente não conseguirão dar apoio a esta mulher. Assim, o trabalho do psicólogo torna-se de grande valia tanto para a família quanto e principalmente para a paciente, que tem a oportunidade de expressar todas as suas angústias, medos (da recorrência do câncer, de ser abandonada por familiares e amigos, do desfiguramento e principalmente o medo da morte) e incertezas frente ao câncer, seu tratamento e sua expectativa de vida (Maluf, 2006c, 2005; Campos, 1995; Valle, 1997; Kornblith e Ligibel, 2003).

As diversas fases de conflito interno vivenciada pela mulher ao longo do processo de diagnóstico e tratamento do câncer de mama, constituem o processo de luto, sendo: o primeiro pela existência da possibilidade de ter 
câncer, o segundo quando do diagnóstico, o terceiro quando do tratamento cirúrgico, um quarto luto gerado pela perda da imagem-corporal e pelas modificações em sua auto-imagem, um quinto luto causado pelas possíveis limitações que terá em conseqüência da cirurgia. O último luto é o causado pelos tratamentos quimioterápicos, radioterápicos e hormonioterápicos.

O processo de luto é, por definição um conjunto de reações diante de uma perda, por separação ou afastamento, envolvendo uma sucessão de quadros clínicos que se mesclam e se substituem (Parkers, 1998; Franco, 2002). No sentido empregado por Freud (1996b), pode significar tanto o afeto da dor como sua manifestação externa. O luto também pode ser entendido como uma emoção e uma doença (Averill e Nuley, 1993).

De modo geral, o luto é a reação à perda de um ente querido, à perda de alguma abstração que ocupou o lugar de um ente querido, como o país, a liberdade ou o ideal de alguém, entre outros. É um processo de aperceberse, de tornar real o fato da perda. O processo do luto leva tempo e qualquer coisa que force o teste de realidade no período inicial tende a causar dificuldades (Parkers, 1998).

O diagnóstico de doenças orgânicas pode trazer consigo a perda da condição de sadio para a condição de doente. Nessa condição o paciente passa a lidar com o risco eminente de adoecer, sofrer e morrer. Essa condição, representa não somente uma ameaça ao seu corpo, como também uma ameaça ao seu psiquismo devido à possibilidade de aniquilamento: luto pela perda da saúde (Franco, 2002). 
Baseando-se nestas premissas, o processo de luto pelo qual passa a mulher com câncer de mama é um momento em que esta tem a possibilidade de entrar em contato com seus conteúdos internos e os confronta com a nova realidade, elaborando esses significados, para que possa refazer psiquicamente sua auto-imagem, através do choque (contato) com uma nova realidade: estar mastectomizada, não importando se esta condição é transitória (havendo reconstrução) ou permanente, isto é, elaborando a perda da saúde (Maluf, 2006c).

Porém este processo é difícil e doloroso, sendo acompanhado desde tristeza até profunda depressão, além de sentimentos como angústia, medo e desesperança (Maluf, 2005, 2006d). Assim, é muito importante que a equipe médica fique atenta aos sinais demonstrados pela paciente, sabendo diferenciar a tristeza e a melancolia da depressão que costuma acompanhar os pacientes com câncer (Maluf, 2006c).

As etapas do luto abrangem cinco estágios que, didaticamente podem ser separadas, mas que ocorrem de forma dinâmica ${ }^{\ddagger}$ :

$1^{\circ}$. Negação e isolamento: há negação inicial, no qual a paciente se mostra assombrada num primeiro momento, recusando-se depois a acreditar no diagnóstico. Há isolamento do convívio com os familiares e amigos. A intensidade estes vai depender de como as pessoas ao redor são capazes de acolher a dor daquele que sofre.

\footnotetext{
${ }^{\ddagger}$ Estes estágios são na realidade, os estágios da morte, descritos por Kübler-Ross, em trabalho desenvolvido com pacientes terminais.
} 
$2^{\circ}$. Raiva: na impossibilidade de manter o primeiro estágio de negação, ele é substituído por sentimentos de raiva, revolta, inveja e de ressentimento. Nessa fase, os relacionamentos tornam-se conflitivos, todo o ambiente é atingindo pela revolta de quem sofre. A dor psíquica pela necessidade de enfrentamento da doença aparece em atitudes agressivas.

$3^{\circ}$. Barganha: é uma tentativa de adiamento. O paciente tenta negociar com médicos, parentes e amigos, no sentido de, em troca da cura, cumprir promessas. Na maioria das vezes a barganha é feita com Deus e mantida em segredo.

$4^{\circ}$. Depressão: quando o paciente já não consegue negar sua condição, quando já expressou sua raiva e revolta, quando percebe que não resolve fazer barganhas, surge então sentimento de grande perda e experiência de sintomas clínicos de depressão, não conseguindo mais negar a doença. É o sofrimento psíquico de quem percebe a realidade como ela realmente se apresenta, com todas as perdas e dificuldades inerentes aos momentos de separação.

$5^{\circ}$. Aceitação: a paciente já não se debate em desespero, não nega sua realidade, não negocia com Deus, não sente raiva nem depressão. A paciente descobre que a morte é inevitável e aceita a universalidade da experiência. Neste momento a paciente encontra-se geralmente fraca e cansado. 
Quando abordamos o luto através do tratamento cirúrgico, queremos dizer que por um lado a cirurgia possui um lado "reconfortante" para a paciente, pois assim poderá acabar com o sofrimento, sendo tratada de um "mal' que the tirou a saúde. Esta "alegria e o alívio" causado pela primeira etapa do tratamento tem duração limitada, até o momento em que a paciente cai em si e se percebe: instala-se assim o processo do luto. O luto pelo corpo perdido, pela feminilidade "roubada", os sentimentos de menos valia por ser "menos mulher que as demais" (que possuem mamas), entre outros (Maluf, 2006c; Fallowfield e Hall, 1991).

Após a mastectomia, há mudança na relação com o corpo, já que a mama que antes era parte valorizada do corpo, associada ao prazer e fonte de atração, foi extirpada. Para muitas mulheres, são as mamas que primeiro as define-como mulheres e, perdê-las é perder a feminilidade (Oktay, 1998).

A amputação da mama promove grande impacto emocional que se sobrepõe, muitas vezes, ao impacto do diagnóstico, ou seja, a expectativa da mutilação da mama desencadeia reações emocionais tão intensas que poderiam ser comparadas às fantasias de morte (Basegio, 1999). Sua perda afeta o comportamento social, levando a mulher a distinguir a perda da mama e evitar o contato físico, podendo causar inibição do desejo sexual (Wapnir et al, 1999). Mesmo posteriormente a reconstrução mamária, isto é, após a reestruturação estética da feminilidade roubada pela mastectomia, o processo de luto pela perda do corpo real (perfeito até a cirurgia) continua a ocorrer, sendo veículo para reconstrução de uma auto-imagem integrada a nova imagem corporal (Maluf, 2006a). 


\subsection{O impacto psicológico do câncer de mama}

O impacto psicológico e a reação ao diagnóstico de câncer de mama variam de mulher para mulher, dependem da idade, da personalidade da paciente, de suas experiências de vida, de seus relacionamentos sociais e familiares e de sua história psicológica e psiquiátrica (Backus, 2002; Daune, 1995; Fallowfield e Hall, 1991).

Algumas pacientes usam predominantemente defesas intelectuais e aprendem tudo que podem sobre a doença, outras exibem vários graus de negação e resistência à informação. Alguns preferem deixar as decisões para os médicos (Backus, 2002).

Após um ano do diagnóstico de câncer de mama, mais que $30 \%$ das mulheres permanecem ansiosas, apresentando grande sofrimento e depressão (Hordern, 2000)

A presença de depressão maior ou de transtornos de ajustamento foi observada em pesquisa realizada por Okamura et al. (2000), com 55 pacientes, entre 30 e 73 anos de idade com recidiva de câncer de mama. A depressão maior esteve presente em $42 \%$ das pacientes, sendo este quadro presente em quatro delas (7\%). Os transtornos mais prevalentes foram: $35 \%$ de ajustamento, seis de ansiedade e nove depressão maior e transtorno de ansiedade. 
Os fatores significantemente associados à depressão maior ou transtorno de ajustamento foram: idade inferior aos 50 anos, tratamento quimioterápico simultâneo e intervalo livre de doença de 24 meses.

A prevalência de depressão maior (7\%) observada, foi similar a encontrada após o diagnóstico primário demonstrando assim, a dificuldade que as pacientes têm em se readaptar após um evento estressor.

No entanto, a pesquisa randomizada conduzida em 2004 por Ganz et al., com 112 pacientes submetidas à mastectomia com e 71 sem quimioterapia e 167 a tumorectomia com e 208 sem quimioterapia ao final do tratamento primário de câncer de mama, obteve níveis normais de saúde mental, com pequenas evidências de depressão ou afeto negativo, apesar dos tratamentos complexos prolongados. Entretanto estas pacientes informaram ampla variedade de sintomas físicos, incluindo calores, suores noturnos, dores continuas e agudas e ressecamento vaginal. Problemas sexuais como falta de interesse sexual, dificuldades de lubrificação e dor durante o intercurso foram relatadas por $50 \%$ das pacientes que receberam quimioterapia adjuvante do que naquelas submetidas somente à cirurgia.

Goin e Goin (1981) avaliaram os distúrbios psicológicos que se seguiam à mastectomia, relacionados a pseudoaceitação, sexualidade e depressão em 17 mulheres, entre 34 e 65 anos.

As pacientes admitiam sentir-se deprimida desde a mastectomia mas ocultaram este sentimento de outras pessoas, mas quando sozinhas, apresentavam sentimentos de tristeza e acessos de choro. Esta estava relacionada ao sentimento de auto-piedade. Houve queda ou 
desaparecimento do desejo sexual, que consideravam ridículo pensar nelas mesmas como sexualmente atraentes. Os temores de uma luta contra dependência e desamparo eram temas dominantes na vida destas mulheres. Após a reconstrução, estes sentimentos gradativamente foram melhorando e o desejo sexual retornou.

A presença de sentimentos depressivos e pensamentos transitórios sobre suicídio foram mais prevalentes nas pacientes mastectomizadas durante o período entre o tratamento e as entrevistas $(40 \%)$, do que naquelas submetidas a tumorectomia (7\%) (Margolis et al., 1990)

Indícios de depressão em pacientes submetidas à mastectomia radical também foram observados por Maluf (2004), desde os primeiros meses que se seguiram a cirurgia $(15,78 \%$ das pacientes). Destas $66,66 \%$ não apresentam perspectivas em relação ao futuro e duas pacientes haviam pensado em suicídio.

A literatura é abundante em estudos sobre os aspectos psicológicos envolvidos no câncer de mama, principalmente após cirurgias radicais ou comparando-se intervenções radicais a conservadoras. Porém, estes estudos medem o psicológico através de inventários de qualidade de vida (abrangem questões sobre auto-estima, imagem-corporal e sexualidade) e não através de inter-relação entre estes instrumentos e o acompanhamento psicológico adequado. Por meio destes instrumentos, avaliam-se ou tentamse avaliar os fatores internos constituintes do "self" psicológico feminino (Wilmoth e Ross, 1997). 
De modo geral, o câncer de mama tem como características, no "self" feminino, aumento no senso de responsabilidade em relação a si mesma, maior vulnerabilidade, mudanças na auto-estima, raiva, medo da morte, de mudanças e da perda e alterações na auto-imagem (Wilmoth e Ross, 1997), perda da feminilidade (Wilmoth, 2001).

\subsection{Câncer de mama e relacionamento conjugal}

O marido ou companheiro, desempenha papel relevante e singular no câncer de mama, sendo provedor de um suporte instrumental (prático) ou afetivo (emocional).

Em grande parte dos casos o que ocorre é que o marido consegue e está acostumado, a fornecer um suporte instrumental, porém a experiência relativa ao suporte emocional encontra-se diminuída. As mulheres com câncer de mama às vezes queixam-se que seus maridos são maravilhosos quando há algo concreto para eles fazerem como por exemplo, buscar receitas, fazer anotações, organizar transporte e encontrar informações na Internet, mas têm dificuldade com as tarefas mais "sentimentais", tais como escutar, segurar as mãos, tocar, mesmo que estejam com suas esposas (Oktay, 1998). 
Estas dificuldades "sentimentais" mostradas pelos maridos, muitas vezes estão relacionadas às tensões por estes manifestas e relatadas, que incluem solidão, incertezas, modificações nos padrões de comunicação com a parceira, confusão sobre o que contar aos filhos, dificuldade relacionada ao aumentado de suas atividades no lar e o temor concernente ao impacto que a doença de sua esposa terá sobre toda a família (Rabinowitz, 2002).

No caso da recorrência do câncer de mama, fatores como o suporte, incerteza, sintomas de dor e esperança explicam a divergência existente entre a angústia das esposas e dos maridos (43\% e $32 \%$, respectivamente), além das mudanças relativas aos papéis de marido (57\%) e mulher $(66 \%)$. Os sintomas de angústia e esperança explicaram a maioria das mudanças adaptativas em mulheres e na adaptação dos maridos. Relação positiva e significativa foi encontrada entre as mulheres e a adaptação dos maridos, indicando que o casal têm uma influência mútua em si. Os resultados sugerem que há múltiplos fatores que influenciam a adaptação do casal à recorrência do câncer de mama, e que estes devem ser tomados em consideração quanto ao planejamento do cuidado das mulheres e de seus maridos (Northouse et al.,1995)

Quanto às mulheres solteiras, estas podem temer que um parceiro em potencial as rejeite, devido ou pelas mudanças físicas ocorridas como resultado do tratamento do câncer de mama (efeitos da quimioterapia) ou pelo medo de perdê-los com a recorrência do câncer (Holmberg et al., 2001).

Em 2001, Holmberg et al. avaliaram através da técnica de grupos focais, o impacto do câncer de mama sobre dimensões específicas do 
relacionamento em 10 mulheres (duas submetidas à tumorectomia e às demais à mastectomia radical).

As mulheres solteiras eram notavelmente mais zangadas, tristes e machucadas do que as casadas. Os relacionamentos íntimos destas mulheres foram problemáticos, causando considerável sofrimento durante o processo diagnóstico do câncer de mama, sendo este catalisador para um final infeliz e em um caso, uma relação destrutiva.

A preocupação presente neste grupo de mulheres era sobre como informar ao novo parceiro sobre seu diagnóstico de câncer e sua aparência física alterada (cicatriz cirúrgica e a diferença entre a mama natural e a reconstruída). Este fato foi tratado penosamente por elas, sugerindo que nenhuma delas estava apta a propor boa solução para discutir sobre sua doença com um futuro parceiro que venha a se interessar por elas.

Já as mulheres casadas ou com relacionamento estável, os parceiros provinham todo o suporte instrumental necessário. Porém, em relação ao exercício da sexualidade, estas mulheres sentiam-se parcialmente responsáveis por qualquer diminuição na atividade sexual. Referiram seu próprio decréscimo na resposta sexual e no desejo, sempre atribuindo aos efeitos do tratamento como a fadiga, alterações corporais promovidas pelos sintomas da menopausa ou sentimentos de depressão e perda do desejo sexual.

Em relação à resposta sexual, nenhuma das mulheres casadas referiu que seus parceiros tiveram alguma dificuldade em responder sexualmente, porém os homens revelaram em suas entrevistas que seu próprio desejo 
sexual havia diminuído e também o grande estresse pelo qual atravessaram quando consideraram a possível perda das parceiras, quando o sexo foi considerado "não evento" mesmo para os jovens, mais recentemente casados.

Os homens foram unânimes em expressar que a mudança na aparência das esposas não era importante, mas que a sobrevivência e a boa saúde eram o aspecto mais relevante. Para eles, a cirurgia de reconstrução era completamente desnecessária ou poderia resultar numa dor desnecessária e em sofrimento para as parceiras, apesar de sentirem dor e pesar pela perda da mama delas. Metade dos maridos foi consultada quanto à reconstrução antes da decisão das esposas.

Os casamentos constituídos por uma sólida relação antes do surgimento do câncer de mama costumam se tornar mais consistentes (Dorval et al, 1999), o que já não ocorre naqueles em que o ajustamento conjugal no momento do diagnóstico passava por dificuldades (Oktay, 1998). A separação ou o divórcio não é comum em pacientes com câncer de mama quando comparados ao grupo controle, nem entre àqueles submetidos à mastectomia versus tumorectomia (Kornblith e Ligibel, 2003).

Os resultados de pesquisas sobre o impacto do câncer de mama sobre o relacionamento conjugal, indicam evidências empíricas contraditórias a respeito tanto do grau, como da duração do sofrimento psicológico no relacionamento (Mahoney e Carroll, 1997).

Scott et al. (2004) avaliaram os efeitos do "treinamento" em adaptação ao câncer em 94 casais no momento do diagnóstico, no pós-operatório e no 
seguimento (6 e 12 meses). Dentre estes casais, havia 57 mulheres com câncer de mama e 37 com câncer ginecológico.

De modo geral, houve melhoras significativas na comunicação do casal, com diminuição no sofrimento psicológico e no esforço de enfrentamento e aumento no ajustamento sexual. O "treinamento" do casal se mostrou mais eficiente em facilitar adaptação ao câncer, do que se fosse realizado somente pela paciente.

No tocante à separação conjugal, a experiência de câncer de mama não aumenta este, embora possa criar uma tensão conjugal. As estimativas indicam que de $1 / 4$ a $1 / 3$ dos casais estão propensos a experimentar dificuldades sexuais após o diagnóstico de câncer de mama (Hordern, 2000). 
79

4. CASUÍSTICA E MÉTODO

Roland Humberto de Matos, 1943

Aguada de nanquim sobre canson 


\subsection{Sujeitos}

Foram selecionadas 52 mulheres, com idade entre 50 e 60 anos de idade, oriundas do Ambulatório de Mastologia do Hospital das Clínicas da Universidade de São Paulo e do Núcleo de Mastologia do Hospital Sírio Libanês, pacientes da Responsabilidade Social (anexo C), com diagnóstico de câncer de mama submetidas a mastectomia radical como tratamento e mulheres com tumores benignos de mama (anexo $\mathrm{G}$ ).

Estas pacientes foram divididas em dois grupos, sendo:

$\checkmark 15$ pacientes submetidas à mastectomia radical

$\checkmark 37$ pacientes com doenças benignas da mama (grupo controle).

\subsection{Critérios de inclusão}

$\checkmark$ Faixa etária entre 50 e 60 anos de idade

$\checkmark$ Escolaridade fundamental

$\checkmark$ História de funcionamento afetivo sexual satisfatório prévio 


\subsection{Critérios de exclusão}

Histórico de:

$\checkmark$ disfunção sexual prévia;

$\checkmark$ problemas sexuais prévios;

$\checkmark$ doenças físicas que impossibilitem a função sexual;

$\checkmark$ doenças mentais;

$\checkmark$ dependência a substâncias psicoativas;e,

$\checkmark$ recidiva de câncer de mama.

\subsection{Instrumento}

O WSFQ (Watts Sexual Function Questionnaire) é um instrumento auto-aplicável, composto por dezessete questões que avaliam os quatro componentes da experiência sexual, incluindo as percepções sobre desejo sexual, interesse, orgasmo e satisfação. Estas perguntas são divididas da seguinte forma: itens 1 a 6 , avaliam questões relacionadas ao desejo sexual, os itens 7 a 10, o interesse sexual, os itens 11 a 14, o orgasmo e os itens 15 a 17 a satisfação sexual (anexo F).

As repostas dadas são avaliadas por meio de uma escala de cinco pontos, que variam de 'sempre a nunca'. Quando o total de escores é 
calculado é possível uma variação entre 17 - 85 pontos. Algumas questões tiveram sua ordem de grandeza mantida, porém com termos alterados para melhor adequar-se a realidade brasileira, o que ocorreu nas questões 1,8 e 14, modificando-se a escala "sempre - nunca", para outra mais adequada:

Questão 1: muito importante - sem importância

Questão 8:imediatamente - não fico

Questão 14: muito importante - sem importância

Ao WSFQ original foram adicionadas perguntas abertas objetivando a avaliação e observação das reações da paciente frente ao diagnóstico cirúrgico e as possíveis alterações que a mastectomia teria para sua autoimagem, seu estado de humor, sua capacidade de planejar o futuro e na manutenção do relacionamento afetivo-sexual.

Estas questões foram adicionadas por ser o WSFQ um questionário que avalia apenas a presença de disfunções sexuais, tendo um cunho biológico, não abordando temas de caráter sócio-psicológico (causas psicogênicas das disfunções sexuais), pois a sexualidade é biopsicossocial, como conceituado por Abdo, 2000 (Maluf, 2006a).

Questões qualitativas foram, em sua maioria, fechadas de forma a permitir análise mais quantitativa dos resultados, e questões para avaliação de depressão.

Novas questões foram elaboradas, outras eliminadas e um terceiro grupo de questões foi juntado de forma a melhor atender a metodologia do trabalho proposto. 
Foi também realizada, a adequação de identificação dos pacientes como, por exemplo, a inclusão de classes profissionais, no item "profissão".

A este instrumento foi acrescido de uma questão que detecta com precisão, a presença ou não de depressão, utilizando-se os critérios diagnósticos do DSM IV-TR (APA, 2002), sendo também inseridas questões para avaliação psicológica frente ao diagnóstico e tratamento da neoplasia mamária e a realização da mastectomia. Algumas questões que anteriormente eram abertas, foram fechadas e readequadas para este estudo (anexos G, H, I, J).

Assim, elementos como a situação conjugal, os conhecimentos e crenças acerca da sexualidade, a capacidade de identificar e comunicar as dificuldades sexuais, os antecedentes pessoais do sujeito (história de vida, iniciação sexual, seus relacionamentos, a cultura no qual está inserido), comorbidades e fatores hormonais influenciam e são influenciados pela sexualidade (Abdo, 2000), justificando-se pois, a inclusão de outras questões que abordem tais temas, tornando assim, o instrumento mais adequado aos propósitos desta pesquisa.

Desta forma iniciamos o processo de tradução, reprodutibilidade, adaptação e validação do WSFQ para o Brasil como melhor descrito nos anexos G, H, I, J. 


\subsection{Procedimentos}

Primeiramente, o projeto de pesquisa foi cadastrado no Ministério da Saúde, sob número FR-003512 (anexo A), sendo posteriormente levado ao conhecimento e apreciação da Diretora responsável pelo Departamento de Psicologia do HC-FMUSP, sendo-Ihes também encaminhado, o Termo de Consentimento Livre e Esclarecido, o Cadastro de Pesquisador e o Cadastro de Protocolo de Pesquisa.

Após esta etapa, o projeto foi encaminhado a Comissão de PósGraduação do Departamento de Obstetrícia e Ginecologia da Faculdade de Medina da Universidade de São Paulo e para Comissão de Ética para Análise de Projetos de Pesquisa (CAPPesq), sob número 1006/03, onde obteve a aprovação final (anexo B).

Obtidas as aprovações, o que ocorreu em dois meses, deu-se início à pesquisa, na primeira semana de outubro de 2004 com o levantamento dos prontuários das pacientes do Setor de Mastologia da Clínica de Ginecologia da Faculdade de Medina da Universidade de São Paulo, com diagnóstico ou não de câncer de mama, visando a pré-triagem das mesmas.

Devido a dificuldade de se selecionar pacientes que preenchem os critérios de inclusão, foi necessário iniciar a coleta de dados em outro serviço: Núcleo de Mastologia do Hospital Sírio Libanês, sendo as pacientes participantes, pertencentes à Responsabilidade Social, isto é, oriundas do Sistema Único de Saúde (SUS). 
Este procedimento foi adotado para facilitar a identificação das pacientes recentemente diagnosticadas com câncer de mama, cujo tratamento proposto seria mastectomia radical daquelas que já foram operadas e que já estão em acompanhamento pós-cirúrgico, além de auxiliar na identificação de pacientes com doenças benignas da mama.

Optou-se por pacientes com tumores benignos de mama como referência comparativa para verificarmos o impacto na sexualidade do diagnóstico de malignidade pois a existência do diagnóstico de tumor de mama e a necessidade de exames de rastreamento como biópsias fere a mama, causando algumas vezes imperfeições que, para algumas mulheres, alteram sua imagem corporal dificultando a vivência da sexualidade.

Assim, formaram-se dois grupos de pacientes: aquelas com diagnóstico de câncer de mama que seriam submetidas à mastectomia radical e outras com tumores benignos de mama.

Após cada etapa de triagem de prontuários, foram feitas e entregues listas contendo nome e registro geral (RGHC), à Diretoria de Prontuário Médico do Instituto Central do HCFMUSP, que forneceu os telefones solicitados das pacientes.

A seguir, as pacientes foram contactadas por via telefônica e convidadas a participar da pesquisa. Neste contato a pesquisadora se identificou e forneceu explicações sobre a pesquisa: a metodologia a ser utilizada (questionário sobre sexualidade) e o número de encontros, cinco, com freqüência trimestral. 
Desta forma, dentre as 253 pacientes selecionadas que preenchiam os critérios de inclusão, 21 foram prontamente excluídas por não terem número de telefone cadastrado. Outras pacientes também foram excluídas neste momento devido a:

$\checkmark$ dados cadastrais errados $(n=2)$;

$\checkmark$ problemas com telefone $(n=15)$;

$\checkmark$ ter dificuldade para vir Hospital em cinco momentos $(n=25)$;

$\checkmark$ recidiva de câncer de mama $(n=4)$;

$\checkmark$ já operada - data cirurgia adiantada $(n=15)$;

$\checkmark$ óbito $(n=1)$;

$\checkmark$ cuidam de netos e não podem vir $(n=4)$;

$\checkmark$ derrame com perda de memória há 6 meses $(n=1)$;

$\checkmark$ sem interesse em participar da pesquisa $(n=60)$;

$\checkmark$ rebaixamento intelectual (certo nível de retardo mental, $n=1$ );

Mediante aceitação foi marcado dia e hora para aplicação do instrumento de pesquisa, sendo-lhes repetidos os objetivos da pesquisa e sendo-lhes entregue o 'Termo de Consentimento Livre e Esclarecido' (foiIhes explicado qual era a função). Uma cópia do Termo ficou em posse das pacientes e demais, assinadas por elas, foram uma anexada ao prontuário das mesmas e a outra guardada em poder da pesquisadora, juntamente aos respectivos questionários.

Entregou-se às pacientes o WSFQ. Conforme foram surgindo dúvidas as pacientes foram perguntando. Os dados coletados nestes grupos foram 
analisados e comparados entre si qualitativa e quantitativamente através de questões abertas / fechadas e do WSFQ, respectivamente.

Todas as pacientes foram reavaliadas trimestralmente, totalizando um ano de seguimento. A primeira aplicação foi realizada no período anterior à cirurgia, diagnóstico (T0) e as demais em três (T3), seis (T6), nove (T9) e doze (T12) meses de pós-diagnóstico,

Todas as aplicações foram realizadas pela pesquisadora, com duração média de 40 minutos.

Em duas pacientes do grupo de mastectomia radical, não foi possível a aplicação devido a seu estado emocional, sendo-lhes prestado suporte psicológico. Uma outra paciente deste grupo com transtorno bipolar foi excluída.

Duas pacientes do grupo de tumores benignos com disfunção sexual prévia, desejo sexual hipoativo também foram excluídas.

Desta iniciaram a pesquisa 108 pacientes, divididas em dois grupos: 86 com tumores benignos de mama e 22 com tumores malignos de mama, submetidas à mastectomia radical.

Destas 86 pertencentes ao grupo controle:

11 foram excluídas devido ao diagnóstico de mamas normais, segundo prontuário

$\checkmark 29$ excluídas por diagnóstico de depressão em T0, isto é, na aplicação do primeiro questionário

8 desistiram em algum momento posterior das aplicações, entre T3 e T6, sendo pois excluídas da pesquisa, distribuídas da seguinte maneira: 
$\checkmark 5$ pacientes em T3

$\checkmark 3$ pacientes em T6

Assim o total de pacientes que compôs o grupo controle foi de 37 pacientes com diagnóstico de tumores benignos de mama.

Já o grupo cirúrgico, composto por pacientes submetidas à mastectomia radical, iniciou-se com 22 pacientes, sendo 7 excluídas por desistirem do seguimento da pesquisa em algum momento, entre T3 e T6, totalizando 15 pacientes que finalizaram o estudo.

Neste grupo, 7 pacientes não fizeram reconstrução mamária e 8 a fizeram.

\subsection{Análise estatística}

Foram realizadas as seguintes análises:

$\checkmark$ Análise estatística exploratória: trata-se da utilização de métodos estatísticos para sumarização de dados multidimensionais, objetivando-se obter uma fotografia dos resultados coletados. Uso de tabelas, gráficos e medidas.

Testes de Hipóteses por medidas repetidas: técnica de inferência estatística, que tem como objetivo avaliar um mesmo grupo de indivíduos, 
submetidos ao mesmo instrumento de coleta de dados, em tempos diferentes.

$\checkmark$ Testes de Hipóteses para comparação entre grupos: técnica de inferência estatística que objetiva comparar medidas entre grupos.

$\checkmark$ Análise de Relação entre variáveis: métodos estatísticos utilizados para verificar a existência de relação entre variáveis. Essas técnicas objetivam avaliar o nível de influência entre as respostas obtidas. A associação é utilizada para medir a relação entre variáveis qualitativas. A correlação, utilizada para medir a relação entre variáveis quantitativas.

Estudo de caso: método empírico que objetiva sintetizar as respostas obtidas ao avaliarmos questões qualitativas.

Para corrigirmos eventuais distorções causadas pela falta do ' $n$ ' estipulado dentre a amostra do grupo cirúrgico (MR), adotamos o método estatístico de bootstrap, ou seja, trata-se de um método de extrapolação amostral para checagem das condições de precisão e certeza dos dados coletados.

O software estatístico utilizado foi o SPSS for Windows verão 13.0. 
5. RESULTADOS 
Os resultados referem-se ao seguimento durante período de um ano, de 37 mulheres pertencentes ao grupo controle, isto é, com tumores benignos de mama, e 15 submetidas à mastectomia radical. Neste último grupo dois casos foram censurados por morte e um questionário pendente por estado terminal da paciente.

A tabela 2 ilustra o perfil sócio-demográfico das entrevistadas.

Tabela 2: Perfil sócio-demográfico das entrevistadas

\begin{tabular}{lccc}
\hline Variável & \multicolumn{2}{c}{ Mastectomia radical (\%) } & Grupo controle (\%) \\
\hline$\underline{\text { Idade }}$ & & & \\
& 50 a 53 & 40 & 37 \\
& 54 a 56 & 27 & 31 \\
& 57 a 60 & 33 & 31
\end{tabular}

Estado civil

$\begin{array}{rcc}\text { solteira } & 0 & 11 \\ \text { casada } & 86 & 69 \\ \text { separada } & 07 & 11 \\ \text { viúva } & 07 & 09\end{array}$

Filhos

$\begin{array}{lll}\operatorname{sim} & 87 & 86 \\ \text { não } & 13 & 14\end{array}$

Escolaridade

$\begin{array}{lll}1^{\circ} . \text { grau } & 46 & 75 \\ 2^{\circ} . \text { grau } & 27 & 11 \\ \text { superior } & 27 & 14\end{array}$

Profissão

$\begin{array}{rrr}\text { Do lar } & 47 & 51 \\ \text { Trabalha fora } & 53 & 49\end{array}$

$\underline{\text { naturalidade }}$

$\begin{array}{rcc}\text { São Paulo } & 27 & 29 \\ \text { Sudeste } & 13 & 14 \\ \text { / Noroeste } & 0 & 0 \\ \text { Nordeste } & 33 & 43 \\ \text { Sul } & 07 & 11 \\ \text { Exterior } & 0 & 03\end{array}$

Religião

católica $\quad 73 \quad 66$

$\begin{array}{ll}\text { outras } & 27 \\ \end{array}$


Nas tabelas $3 a$ e $3 b$, observa-se à realização dos exames de seguimento dos grupos avaliados durante um ano de seguimento.

Tabela 3a: Exames de seguimento

\begin{tabular}{c|c|c}
\hline Exames de seguimento & Mastectomia radical \% & Grupo controle\% \\
\hline Não & 0 & 0 \\
Sim & 100 & 100 \\
\hline
\end{tabular}

Tabela 3b: Exames de seguimento realizados

\begin{tabular}{|c|c|c|c|c|c|c|c|c|c|c|c|c|}
\hline \multirow{2}{*}{$\begin{array}{c}\text { EXAMES } \\
\text { Mamografia }\end{array}$} & \multicolumn{4}{|c|}{ MR } & \multicolumn{4}{|c|}{ MRR } & \multicolumn{4}{|c|}{ GC } \\
\hline & $3 m$ & $6 m$ & $9 m$ & $12 m$ & $3 m$ & $6 m$ & $9 m$ & $12 m$ & $3 m$ & $6 m$ & $9 m$ & $12 m$ \\
\hline Sem alteração & 1 & 1 & 1 & 1 & 1 & 2 & 2 & 2 & 13 & 11 & 8 & 8 \\
\hline Alteração & 2 & & & & & & & & 5 & 5 & 4 & 6 \\
\hline Não saiu o resultado & & & 1 & 1 & & & 1 & 1 & 5 & 4 & 1 & 2 \\
\hline Ultrassom & $3 m$ & $6 m$ & $9 m$ & $12 m$ & $3 m$ & $6 m$ & $9 m$ & $12 \mathrm{~m}$ & $3 m$ & $6 m$ & $9 m$ & $12 \mathrm{~m}$ \\
\hline Sem alteração & 1 & & 1 & & 1 & 1 & 2 & 2 & 3 & 5 & 5 & 4 \\
\hline Alteração & 1 & & & & & & & & 2 & 2 & 1 & 3 \\
\hline Não saiu o resultado & & & & & & 1 & 1 & 1 & 4 & 3 & & 2 \\
\hline
\end{tabular}

NOTE: MR: mastectomia radical; MRR: mastectomia radical com reconstrução; GC: grupo controle

Pela análise de perfil, constatamos certa similaridade demográfica entre os dois grupos, permitindo afirmar que qualquer diferença estatística observada nos escores e demais resultados entre os grupos, não resulta única e exclusivamente de interferências de perfis, dado a homogeneidade da amostra. 
Tabela 4: Análise exploratória das questões quantitativas em T12

\section{Amostra Analisada}

Grupo Controle $(\mathrm{GC})=35$ pacientes

Grupo mastectomia radical $(\mathrm{MR})=13$ pacientes (dois casos censurados)

\begin{tabular}{rcc}
\hline Questão 1: sexo é importante na sua vida & MR & GC \\
\hline muito importante & $46 \%$ & $17 \%$ \\
importante & $0 \%$ & $34 \%$ \\
razoavelmente importante & $8 \%$ & $17 \%$ \\
quase sem impor. & $23 \%$ & $3 \%$ \\
sem importância & $23 \%$ & $29 \%$ \\
\hline
\end{tabular}

$\overline{p=0.9}$

\begin{tabular}{rcc}
\hline Questão 2: freqüência que gostou das relações & MR & GC \\
\hline sempre & $23 \%$ & $26 \%$ \\
quase sempre & $0 \%$ & $20 \%$ \\
algumas vezes & $54 \%$ & $11 \%$ \\
quase nunca & $0 \%$ & $0 \%$ \\
nunca & $23 \%$ & $43 \%$ \\
\hline
\end{tabular}

$\overline{p=0.9}$

\begin{tabular}{rrrr}
\hline Questão 3: freqüência cansada para ter relações & MR & GC \\
sempre & $8 \%$ & $6 \%$ \\
quase sempre & $8 \%$ & $6 \%$ \\
algumas vezes & $31 \%$ & $29 \%$ \\
quase nunca & $23 \%$ & $14 \%$ \\
nunca & $31 \%$ & $46 \%$
\end{tabular}

$p=0.9$

\begin{tabular}{rcc}
\hline Questão 4: ter fantasias sexuais ou "sonhar acordada" & MR & GC \\
sempre & $15 \%$ & $3 \%$ \\
quase sempre & $0 \%$ & $3 \%$ \\
algumas vezes & $8 \%$ & $23 \%$ \\
quase nunca & $38 \%$ & $6 \%$ \\
nunca & $38 \%$ & $66 \%$ \\
\hline
\end{tabular}

$p=0.9$ 


\begin{tabular}{|c|c|c|}
\hline Questão 5: sentir desejo se fazer sexo com o parceiro & MR & GC \\
\hline sempre & $38 \%$ & $20 \%$ \\
\hline quase sempre & $0 \%$ & $20 \%$ \\
\hline algumas vezes & $31 \%$ & $17 \%$ \\
\hline quase nunca & $0 \%$ & $3 \%$ \\
\hline nunca & $31 \%$ & $40 \%$ \\
\hline
\end{tabular}

\begin{tabular}{|c|c|c|c|}
\hline Questão 6: querer mais sexo que o parceiro & & MR & $\overline{G C}$ \\
\hline & sempre & $15 \%$ & $14 \%$ \\
\hline & quase sempre & $0 \%$ & $9 \%$ \\
\hline & algumas vezes & $23 \%$ & $26 \%$ \\
\hline & quase nunca & $8 \%$ & $6 \%$ \\
\hline & nunca & $54 \%$ & $46 \%$ \\
\hline
\end{tabular}

\begin{tabular}{|c|c|c|c|}
\hline $\begin{array}{l}\text { Questão 7: percepção da lubrificação } \\
\text { última relacão sexual }\end{array}$ & vaginal durante a & MR & GC \\
\hline & sempre & $15 \%$ & $26 \%$ \\
\hline & quase sempre & $15 \%$ & $11 \%$ \\
\hline & algumas vezes & $8 \%$ & $11 \%$ \\
\hline & quase nunca & $15 \%$ & $3 \%$ \\
\hline & nunca & $46 \%$ & $49 \%$ \\
\hline
\end{tabular}

\begin{tabular}{|c|c|c|}
\hline $\begin{array}{l}\text { Questão 8: tempo para a vagina ficar molhada assim que } \\
\text { fica sexualmente excitada }\end{array}$ & MR & GC \\
\hline imediatamente & $23 \%$ & $14 \%$ \\
\hline pco tempo depois & $15 \%$ & $23 \%$ \\
\hline tempo razoável & $23 \%$ & $14 \%$ \\
\hline mto tempo & $8 \%$ & $9 \%$ \\
\hline não fico & $31 \%$ & $40 \%$ \\
\hline
\end{tabular}

\begin{tabular}{rcc}
\hline Questão 9: vagina seca durante a relação sexual & MR & GC \\
\hline sempre & $8 \%$ & $14 \%$ \\
quase sempre & $0 \%$ & $6 \%$ \\
algumas vezes & $31 \%$ & $11 \%$ \\
quase nunca & $8 \%$ & $6 \%$ \\
nunca & $54 \%$ & $63 \%$ \\
\hline
\end{tabular}




\begin{tabular}{lcc}
\hline Questão 10: dor ou desconforto durante a relação sexual & MR & GC \\
\hline sempre & $8 \%$ & $6 \%$ \\
quase sempre & $0 \%$ & $6 \%$ \\
algumas vezes & $46 \%$ & $20 \%$ \\
quase nunca & $8 \%$ & $6 \%$ \\
nunca & $38 \%$ & $63 \%$ \\
\hline
\end{tabular}

\begin{tabular}{lrrr}
\hline Questão 11: percepção de transpiração, aceleração & & \\
$\begin{array}{l}\text { batimentos cardíacos com aumento da excitação sexual } \\
\text { sexual }\end{array}$ & MR & GC \\
& sempre & $31 \%$ & $29 \%$ \\
& quase sempre & $15 \%$ & $14 \%$ \\
& algumas vezes & $15 \%$ & $11 \%$ \\
& quase nunca & $8 \%$ & $0 \%$ \\
$p=0.9$ & nunca & $31 \%$ & $46 \%$ \\
\hline
\end{tabular}

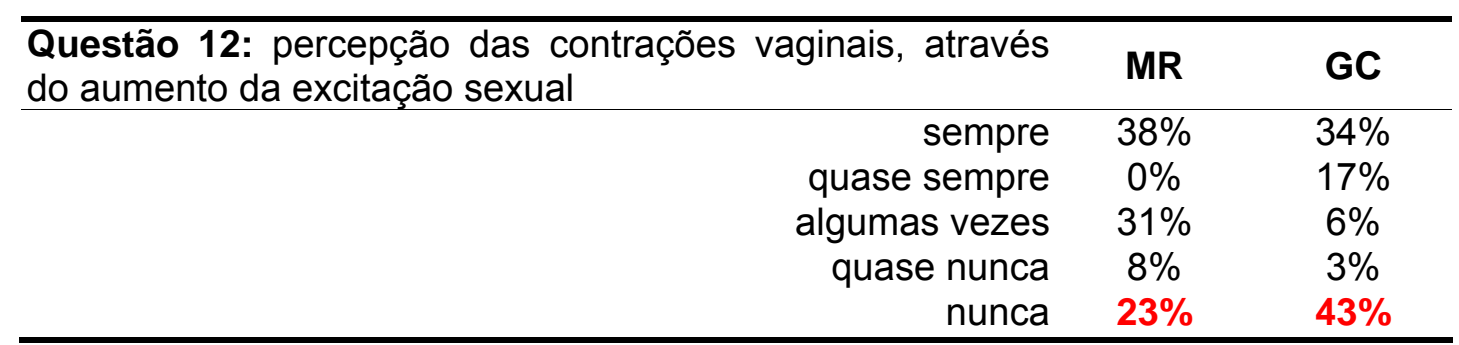

$p=0.9$

\begin{tabular}{|c|c|c|}
\hline Questão 13: capacidade de gozar & MR & GC \\
\hline sempre & $31 \%$ & $34 \%$ \\
\hline quase sempre & $8 \%$ & $9 \%$ \\
\hline algumas vezes & $23 \%$ & $14 \%$ \\
\hline quase nunca & $15 \%$ & $3 \%$ \\
\hline nunca & $23 \%$ & $40 \%$ \\
\hline
\end{tabular}

\begin{tabular}{rcc}
\hline Questão 14: importância de chegar ao clímax (gozar) & MR & GC \\
\hline muito importante & $38 \%$ & $34 \%$ \\
importante & $8 \%$ & $26 \%$ \\
razoavelmente importante & $23 \%$ & $3 \%$ \\
quase sem importância & $8 \%$ & $3 \%$ \\
sem importância & $23 \%$ & $34 \%$ \\
\hline
\end{tabular}




\begin{tabular}{rrr}
\hline Questão 15:satisfação após a relação sexual & MR & GC \\
\hline muito satisfeita & $23 \%$ & $17 \%$ \\
satisfeita & $15 \%$ & $26 \%$ \\
razoavelmente satisfeita & $15 \%$ & $11 \%$ \\
pouco satisfeita & $15 \%$ & $3 \%$ \\
não me satisfaço & $31 \%$ & $43 \%$ \\
\hline
\end{tabular}

\begin{tabular}{|c|c|c|}
\hline Questão 16: satisfação com freqüência da atividade sexual & MR & GC \\
\hline sempre & $38 \%$ & $31 \%$ \\
\hline quase sempre & $23 \%$ & $17 \%$ \\
\hline algumas vezes & $8 \%$ & $6 \%$ \\
\hline quase nunca & $8 \%$ & $6 \%$ \\
\hline nunca & $23 \%$ & $40 \%$ \\
\hline
\end{tabular}

\begin{tabular}{rcc}
\hline Questão 17: sentir-se tensa ou nervosa após a relação sexual & MR & GC \\
\hline sempre & $0 \%$ & $3 \%$ \\
quase sempre & $15 \%$ & $3 \%$ \\
algumas vezes & $31 \%$ & $6 \%$ \\
quase nunca & $8 \%$ & $11 \%$ \\
nunca & $46 \%$ & $77 \%$ \\
\hline
\end{tabular}

$\overline{p=0.9}$

\begin{tabular}{lcc}
\hline Relações sexuais semanais & MR & GC \\
\hline Mais de duas & $8 \%$ & $6 \%$ \\
Duas vezes & $23 \%$ & $20 \%$ \\
Uma vez & $23 \%$ & $14 \%$ \\
1 vez no mês & $15 \%$ & $14 \%$ \\
Sem relações & $31 \%$ & $46 \%$ \\
\hline$p=0.9$ & &
\end{tabular}

Os pontos em vermelho, mostram diferenças estatisticamente relevantes e nos extremos das respostas, revelando importantes e claras divergências entre os grupos mastectomia radical (MR) e controle (GC).

Nos gráficos 3 e 4 observam-se os escores comparativos do comportamento sexual das pacientes durante o período de seguimento. 
Gráfico 3: Escore médio em desejo, excitação, orgasmo e resolução mastectomia radical $(\mathrm{MR})-(\mathrm{t} 0 \times \mathrm{t} 3 \times \mathrm{t} 6 \times \mathrm{t} 9 \times 12)$

\begin{tabular}{|r|r|c|c|c|}
\hline \multicolumn{5}{|c|}{ Evolução WSFQ nos Diferentes Momentos do Ciclo Sexual Feminino - } \\
Grupo MR \\
\hline 60,00
\end{tabular}

Gráfico 4: Escore médio em desejo, excitação, orgasmo e resolução grupo controle (GC)- (t0 x t3 x t6 x t9 x 12)

\begin{tabular}{|r|r|r|r|r|}
\hline \multicolumn{5}{|r|}{ Evolução WSFQ nos Diferentes Momentos do Ciclo Sexual Feminino - } \\
Grupo Controle \\
\hline 60,00
\end{tabular}


Teste de Hipóteses medidas repetidas para avaliar diferenças em Desejo (D), Excitação (E), Orgasmo (O), Resolução (R), Total (T) para os dois grupos ao longo das coletas

Para Grupo de mastectomia radical (MR), temos:

Teste 01 - Hipótese: $\mu \mathrm{D}$ T0 $(\mathrm{MR})=\mu \mathrm{D}$ T3 $(\mathrm{MR})=\mu \mathrm{D}$ T6 $(\mathrm{MR})=\mu \mathrm{D}$ T9 $(\mathrm{MR})=\mu \mathrm{D}$ T12 $(\mathrm{MR})$

Teste $02-$ Hipótese: $\mu \mathrm{E}$ T0 $(\mathrm{MR})=\mu \mathrm{E}$ T3 $(\mathrm{MR})=\mu \mathrm{E}$ T6 $(\mathrm{MR})=\mu \mathrm{E}$ T9 (MR) $=\mu \mathrm{E} T 12(\mathrm{MR})$

Teste 03 - Hipótese: $\mu \mathrm{O}$ T0 $(\mathrm{MR})=\mu \mathrm{O}$ T3 $(\mathrm{MR})=\mu \mathrm{O}$ T6 (MR) $=\mu \mathrm{O}$ T9 $(\mathrm{MR})=\mu \mathrm{O} \mathrm{T} 12(\mathrm{MR})$

Teste 04 - Hipótese: $\mu \mathrm{R}$ T0 (MR) $=\mu \mathrm{R}$ T3 (MR) $=\mu \mathrm{R}$ T6 (MR) $=\mu \mathrm{R}$ T9 $(\mathrm{MR})=\mu \mathrm{R}$ T12 (MR)

Teste 05 - Hipótese: $\mu \mathrm{T}$ T0 $(\mathrm{MR})=\mu \mathrm{T} \mathrm{T} 3(\mathrm{MR})=\mu \mathrm{T} \mathrm{T} 6(\mathrm{MR})=\mu \mathrm{T}$ T9 $(\mathrm{MR})$ $=\mu \mathrm{T} T 12(\mathrm{MR})$

Considerando $p=0.10$, podemos afirmar que para o grupo mastectomia radical as hipóteses 02 e 05 não se confirmam, ou seja, na fase da Excitação encontrou-se diferenças estatisticamente significantes entre os instantes de coleta o que pode ter impactado nas diferenças observadas entre os instantes para o indicador Total do WSFQ. 
Para Grupo de Controle (GC), temos:

Teste 06 - Hipótese: $\mu \mathrm{D}$ T0 $(\mathrm{GC})=\mu \mathrm{D}$ T3 $(\mathrm{GC})=\mu \mathrm{D}$ T6 $(\mathrm{GC})=\mu \mathrm{D}$ T9 $(\mathrm{GC})$ $=\mu \mathrm{DT} 12(\mathrm{GC})$

Teste 07 - Hipótese: $\mu \mathrm{E}$ T0 (GC) $=\mu \mathrm{E}$ T3 (GC) $=\mu \mathrm{E}$ T6 (GC) $=\mu \mathrm{E}$ T9 (GC) $=\mu \mathrm{E} T 12(\mathrm{GC})$

Teste 08 - Hipótese: $\mu \mathrm{O}$ T0 $(\mathrm{GC})=\mu \mathrm{O}$ T3 (GC) $=\mu \mathrm{O}$ T6 (GC) $=\mu \mathrm{O}$ T9 $(\mathrm{GC})=\mu \mathrm{O} \mathrm{T} 12(\mathrm{GC})$

Teste 09 - Hipótese: $\mu R$ T0 (GC) $=\mu R$ T3 (GC) $=\mu R$ T6 (GC) $=\mu R$ T9 (GC) $=\mu \mathrm{R} T 12(\mathrm{GC})$

Teste 10 - Hipótese: $\mu \mathrm{T}$ T0 $(\mathrm{GC})=\mu \mathrm{T}$ T3 $(\mathrm{GC})=\mu \mathrm{T}$ T6 $(\mathrm{GC})=\mu \mathrm{T}$ T9 $(\mathrm{GC})$ $=\mu \mathrm{T} T 12(\mathrm{GC})$

Considerando $p=0.10$, podemos afirmar que para o grupo de controle APENAS a hipótese 06 não se confirma, ou seja, somente na fase do Desejo encontrou-se diferenças estatisticamente significantes entre os instantes de coleta. Possivelmente decorrente da queda no índice observada entre t0 e t3. O Impacto também ocorre no escore total.

Na tabela 5 mostra-se o cálculo do Delta Esore comparativo entre os grupos nos momentos finais e inicias do estudo.

Tabela 5: Cálculo do Delta Escore (t12 - t0) para comparação Grupo Controle $x$ MR

\begin{tabular}{|c|c|c|c|c|c|c|c|}
\hline \multicolumn{4}{|c|}{ Grupo de Controle } & \multicolumn{4}{|c|}{ Grupo MR } \\
\hline & to & t12 & delta & & to & t12 & delta \\
\hline$\overline{\text { Desejo }}$ & 25,81 & 15,97 & $-9,84$ & Desejo & 16,86 & 16,30 & $-0,56$ \\
\hline Excitação & 13,65 & 13,22 & $-0,43$ & Excitação & 13,46 & 12,15 & $-1,31$ \\
\hline Orgasmo & 12,16 & 11,11 & $-1,05$ & Orgasmo & 11,20 & 12,00 & 0,80 \\
\hline Resolução & 10,08 & 9,84 & $-0,24$ & Resolução & 9,53 & 9,76 & 0,23 \\
\hline TOTAL & 54,11 & 50,14 & $-3,97$ & TOTAL & 51,06 & 50,23 & $-0,83$ \\
\hline
\end{tabular}


Aparentemente, o grupo controle mostrou-se mais afetado na fase de desejo ao compararmos o início e o fim do período de observação do estudo. Tal fato impactou também no escore total desse grupo. Ao avaliarmos o grupo MR, não se observou grande alteração.

\section{Teste de Hipóteses para avaliar diferenças entre os grupos}

Teste 11 - Hipótese estatística: D T12-T0 (GC) = D T12-T0 (MR)

Teste 12 - Hipótese estatística: E T12-T0 (GC) = E T12-T0 (MR)

Teste 13 - Hipótese estatística: O T12-T0 (GC) = O T12-T0 (MR)

Teste 14 - Hipótese estatística: R T12-T0 (GC) = R T12-T0 (MR)

Teste 15 - Hipótese estatística: T T12-T0 (GC) = T T12-T0 (MR)

Considerando $p=0.10$, podemos afirmar que apenas para o momento de Desejo a mudança de comportamento do grupo Controle foi diferente a observada no grupo MR. Talvez fato observado pela surpresa do diagnóstico, ou seja, não havia impacto em to, dado que o indicador de partida desse grupo para Desejo é bem superior ao indicador de partida observado em MR. 
Estudo de relação entre algumas das variáveis coletadas, escolhidas como chaves segundo o escore (controle $+M R$ ) em to com $n$ total $=52$

Através dos quadros (quadro 1, 2, 3 e 4) é possível verificar quais variáveis influenciam na resposta de outra questão ao compararmos os diferentes grupos de questões da metodologia WSFQ, independentemente de observarmos as pacientes no grupo caso ou controle, e considerando apenas os 52 casos, tomando T0 - mensuração basal, como a mais indicada para construção da matriz.

Quadro 1: Desejo

\begin{tabular}{||c|c|c|c|c|c|c||}
\hline \hline \multicolumn{7}{|c||}{ Matriz de análise de relação entre variáveis } \\
\hline Q1 & Q1 & Q2 & Q3 & Q4 & Q5 & Q6 \\
\hline Q2 & tem & tem & tem & tem & tem & tem \\
\hline Q3 & tem & não tem & - & tem & não tem & não tem \\
\hline Q4 & tem & não tem & tem & - & não tem & tem \\
\hline Q5 & tem & não tem & não tem & não tem & - & tem \\
\hline Q6 & tem & não tem & não tem & tem & tem & - \\
\hline \hline
\end{tabular}


Quadro 2: Excitação

\begin{tabular}{||c|c|c|c|c||}
\hline \multicolumn{5}{||c||}{ Matriz de análise de relação entre variáveis } \\
\hline & Q7 & Q8 & Q9 & Q10 \\
\hline Q7 & - & não tem & tem & não tem \\
\hline Q8 & não tem & - & tem & tem \\
\hline Q9 & tem & tem & - & tem \\
\hline Q10 & não tem & tem & tem & - \\
\hline
\end{tabular}

Quadro 3: Orgasmo

\begin{tabular}{||c|c|c|c|c||}
\hline \multicolumn{5}{||c||}{ Matriz de análise de relação entre variáveis } \\
\hline & Q11 & Q12 & Q13 & Q14 \\
\hline Q11 & - & não tem & não tem & tem \\
\hline Q12 & não tem & - & não tem & tem \\
\hline Q13 & não tem & não tem & - & tem \\
\hline Q14 & tem & tem & tem & - \\
\hline
\end{tabular}

Quadro 4: Resolução

\begin{tabular}{|c|c|c|c||}
\hline \multicolumn{4}{||}{ Matriz de análise de relação entre variáveis } \\
\hline & Q15 & Q16 & Q17 \\
\hline Q15 & - & não tem & não tem \\
\hline Q16 & não tem & - & não tem \\
\hline Q17 & não tem & não tem & - \\
\hline
\end{tabular}


É observado maior relação entre variáveis ao avaliarmos as questões nos grupo desejo e excitação. No grupo resolução, as três questões observadas podem ser consideradas independentes entre si.

Avaliação qualitativa via análise-síntese das questões subjetivas em t12, com $n=49$ comparando MR $\times$ GC

Nota: observações em vermelho após questões são referentes ao grupo de mastectomia radical com reconstrução. Quando em preto, ao sem reconstrução.

19. Realização de exames de seguimento (benigno $x$ maligno)

\begin{tabular}{lcc}
\hline Grupo MR & MR & MRR \\
$\begin{array}{l}\text { Muito mal } \\
\text { mal e ainda estou insegura }\end{array}$ & & \\
Não pensei sobre isso & & \\
Bem & 3 & 5 \\
Muito bem & 1 & 2 \\
Outros: & & 1 \\
\cline { 2 - 3 } & $\mathbf{4}$ & $\mathbf{8}$ \\
\hline
\end{tabular}

\section{Grupo Controle}

Muito mal 2

mal e ainda estou insegura $\quad 5$

não tive reação 5

Aliviada por não ter câncer $\quad 15$

Outros (abaixo):

\begin{tabular}{lr} 
& 10 \\
& $\mathbf{3 7}$ \\
\hline
\end{tabular}

ARL: mal

GTG: primeiro não se sabia que era benigno, depois fiquei mal - procurei resolver o problema 


\section{Como se sente em relação ao parceiro}

\begin{tabular}{|c|c|c|}
\hline \\
\hline \multicolumn{3}{|l|}{ Grupo MR } \\
\hline não tenho parceiro & 1 & \\
\hline sendo mto próximo & 2 & 7 \\
\hline sendo mto afastado & 0 & 1 \\
\hline$<$ do q o recebido por outros & 1 & \\
\hline TOTAL & 4 & 8 \\
\hline
\end{tabular}

\section{Grupo Controle}

não tenho parceiro

muito próximo

muito afastado

$<$ do q o recebido por filhos, amigos, parentes

$\mathrm{n}$ estou recebendo apoio

22. Como você se sente em relação a sua auto- imagem

\begin{tabular}{|c|c|c|c|}
\hline Grupo MR & & MR & MRR \\
\hline mal & & & \\
\hline $\begin{array}{l}\text { Indiferente ao resultado } \\
\text { como antes do diagnóstico }\end{array}$ & & & 1 \\
\hline Outros: & & 4 & 7 \\
\hline & TOTAL & 4 & 8 \\
\hline
\end{tabular}

ISC: bem

VDL: estou bem, embora tendo as limitações e aprendendo a conviver (inchaço do braço)

NSP: horrível, pois está muito feio. Vai reconstruir novamente

\begin{tabular}{lc}
\hline Grupo Controle & \\
\hline mal & 8 \\
Indiferente ao resultado & 5 \\
como antes do diagnóstico & 3 \\
Outros (abaixo) & 21 \\
\hline
\end{tabular}

$\underline{A R L}:$ depois que tirei o nódulo fiquei bem, gostei do resultado da operação CHSA: bem

DGF: normal 
23. Sentir-se desejável

\begin{tabular}{lccc}
\hline Grupo MR & MR & MRR \\
\hline sim & 3 & 5 \\
nunca pensei sobre isso & 1 & 3 \\
não & & \\
\cline { 3 - 4 } & TOTAL & $\mathbf{4}$ & $\mathbf{8}$ \\
\hline
\end{tabular}

\begin{tabular}{lcc}
\hline Grupo Controle & & \\
\hline sim & 14 \\
nunca pensei sobre isso & 16 \\
não & 7 \\
\cline { 2 - 2 } & TOTAL & $\mathbf{3 7}$ \\
\hline
\end{tabular}

\section{Procura do parceiro}

\begin{tabular}{|c|c|c|c|}
\hline Grupo MR & & MR & MRR \\
\hline \multicolumn{4}{|l|}{ diariamente } \\
\hline semanalmente & & 1 & 3 \\
\hline quinzenalmente & & 0 & 1 \\
\hline mensalmente & & 0 & 0 \\
\hline esporadicamente & & 1 & 1 \\
\hline não tem procurado & & 1 & 3 \\
\hline \multirow[t]{2}{*}{ sem parceiro } & & 1 & \\
\hline & TOTAL & 4 & 8 \\
\hline
\end{tabular}

\begin{tabular}{lc}
\hline Grupo controle & \\
\hline diariamente & 3 \\
semanalmente & 12 \\
quinzenalmente & 1 \\
mensalmente & 3 \\
esporadicamente & 2 \\
não tem procurado & 5 \\
sem parceiro & 11 \\
\cline { 2 - 2 } \multicolumn{1}{r}{ TOTAL } & $\mathbf{3 7}$ \\
\hline
\end{tabular}

25. Você tem sido receptiva?

\begin{tabular}{lcc}
\hline Grupo MR & MR & MRR \\
\hline sim & 1 & 5 \\
não & 1 & 0 \\
sem parceiro & 1 & 0 \\
Não tem procurado & 1 & 3 \\
\cline { 2 - 3 } \multicolumn{1}{r}{ TOTAL } & $\mathbf{4}$ & $\mathbf{8}$ \\
\hline
\end{tabular}




\begin{tabular}{lc}
\hline Grupo controle & \\
\hline sim & 20 \\
não & 1 \\
não tem procurado & 5 \\
sem parceiro & 11 \\
\cline { 2 - 2 } \multicolumn{1}{r}{ TOTAL } & $\mathbf{3 7}$ \\
\hline
\end{tabular}

A inatividade sexual deveu-se a falta de parceria em, $25 \%$ no grupo de mastectomia radical e $29,73 \%$ no grupo controle e a ausência de procura pelo parceiro em $37,5 \%$ grupo mastectomia radical com reconstrução, $25 \%$ no grupo de mastectomia radical e $13,51 \%$ no grupo controle. Uma das pacientes do grupo controle tinha marido com disfunção erétil de causa mista.

\section{Idéias de menos valia, desesperança, morte, auto-estima negativa}

\section{Grupo MR}

JFS: Deus me livre. Eu quero é viver muito se Deus permitir. Quero é me livrar do cigarro. Do câncer me livrei, quero agora é me livrar do cigarro.

LL: eu não apresentei nenhum destes itens pois tenho uma família maravilhosa, sou muito amada e não irei deixar meu marido para outra, meus filhos e netos tão cedo VD: tive momentos muito tristes a ponto de aumentar a depressão. Só não pensei em morrer!!!! Cheguei a ficar sem vontade de tomar banho, cuidar do meu local de trabalho, não arrumar o meu quarto, tirar pó, varrer, etc. Atualmente não estou assim, estou bem melhor, fazendo minhas coisas, fazendo a unha de algumas clientes que vem me procurar.

\section{Grupo Controle}

CBM: não, pelo contrário

$\underline{\mathrm{COR}}$ : às vezes sim, às vezes você quer consertar o mundo, não dá - são pensamentos passageiros.

DGF: a morte é coisa natural. O importante é viver bem todos os dias, curtindo tudo que tiver no alcance: o sol, a natureza. Nada melhor que um novo amanhecer. 
Sempre pensamentos para cima. Desesperança nunca. Para tudo se dá um jeito. Crer em Deus

Observa-se na tabela 6, os resultados dos sintomas de depressão segundo critérios diagnósticos do DSM IV TR (APA, 2000)

Tabela 6: Avaliação de depressão (questão 27.)

Grupo mastectomia radical

MR MRR

1 Sente-se triste ou com uma sensação de vazio, chora muito

2 Sente desinteresse ou prazer diminuído em fazer as tarefas do dia-adia

12 Teve uma perda ou ganho peso significativo sem estar de dieta (regime), ou aumento ou diminuição do apetite, quase todos os dias

1 Teve insônia ou estava com muito sono, quase todos os dias

12 Estava muito agitada (inquieta) ou muito devagar (senti-se lenta), sendo isto percebido por você ou por outras pessoas

3 Sentia-se cansada ou com perda de energia, quase todos os dias

Sentiu-se inútil ou com excessiva culpa ou inadequada, quase todos os dias

Estava com a capacidade de pensar ou concentra-se diminuídas ou indecisa, quase todos os dias

Pensou várias vezes em morrer, quis várias vezes se suicidar (tendo ou não um plano específico para fazer isso)

\begin{tabular}{|l|l|l|l|l|l|}
\hline \multicolumn{7}{|c|}{ MR } \\
\hline $\mathbf{1}$ & & $\mathbf{4}$ & & $\mathbf{7}$ & \\
\hline $\mathbf{2}$ & 1 & $\mathbf{5}$ & & $\mathbf{8}$ & \\
\hline $\mathbf{3}$ & & $\mathbf{6}$ & & $\mathbf{9}$ & \\
\hline
\end{tabular}

Nenhuma: 3

\begin{tabular}{|l|l|l|l|l|l|}
\hline \multicolumn{7}{|c|}{ MRR } \\
\hline $\mathbf{3}$ & 2 & 4 & 1 & 7 & \\
\hline $\mathbf{2}$ & 2 & $\mathbf{5}$ & & $\mathbf{8}$ & \\
\hline $\mathbf{3}$ & & $\mathbf{6}$ & & 9 & \\
\hline
\end{tabular}

Nenhuma: 2 


\section{Grupo controle}

12 Sente-se triste ou com uma sensação de vazio, chora muito

8 Sente desinteresse ou prazer diminuído em fazer as tarefas do dia-a-dia

11 Teve uma perda ou ganho peso significativo sem estar de dieta (regime), ou aumento ou diminuição do apetite, quase todos os dias

7 Teve insônia ou estava com muito sono, quase todos os dias

8 Estava muito agitada (inquieta) ou muito devagar (senti-se lenta), sendo isto percebido por você ou por outras pessoas

13 Sentia-se cansada ou com perda de energia, quase todos os dias

3 Sentiu-se inútil ou com excessiva culpa ou inadequada, quase todos os dias

10 Estava com a capacidade de pensar ou concentra-se diminuídas ou indecisa, quase todos os dias

1 Pensou várias vezes em morrer, quis várias vezes se suicidar (tendo ou não um plano específico para fazer isso)

\section{Nenhuma: 12}

\begin{tabular}{|l|l|l|l|l|l|}
\hline $\mathbf{1}$ & 6 & $\mathbf{4}$ & 2 & $\mathbf{7}$ & 2 \\
\hline $\mathbf{2}$ & 7 & $\mathbf{5}$ & 2 & $\mathbf{8}$ & \\
\hline $\mathbf{3}$ & 3 & $\mathbf{6}$ & 2 & $\mathbf{9}$ & \\
\hline
\end{tabular}

Das 37 pacientes, seis apresentaram critérios para depressão maior (mais que 5)

Obs:

ARL: por dois dias ficou triste, ansiosa e ficou cansada, mas nada muito significante.

EAS: angustiada com problemas que não pode falar para os filhos, o que a deixa triste e angustiada

JAS: fez a cirurgia no joelho e ainda não consegue fazer as tarefas mais pesadas da casa, mas no aspecto afetivo-emocional-conjugal, está tudo bem, sem alterações.

$\underline{\mathrm{SM}}$ : passou por mudança muito significativas em sua vida nestes últimos meses FRT: preenche 7 critérios, mas está em crise de rinite o que está lhe deixando sem força para fazer_suas tarefas e cansada, devido aos antialérgicos que está tomando devido à cirurgia para incontinência - está com dor

MJN: problemas com a filha que está bebendo, ficando agressiva (justificando 7 sintomas)

RSS: está com problemas com o marido 


\section{Sexualidade e auto-imagem}

\begin{tabular}{|c|c|c|}
\hline \multicolumn{3}{|l|}{ Grupo MR } \\
\hline & MR & MRR \\
\hline boa auto-imagem e uma sexualidade adequada & 1 & 3 \\
\hline boa auto-imagem porém não exerço minha sexualidade & 2 & 2 \\
\hline nunca pensei sobre isso & 0 & 2 \\
\hline $\begin{array}{l}\text { não tenho uma boa auto-imagem, mas exerço minha } \\
\text { sexualidade e uma sexualidade adequada }\end{array}$ & 0 & 0 \\
\hline $\begin{array}{l}\text { não tenho uma boa auto-imagem e não exerço minha } \\
\text { sexualidade }\end{array}$ & 1 & 1 \\
\hline TOTAL & 4 & 8 \\
\hline
\end{tabular}

\section{Grupo controle}

boa auto-imagem e uma sexualidade adequada 18

boa auto-imagem porém não exerço minha sexualidade 5

nunca pensei sobre isso

não tenho uma boa auto-imagem, mas exerço minha sexualidade 0

não tenho uma boa auto-imagem e não exerço minha sexualidade 7

TOTAL 37

\section{Você apresenta perspectivas em relação ao futuro?}

\section{Grupo MR}

L L: estou mal. Motivo: mutilada. Espero q o cirurgião plástico agende o mais breve possível a minha reconstrução do meu seio esquerdo.

M A: ficar curada.

M J P: ficar boa.

MMAF: é trabalhar e cuidar dos meus filhos e da minha casa, espero com muita fé em Deus. 


\section{Grupo Controle}

ARL: não penso sobre isso. Gosto de tudo bem ... no carnaval já vou descer para Santos

ABS: viver em paz, tranqüila ao lado do meu marido e procurar ser melhor do que agora.

CMBM: sinceramente, que meu pai estivesse bem. Ver minha filha mais nova formada (não só na universidade, mas em todos os aspectos), ficar com meu marido até o fim

DZAP: tenho medo do futuro, não me sinto segura.. insegurança em relação à idade. Dá vontade de chorar quando faz balanço da vida, de tudo que poderia ter conseguido e não conseguido.

Por meio das análises realizadas, pode-se observar que:

$\checkmark$ Condição comparativa entre os grupos é satisfeita pela premissa de homogeneidade de perfis, ou seja, variáveis demográficas não devem influenciar TOTALMENTE nos resultados alcançados.

$\checkmark$ Os testes e medidas estatísticas revelam diferenças entre os instantes de coletas (importantes) dentre e na comparação entre os grupos.

$\checkmark$ Avaliação qualitativa: mostra a amplitude de variações nos sentimentos/ atitudes que a doença causa em cada entrevistada, não sendo possível uma padronização do comportamento e complementando de forma decisiva na avaliação objetiva realizada através da escoragem WSFQ. 
6. DISCUSSÃO 
Série de estudos sobre mastectomia radical vêm sendo conduzida há anos. Grande parte destes, comportam aspectos sobre tratamentos adjuvantes e neoadjuvantes para o câncer de mama, como os quimioterápicos, hormonioterápicos e radioterápicos, atualizando assim o conhecimento sobre novas drogas para o tratamento do câncer, aumento a sobrevida das pacientes (Barret-Connor, 1998; Broeckel et al, 2002; Lobo, 1993; Hermann et al, 1993)

Outros, porém, abordam aspectos técnicos da mastectomia radical, como, por exemplo, a reconstrução mamária. Nestes estudos é muito comum encontrarmos comparações entre técnicas cirúrgicas, ou seja, entre as indicações e benefícios da cirurgia conservadora (tumorectomia, quadrantectomia) frente a mastectomia radical com ou sem reconstrução, abordando questões sobre possíveis impactos destas técnicas sobre a morbidade psicológica das pacientes (Al-Ghazal, 2000 a.b; Cohen et al, 2000; Dorval et al, 1998; Fischer et al, 2002; Frischenschlarge et al; 2002; Frost et al, 2000b; Harcourt et al., 2003; Malata et al, 2000). Entre estes estudos, encontramos aqueles que abordam a sexualidade (Bruner e Boyd, 1999; Buković et al, 2005; Greendale et al, 2001; Meyerowitz et al, 1999; )

Porém, o conhecimento sobre impacto psicológico das cirurgias para o câncer de mama na sexualidade feminina provém de outros países, incluindo os grandes estudos de seguimento (Frischenschlarger et al, 1990; Ganz et al, 1992; Kornblith e Ligibel, 2003; Maguire, 1999; Janni et al, 2001, Margolis et al, 1990; Oktay 1998; Poulsen et al, 1997;:Pozo et al, 1992; Rabinowitz 2002; Yilmazer et al, 1994; Urbánek et al, 1994a, Van't Spijker et 
al, 1994). Em nosso país não encontramos estudos relacionando os efeitos da mastectomia radical sobre a sexualidade, sendo pela primeira vez realizado por Maluf $(2004,2006)$, com pacientes com três meses de pósoperatório, observando nesta população indícios de disfunção orgásmica.

Frente a isto, o presente trabalho teve caráter pioneiro ao promover o seguimento de pacientes que seriam submetidas à mastectomia radial, desde o momento diagnostico pelo período de um ano, até então fora de nosso conhecimento. Algo também inédito, foi também à utilização do grupo controle composto por mulheres com tumores benignos de mama, cujos estudos em sexualidade também são raríssimos fora do país.

Estes grupos foram comparados visando investigar e compreender a vivência da sexualidade destas mulheres.

No segmento de questões qualitativas foi possível perceber que os efeitos da mastectomia sobre a sexualidade feminina, são dependentes da estrutura psicológica, do auto-conceito e da auto-imagem das pacientes, além da forma como seus relacionamentos afetivo-emocionais estão estruturados, ou seja, a presença ou ausência de relacionamento conjugal e também os relacionamentos familiares, da rede de amizades e profissional. Estes itens também foram observados na meta-análise conduzida por Moyer (1997), no qual a autora comparou os efeitos psicológicos entre cirurgias conservadoras e radicais. Assim, a autora identificou e categorizou seis tipos de ajustamento apresentado pelas pacientes:

a) Ajustamento psicológico: inclui depressão, ansiedade, culpa, medo e hostilidade 
b) Ajustamento sexual-conjugal

c) Social

d) Auto-imagem e imagem corporal

e) Medos e assuntos relacionados ao câncer

f) Ajustamento global.

A estrutura apresentada por Moyer (1997) também se aplica as pacientes do grupo controle já que muitas delas foram submetidas à biópsia e ficaram com as mamas com cicatrizes que as incomodam ou achavam que as mamas ficaram disformes e/ou assimétricas em função de biópsias cirúrgicas, alterando sua imagem corporal e auto-imagem, e conseqüentemente a vivência da sexualidade.

Pacientes com tumores benignos de mama narraram também o medo de ter câncer: "fico cismada, em de repete, virar câncer" (VSS - controle T0) e seu ajustamento psicológico foi muito pior que das pacientes do grupo cirúrgico, sendo diagnosticada depressão em T0 em 27 pacientes, excluídas da pesquisa, algumas encaminhadas para tratamento farmacológico e outras somente para psicoterápico. Este dado vem de encontro aos achados de Chessear e Anderson (1975).

Este grupo mostrou também a presença de disfunções sexuais ligadas à falta de desejo, talvez relacionado ao medo inconsciente de ter câncer, já que uma parte delas tinha amigas que tiveram câncer, algumas delas falecendo da doença. Outro fator relacionado a isso era o relacionamento marital, muito ruim para algumas, o que é fator primordial para o bom 
desempenho sexual nas mulheres (Abdo, 2000; Carrasco, 2001; Kaplan, 1999).

Quanto aos efeitos psicológicos do diagnóstico do câncer de mama, todas as pacientes apresentaram alguma forma de reação que demonstra entrada em contato a realidade da perda da saúde, como: choque, tristeza, sentir-se muito mal, estar mal e ainda insegurança, querer morrer, entre outros.

Estas reações são a primeira etapa do processo de luto que ocorre durante todo o tratamento do câncer de mama (Maluf, 2006) e que é necessário para o restabelecimento do psiquismo, do auto-conceito, da autoimagem e da imagem corporal após a mastectomia radical.

O processo de luto pode demorar um pouco para instalar-se ou ser mais rápido, mas acompanha cada etapa do tratamento, relembrando: diagnóstico, mastectomia radical, quimio, radio e hormonioterapia.

Nos casos em que a reconstrução mamária não é realizada, o processo de luto pela perda da mama é mais sofrido, pois a mutilação é sempre vivível, sendo que algumas vezes as pacientes não se olham mais ao espelho e a área de cicatriz nem sempre é tocada: "me sinto mal pois me sinto mutilada" (LSL- MR T6). Outras pacientes, porém por mais que não façam a reconstrução, por terem uma condição psicológica melhor, rede de apoio, enfrentam esta situação de forma diferenciada "me olho no espelho, não tenho preconceito contra mim" (JFS MR T6).

Sendo assim, a reação frente à mutilação gerada pela mastectomia radical parece ser pessoal e requer uma rede de apoio para auxiliar a mulher 
na reconstrução do eu, de seu auto-conceito, auto-imagem e imagemcorporal.

O tratamento quimioterápico, seja pré e principalmente pós-cirúrgico provoca reações de luto pelo impacto nas mudanças corpóreas como a alopécia, muitas vezes expressa como maior preocupação: no íntimo esta espelha e representa na psique da paciente a diminuição de sua feminilidade, o estigma do câncer, o estigma da morte, a rejeição social, sentimento de piedade, o preconceito, autodefesa ... uma fase de rejeição.

Assim, ao início da quimioterapia o luto reaparece, vinculado a alopecia. Porém há uma nova mutilação, pois o cabelo encontra-se, da mesma forma que as mamas, ligado ao conceito de feminilidade, eles são pintados, escovados, presos, sendo exibidos e cuidados: “... a única coisa que fiquei mal foi quando o cabelo começou a cair. Fiquei mal. Fiquei agoniada, sentindo uma dor por dentro (no couro cabeludo) ... vieram lágrimas aos olhos.... peguei a tesoura e cortei (como disse o médico, 14 dias depois do início da quimioterapia o cabelo começou a cair)" (JFS - MR T3).

A alopécia é considerada por algumas mulheres como uma agressão maior que a própria mastectomia, já que os cabelos são símbolos de feminilidade e sensualidade (Maluf, 2006). O volume da mama operada pode ser conseguido nas pacientes sem reconstrução, com próteses externas, através das quais, por detrás da roupa, não se nota a assimetria entre as mamas.

Porém a cabeça coberta pelo lenço é o sinal social do câncer, do preconceito que ainda há na sociedade, fazendo com que os olhares se 
atraiam à mulher que está em tratamento. Desta forma algumas se sentem inferiorizadas perante as demais, novamente castradas em sua feminilidade.

O cabelo, desde a Antigüidade, tem simbologia ligada à força, virilidade, sensualidade e personalidade. Na China, por exemplo, o corte rente dos cabelos era considerado uma mutilação que impedia o acesso a certas funções. O ato de cortar os cabelos correspondia não só a um sacrifício, mas também a uma rendição: era a renúncia (voluntária ou imposta) às virtudes, aos direitos, em fim à própria personalidade (Chevalier e Cheerbtant, 1996).

A ordem da cidade é par: o homem fica de pé sobre duas pernas, trabalha com dois braços e vê a realidade com dois olhos. Ao contrário da ordem humana ou divina, a ordem oculta, noturna, transcendental é por princípio, uma e se apóia sobre um vértice, como a dançarina ou a pirâmide invertida. O deformado, o amputado e o estropiado têm isso em comum: achamse colocados à margem da sociedade humana (ou diurna) pelo fato de que a paridade entre eles é atingida: eles participam de outra ordem, a da morte, infernal ou celeste, satânica ou divina (Chevalier e Cheerbtant, 1996).

A quimioterapia promove além da alopécia, outra castração relativa à perda de fertilidade: outro luto a ser elaborado, principalmente em mulheres em idade fértil.

Por meio deste conceito, pode-se fazer uma analogia de que a mulher mastectomizada é duplamente mutilada: uma ao ter sua mama (ou suas mamas) extirpada e outra ao perder o cabelo, sendo e pois marginalizada e 
considerada como uma pessoa "desqualificada", arquétipos ${ }^{\S}$ estes presentes no inconsciente coletivo da sociedade.

Desta forma, durante todo o tratamento do câncer de mama, novos processos de luto são iniciados e findados em cada etapa do tratamento.

Durante todo o seguimento, as pacientes mantiveram perspectivas para seu futuro, principalmente relacionadas ao "aqui e agora", mostrando mudança na visão de vida como, por exemplo "quero aprender as coisas que me alegram (violão), estar de bem como a minha família, passear bastante, dançar com meu esposo, comprar pomar (laranja, uva) .... sorrir" (sic - MRR $3 m)$.

Este fato vem de encontro aos dados observados por Vos et al (2004) em relação ao enfrentamento do câncer de mama: mulheres que expressam meio otimista de enfrentamento, referem menor sofrimento e percebem seu corpo menos desfigurado do que as demais que não se utilizam destas técnicas.

Durante a condução deste estudo, alguns problemas tiveram que ser constantemente superados, tais como: o não comparecimento da paciente na data marcada devido à "esquecimento" (sic) ou a algum "imprevisto" (sic), a não existência de outras consultas médicas agendadas no complexo do Hospital das Clínicas, o que algumas vezes impossibilitava sua vinda fora

\footnotetext{
$\S$ Arquétipos ou imagens primordiais, "são representações simbólicas que se repetem em qualquer época, em qualquer lugar do mundo, mesmo onde não é possível explicar sua transmissão por descendência direta ou por fecundações cruzadas resultantes de migração" (Jung, 1996, p.69)

O termo inconsciente coletivo foi proposto por Carl G. Jung (1998). Encontra-se presente em todos os seres humanos e compreende toda a vida psíquica dos antepassados desde seus primórdios.
} 
destas datas e a desistência durante o processo em ambos os grupos, sendo que esta no grupo cirúrgico foi fator impactante para o tamanho menor do grupo no final da pesquisa.

Este estudo tinha como um entre seus objetivos, realizar também o seguimento dos maridos das pacientes de ambos os grupos, o que se tornou inviável, já que raríssimos eram os que acompanhavam as esposas às consultas. Desta forma, os dados obtidos em relação a conjugalidade / enfrentamento da doença foram obtidos somente por uma via, não podendo ser comparados com as respostas masculinas relacionadas às esposas, sendo sugestão para trabalhos futuros.

Os dados assim obtidos mostraram que $75 \%$ das pacientes submetidas à mastectomia radical percebem e narram que tem o apoio de seus maridos, sendo este instrumental, no cuidado da casa e de outras tarefas diárias e no campo afetivo-emocional.

Dentre as pacientes com vida sexual ativa, esta parece não ter sido influenciada pela mastectomia radical no que diz respeito a procura do parceiro pela relação $(58,33 \%)$, o que vêm de encontro aos resultados obtidos por Maluf em 2004. Algumas pacientes, porém verbalizaram que não manteriam relações se a iniciativa para tal partisse delas, devendo-se isso à mastectomia.

Porém, apesar desta procura dos parceiros pela relação, as pacientes submetidas à mastectomia radical apresentaram transtorno na fase de excitação. Este se deveu às alterações na auto-imagem, imagem corporal, principalmente no grupo que não realizou reconstrução mamária, 
confirmando os achados anteriores de Maluf $(2004,2006)$ e da literatura internacional (Al-Ghazal et al., 2000 a, b; Wilmoth, 1995).

Quando à receptividade à relação, mesmo quando procurada, somente uma das pacientes não o é, sendo esta pertencente ao grupo de mastectomia radical sem reconstrução, mostrando a influencia da não reconstrução para o exercício da sexualidade.

O questionário aplicado mostrou-se de fácil aplicação e a possibilidade de reaplicação em seguimento demonstrou a importância de ter-se instrumentos mistos, isto é, que permitam a avaliação quali e quantitativa da sexualidade e de aspectos a ela relacionados, como o afetivo-relacional, humor, relativos a auto-imagem e ao impacto da doença em sua vida. Desta forma, através do seguimento pois possível avaliar qualitativamente, obtendo-se riqueza de detalhes que permitiu completar os dados inferidos pelo WSFQ original, dando à versão brasileira do WSFQ adaptada à avaliação da sexualidade no câncer de mama, característica abrangente.

Quanto da aplicação do questionário, foi possível observar que as pacientes se mostraram abertas a falar não só sobre sua sexualidade, mas também sobre o processo do adoecer, de como o câncer afetou e está afetando suas vidas, por exemplo, não poder mais trabalhar: "fiquei triste durante três dias porque pensei que não poderia voltar a trabalhar, cuidar da casa, depois passou; falei com uma amiga" (sic MRR T0).

Sobre a possibilidade de se conhecer melhor os aspectos que influenciam o processo de tratamento do câncer de mama, há vasto campo 
de pesquisa que precisaria ser abordado e investigado com trabalhos prospectivos de longo prazo.

Outros estudos poderão ser conduzidos nesta área, para que juntas, ajudem a compor uma amostra da realidade da mulher brasileira no que concerne à mastectomia radical e no impacto que esta causa não só sobre a sexualidade, mas sobre todo o funcionamento psicoemocional das pacientes.

Além das pesquisas, é de suma importância que os centros de referência possibilitem às pacientes com câncer de mama acesso a serviço psicológico desde o momento diagnóstico, para que assim estas mulheres possam receber não só orientações e informações sobre câncer de mama e seu tratamento, como também para que possam ser ouvidas em suas angústias, medos e incertezas, visando assim diminuir a incidência de depressão e uma possível evolução desta para o suicídio.

Deste modo, a orientação médica a paciente e seus familiares quanto à evolução do tratamento são um importante fator para a diminuição da ansiedade, da tensão e do medo do incerto, aliado ao suporte psicológico para a paciente e seus familiares, auxiliando-os pois a lidarem com seus medos, angústias e incertezas frente ao longo tratamento.

Assim, conclui-se que o adoecer é uma experiência ímpar e de desordem, que adquire um sentido específico no momento existencial da mulher, devido aos significados que os sintomas, as experiências com o tratamento e as relações interpessoais passam a ter em seu contexto de vida (Maluf et al, 2005). 
Desta forma, as intervenções psicológicas, individuais ou em grupo, tem o papel primordial na melhora não só da adaptação psicossocial destas mulheres (Kornblith e Ligibel, 2003), como também para o esclarecimento e compreensão das angústias, fantasias e medos (da recorrência do câncer, de ser abandonada por familiares e amigos, do desfiguramento e principalmente o medo da morte) e medos e incertezas frente ao câncer, seu tratamento e sua expectativa de vida (Maluf et al, 2005; Campos, 1995; Valle, 1997; Kornblith e Ligibel, 2003). É importante, pois auxilia na detecção da ansiedade e depressão, agindo em prol de um bom prognóstico (Campos, 1995), pois é sabido que entre $25 \%$ e $35 \%$ das mulheres com câncer de mama irão desenvolver ansiedade e/ou depressão em algum estágio do tratamento e para muitas isso é incessante se não encontrarem ajuda psicológica (Moorey et al., 1989).

Para autores como Nissin et al (2001) a mastectomia com reconstrução está associada a importantes transtornos do humor e baixo bem-estar, após 18 meses de pós-operatório. Isto faz pensar que estudos com seguimento mais longo das pacientes poderiam confirmar ou não os dados do trabalho do autor, além de possibilitar o maior entendimento a respeito da qualidade de vida das pacientes após anos de pós-operatório.

Em suma, grande número de estudos focados no ajustamento psicológico, comparam pacientes mastectomizadas com outras submetidas a cirurgias conservadoras, chegando a conclusões de que quando mais conservadora a cirurgia, menor o impacto psicológico causado pelas alterações na imagem-corporal e no auto-conceito. Porém não há 
unanimidade quanto a isso, havendo outros estudos, como sinalizado pela meta-análise de Fallowfield (1990), afirmam não haver diferença entre o impacto psicológico em pacientes submetidas a mastectomia radical ou cirurgia conservadora, mostrando a necessidade da realização de estudos de seguimento.

Desta forma ao realizarmos este estudo de seguimento anual obtivemos o perfil da sexualidade das mulheres submetidas à mastectomia radical, verificando, a presença de disfunções sexuais como na fase de excitação, os problemas relacionados à isso como as alterações na autoimagem, no auto-conceito e na imagem corporal, além do processo de elaboração do luto ocorrido durante todo o tratamento.

\subsection{Considerações finais}

Em relação ao instrumento aplicado, teve também caráter terapêutico para muitas mulheres que mudaram seu estilo de vida, aprenderam a se posicionar perante a vida, com uma visão mais otimista, e as pessoas, incluindo marido, abriram seu próprio negócio (tinham vontade mas não coragem), isso tanto no grupo cirúrgico quanto no controle, sendo os facilitadores para este processo: o perfil do questionário com questões qualitativas, a freqüência trimestral dos encontros e o vinculo com o aplicador. 
Pôde ser claramente notado, que o seguimento que lhes ofereceu também a oportunidade de reflexão sobre si mesmas e de perceber que há novas oportunidades de vida, apesar da proximidade e da necessidade do pensar na morte que o diagnóstico de câncer promove 
7.CONCLUSÃO 
Com esta pesquisa pudemos traçar o perfil das mulheres com câncer de mama submetidas à mastectomia radical percebendo e afirmando que:

1. A grande maioria das pacientes ao receber o diagnóstico de malignidade, teve reações como tristeza, choque, desconfiança, sentiu-se mal, entre outras.

2. Para as mulheres que não fizeram reconstrução mamária a mastectomia é vista como mutilação, principalmente para aquelas que tinham pior auto-imagem antes da cirurgia. Já para aquela que realizam reconstrução mamária, o efeito mutilante da mastectomia fica minimizado.

3. Todas passaram pelo processo de elaboração do luto ocorrido durante as diversas etapas do tratamento, incluindo também o momento diagnóstico, na qual há a confirmação da perda da condição saudável para a nova condição de portador de câncer de mama.

4. A existência da parceria é relevante para a manutenção da atividade sexual entre as pacientes submetidas à mastectomia radical com e sem reconstrução mamária.

5. A existência de parceria é de fundamental importância para o suporte instrumental e emocional destas pacientes, quando a relação do casal está bem, fazendo com que se sintam queridas e desejadas. 
8. ANEXOS 
ANEXO A

Space Eve (1972), Salvador Dali

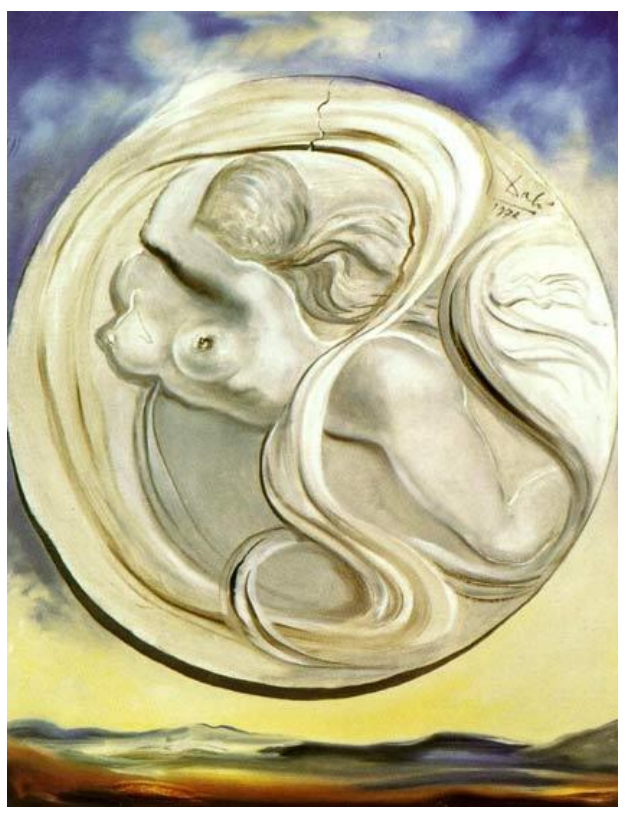


ANEXO B

ESTUDOS ANATÔMICOS, SALVADOR DALI (1937)

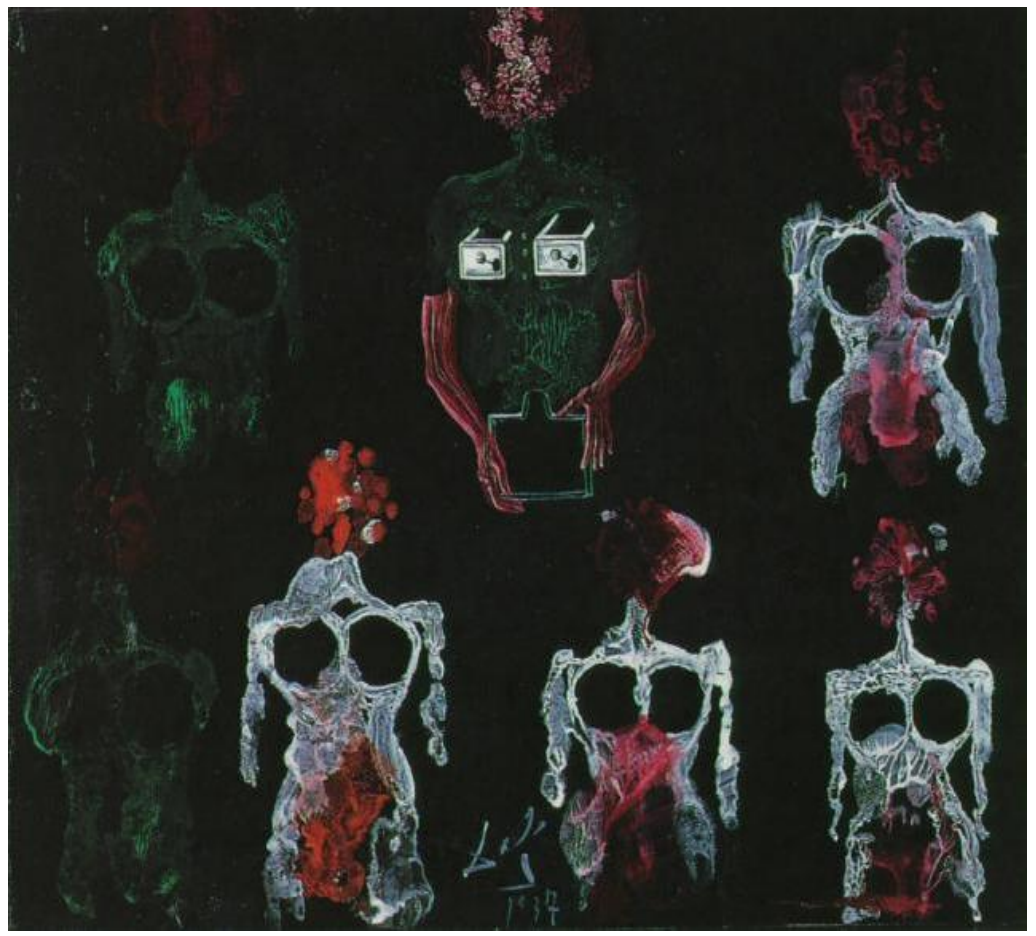


ANEXO C

DISFUNÇÕES SEXUAIS FEMININAS SEGUNDO DSM IV TR (APA, 2000)

\begin{tabular}{|c|c|c|}
\hline Grupos de transtornos & Tipo de transtorno & $\begin{array}{l}\text { Critérios } \\
\text { (critério A) }\end{array}$ \\
\hline \multirow{2}{*}{$\begin{array}{l}\text { Transtorno do } \\
\text { desejo }\end{array}$} & $\begin{array}{c}\text { Desejo sexual } \\
\text { hipoativo (302.71) }\end{array}$ & $\begin{array}{l}\text { Ausência de fantasias e de desejo de } \\
\text { atividade sexual }\end{array}$ \\
\hline & $\begin{array}{l}\text { Aversão sexual } \\
\qquad(302.79)\end{array}$ & $\begin{array}{l}\text { Aversão e evitação ativa da atividade } \\
\text { sexual }\end{array}$ \\
\hline Transtorno de excitação & $\begin{array}{l}\text { Excitação sexual } \\
\text { feminina }(302.72)\end{array}$ & $\begin{array}{l}\text { Incapacidade para obter ou manter a } \\
\text { lubrificação vaginal até o final da relação } \\
\text { sexual }\end{array}$ \\
\hline Transtorno do orgasmo & $\begin{array}{l}\text { Orgasmo feminino } \\
\qquad(302.73)\end{array}$ & $\begin{array}{l}\text { Ausência ou retardo do orgasmo frente } \\
\text { uma fase de excitação normal }\end{array}$ \\
\hline \multirow{2}{*}{ Transtorno doloroso } & $\begin{array}{l}\text { Dispareunia } \\
(302.76)\end{array}$ & Dor genital ao coito \\
\hline & $\begin{array}{l}\text { Vaginismo } \\
(306.51)\end{array}$ & $\begin{array}{l}\text { Contração involuntária do terço inferior } \\
\text { da vagina frente a qualquer intenção de } \\
\text { penetração }\end{array}$ \\
\hline
\end{tabular}

FONTE: DSM-IV - TR (APA, 2002) 
ANEXO D

\section{DIAGNÓSTICO PARA DISFUNÇÕES SEXUAIS DEVIDO À CONDIÇÃO MÉDICA GERAL (DSM IV TR, 2002)}

\begin{tabular}{|c|c|c|}
\hline Cód. & Eixo I & $\begin{array}{c}\text { Características (o termo é utilizado } \\
\text { quando...) }\end{array}$ \\
\hline 625.8 & $\begin{array}{l}\text { Desejo sexual hipoativo } \\
\text { feminino devido a } \ldots\end{array}$ & $\begin{array}{l}\text {.... a deficiência ou ausência de desejo é a } \\
\text { característica predominante. }\end{array}$ \\
\hline 625.0 & $\begin{array}{l}\text { Dispareunia feminina } \\
\text { devido a }\end{array}$ & $\begin{array}{l}\text { X ... a dor que estiver associada ao intercurso } \\
\text { o for a característica principal. }\end{array}$ \\
\hline 625.8 & $\begin{array}{l}\text { Outra disfunção sexual } \\
\text { feminina devido a ... }\end{array}$ & $\begin{array}{l}\text { III .... se outra característica for ou não } \\
\text { predominante (por exemplo, disfunção } \\
\text { orgásmica). }\end{array}$ \\
\hline
\end{tabular}

FONTE: DSM-IV - TR (APA, 2002) 


\section{ANEXO E \\ GRUPOS DE TRANSTORNO SEXUAIS SEGUNDO O DSM-IV TR E A CID}

10

\begin{tabular}{|c|c|c|}
\hline Grupos de transtornos & DSM IV TR & CID 10 \\
\hline \multirow{2}{*}{ Transtorno do desejo } & $\begin{array}{c}\text { Desejo sexual hipoativo } \\
(302.71)\end{array}$ & $\begin{array}{l}\text { Ausência de desejo sexual } \\
\text { (F52.0) }\end{array}$ \\
\hline & $\begin{array}{l}\text { Aversão sexual } \\
\quad(302.79)\end{array}$ & $\begin{array}{l}\text { Aversão sexual } \\
\quad(\text { F52.0) }\end{array}$ \\
\hline Transtorno de excitação & $\begin{array}{c}\text { Excitação sexual feminino } \\
(302.72)\end{array}$ & $\begin{array}{l}\text { Falha de reposta sexual } \\
\text { (F52.2) }\end{array}$ \\
\hline Transtorno do orgasmo & $\begin{array}{l}\text { Orgasmo feminino } \\
\qquad(302.73)\end{array}$ & $\begin{array}{l}\text { Disfunção orgásmica } \\
\text { (F 52.3) }\end{array}$ \\
\hline \multirow{2}{*}{ Transtorno doloroso } & $\begin{array}{l}\text { Dispareunia } \\
(302.76)\end{array}$ & $\begin{array}{c}\text { Dispareunia não-orgânica } \\
\text { (F52.6) }\end{array}$ \\
\hline & $\begin{array}{l}\text { Vaginismo } \\
(306.51)\end{array}$ & $\begin{array}{c}\text { Vagismo não-orgânico } \\
\text { (F52.5) }\end{array}$ \\
\hline
\end{tabular}

FONTE: DSM-IV-TR (APA, 2002) e CID 10 (OMS, 1996) 
HOSPITAL

SírioLibanês

ANEXO F

DECLARAÇÃO NÚCLEO DE MASTOLOGIA DO HOSPITAL SÍRIO

LIBANÊS

São Paulo 30 de outubro de 2006.

\section{DECLARAÇÃO}

Declaramos para devidos fins, que a pós-graduanda Maria Fernanda de Matos Maluf, portadora do CPF 266.372.378-92, RG 27.729.036-3, está em nosso serviço do Núcleo de Mastologia no atendimento de paciente da responsabilidade social, para coletar dados para sua Dissertação de Mestrado.

Atenciosamente,

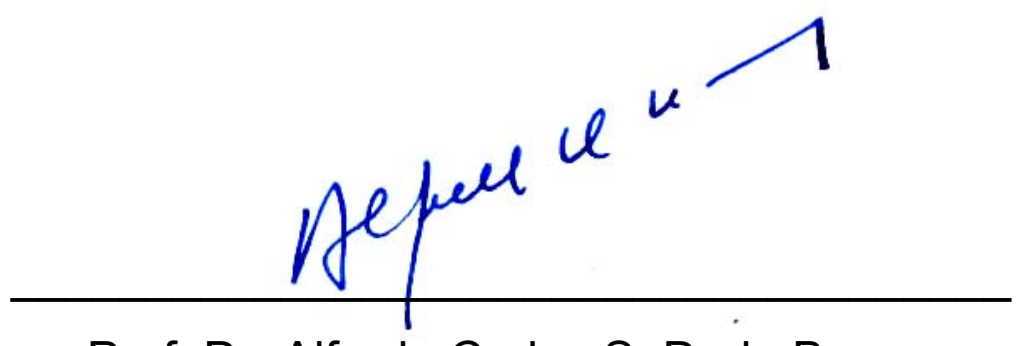

Prof. Dr. Alfredo Carlos S. D. de Barros

Coordenador do Núcleo de Mastologia

do Hospital Sírio Libanês 


\section{ANEXO G}

\section{PACIENTES SELECIONADAS PERTENCENTES A AMOSTRA FINAL COM FILTRO, SEGUNDO DIAGNÓSTICO EM PRONTUÁRIO}

\begin{tabular}{|c|c|c|c|c|c|}
\hline \multirow[b]{2}{*}{1.} & \multirow{2}{*}{\begin{tabular}{|l} 
RGHC \\
3251413 D
\end{tabular}} & \multirow{2}{*}{\begin{tabular}{|l|} 
Paciente \\
A R L \\
\end{tabular}} & \multirow{2}{*}{\begin{tabular}{|l|} 
Idade \\
50 \\
\end{tabular}} & \multirow{2}{*}{$\begin{array}{l}\text { Grupo } \\
\text { controle }\end{array}$} & \multirow{2}{*}{$\begin{array}{l}\text { Diagnóstico } \\
\text { hiperplasia epitelial de padrão ductal usual } \\
\text { alterado }\end{array}$} \\
\hline & & & & & \\
\hline 2. & $13436393 \mathrm{~A}$ & A B S & 59 & controle & fibroadenoma \\
\hline 3. & 13619138E & C M B M & 51 & controle & cistos bi-rads 2 \\
\hline 4. & $2089676 \mathrm{E}$ & COR & 59 & controle & cistos (D), calcificações \\
\hline 5. & 33367341 & CHSA & 54 & controle & fibroadenoma \\
\hline 6. & 2968180D & D G F & 52 & controle & \begin{tabular}{|lcc} 
hiperplasia colunar sem & atipia, \\
micocalcificações fbroesclerose &
\end{tabular} \\
\hline 7. & $2088000 \mathrm{~F}$ & D M & 59 & controle & Bi rads 3 \\
\hline 8. & $13638857 \mid$ & DZAP & 56 & conteole & mastalgia \\
\hline 9. & $13474281 G$ & E F O & 51 & controle & $\begin{array}{l}\text { nódulo isodenso ao tecido fibroglandular de } \\
\text { contorno obscurecidos - bi- } 0\end{array}$ \\
\hline 10. & $2089300 \mathrm{~K}$ & E V M & 53 & controle & mastoplastia fibrocística \\
\hline 11. & $3150626 \mathrm{~B}$ & ERA & 54 & controle & microcalcificações \\
\hline 12. & $2571923 \mathrm{~K}$ & F R T & 54 & controle & cisto \\
\hline 13. & $13600627 \mathrm{G}$ & G T G P & 60 & controle & tumor Filodes \\
\hline 14. & $2069578 \mathrm{H}$ & I M S & 51 & controle & fibroadenoma \\
\hline 15. & SIRIO & ISC & 57 & MR & carcinona ductal invasivo \\
\hline 16. & $2757665 \mathrm{~J}$ & I MESR & 57 & Controle & cisto complexo \\
\hline 17. & $4061977 \mathrm{~F}$ & JAS & 56 & controle & cisto \\
\hline 18. & $13660110 \mathrm{~A}$ & JMAS & 54 & controle & calcificações esparsas \\
\hline 19. & $13481630 \mathrm{E}$ & JFS & 50 & MR & \begin{tabular}{|llll} 
carcinona lobular invasivo associado a \\
neoplasia lobular in situ
\end{tabular} \\
\hline 20. & 33360861 & LS M & 52 & controle & fibroesclerose \\
\hline 21. & 136454741 & L S L & 52 & MR & carcinona ductal invasivo \\
\hline 22. & $3287614 \mathrm{~B}$ & LPS & 52 & controle & alteração microcística \\
\hline 23. & $3102586 \mathrm{H}$ & M B A & 53 & controle & cisto \\
\hline 24. & $13549575 B$ & M L H & 55 & controle & $\begin{array}{l}\text { nódulo hiperecogênico com calcificações no } \\
\text { contorno lobulado de limites bem definidos (D) }\end{array}$ \\
\hline 25. & $3029202 \mathrm{H}$ & MAAS & 50 & controle & tumor Filodes \\
\hline 26. & SIRIO & M A S Q & 55 & MR & carcinoma ductal invasivo \\
\hline 27. & $3296377 \mathrm{C}$ & M A E B & 58 & controle & $\begin{array}{l}\text { hiperplasia epitelial de padrão ductal usual com } \\
\text { atipias, mataplisia apócrina, fibroesclerose de } \\
\text { estroma }\end{array}$ \\
\hline 28. & $2230415 \mathrm{E}$ & M G S & 50 & controle & fibroadenoma \\
\hline 29. & $13470763 \mathrm{~K}$ & MLAD & 53 & MR & câncer de mama \\
\hline 30. & SIRIO & M D R L & 50 & MR & carcinona ductal invasivo \\
\hline 31. & $3033151 \mathrm{~K}$ & M J F & 60 & controle & microcalcificações bilaterais \\
\hline 32. & $2987211 \mathrm{~B}$ & M J A P & 54 & MR & carcinoma lobular invasivo \\
\hline 33. & $2903277 \mathrm{~B}$ & M N F & 53 & controle & microcalcificações \\
\hline 34. & SIRIO & M M A F & 54 & MRR & carcinona ductal invasivo \\
\hline
\end{tabular}




\begin{tabular}{|c|c|c|c|c|c|}
\hline & SIRIO & NSP & 55 & MR & carcinona ductal invasivo \\
\hline 36. & $13701148 \mathrm{H}$ & NCS & 53 & MR & carcinona ductal invasivo, micrometástase (1/9) \\
\hline 37. & 22408751 & NC & 55 & controle & mastite \\
\hline 38. & $2084992 E$ & NG B & 58 & controle & fibroadenoma com microcalcificações, adenose \\
\hline 39. & 2126195 & R S S & 50 & controle & cistos $(E, D)$ \\
\hline 40. & SIRIO & R C S P & 60 & MRR & carcinoma ductal invasivo \\
\hline 41. & $2276335 \mathrm{D}$ & S M S C & 50 & controle & fibroadenoma \\
\hline 42. & $13666489 \mathrm{~F}$ & SMAS & 54 & controle & microcalcificações esparsas \\
\hline 43. & $3373422 \mathrm{~F}$ & VSS & 53 & controle & fibrose estromal, fibroesclerose \\
\hline 44. & 3269607D & VLBA & 54 & controle & estroma sem atipia (em 99) \\
\hline 45. & 2196525E & V C C & 57 & controle & microcalcificações \\
\hline 46. & SIRIO & VDL & 59 & MRR & carcinoma ductal invasivo \\
\hline 47. & 13437574D & VE & 56 & controle & mastalgia \\
\hline 48. & $4086492 \mathrm{~J}$ & VCA & 50 & controle & fibroesclerose, microcalcificações pleomórficas \\
\hline 49. & 3327486E & Z M R G & 54 & controle & fibroadenoma \\
\hline 50. & SIRIO & W M A L & 58 & MRR & carcinoma ductal invasivo \\
\hline
\end{tabular}




\section{ANEXO H \\ WATTS SEXUAL FUNCTION QUESTIONNAIRE - WSFQ}

Foi formulado pela Dra Rosalyn Jones Watts em 1982 para sua tese de doutorado defendida na Temple University (Philadelphia).

$\mathrm{Na}$ área de oncologia mamária o WSFQ ou Sexual Funcion Questionnaire (SFQ), como foi primeiramente denominado, foi aplicado nas pesquisas de Thors et al. (2001), Rowland et al. (2000), Bruner et al. (1999), Ganz et al. (1999), Meyerowitz et al. (1999), Ganz et al. (1998), Wyatt et al. (1998) e Wilmoth e Townsed (1995), e também em artigos em outras áreas, tais como para avaliação de disfunções sexuais antes e durante terapia com antidepressivos (Kennedy et al., 1999; Kennedy et al., 2000; Howell et. al, 1987), sendo reutilizado pela própria autora em 1994 em estudo piloto sobre a função sexual em mulheres afro-americanas diabéticas e não diabéticas.

Pode ser utilizado tanto na avaliação de homens como de mulheres, sendo que as questões relacionadas ao interesse sexual e ao orgasmo são diferentes para cada sexo, sendo que as demais permanecem as mesmas.

No Brasil, este instrumento foi utilizado pela primeira vez em 2004, por Maluf, em estudo piloto sobre a sexualidade das pacientes submetidas à mastectomia radical, permitindo assim que o instrumento fosse adequado à realidade brasileira no que concerne não só a terminologia como também a avaliação da sexualidade em pacientes com câncer de mama

Por ser um instrumento americano, o WSFQ foi traduzido para o português por tradutores independentes, sendo realizada uma junta de profissionais compostos por estatístico, mastologista e psicólogos, posteriormente, para adaptação dos termos utilizados no texto original para termos comumente utilizados na língua portuguesa, facilitando assim, a compreensão das questões propostas. 


\section{WATTS SEXUAL FUNCTION QUESTIONNAIRE (WSFQ)}

Instruções: Leia atentamente cada questão. Circule a melhor resposta para cada questão que melhor descreva seus sentimentos e experiências sexuais durante o último mês.

1. Até que ponto "fazer sexo" é uma parte importante de sua vida? muito importante importante razoavelmente $\begin{gathered}\text { quase sem } \\ \text { importante }\end{gathered} \quad$ sem importância

2. Com que freqüência você curtiu/gostou de suas relações sexuais?

$$
\text { sempre quase sempre algumas vezes quase nunca nunca }
$$

3. Com que freqüência você estava muito cansada para fazer sexo?

$$
\text { sempre quase sempre algumas vezes quase nunca nunca }
$$

4. Com que freqüência você "sonhava acordada" ou tinha fantasias sexuais?

$$
\text { sempre quase sempre algumas vezes quase nunca nunca }
$$

5. Com que freqüência você sentiu desejo em fazer sexo com seu parceiro (s)?

$$
\text { sempre quase sempre algumas vezes quase nunca nunca }
$$

6. Até que ponto você quis mais sexo do que seu parceiro (s)?

$$
\text { sempre quase sempre algumas vezes quase nunca nunca }
$$

$$
\text { Subtotal }
$$

7. Durante sua última experiência sexual, até que ponto você percebeu sua lubrificação vaginal quando você ficou sexualmente excitada?

$$
\text { sempre quase sempre algumas vezes quase nunca nunca }
$$

8. Levava muito tempo para sua vagina começar a ficar molhada ou escorregadia, assim que você ficava sexualmente excitada?

$$
\text { imediatamente pouco tempo tempo razoável muito tempo não fico }
$$

9. Durante a relação sexual, com que freqüência você sentiu que sua vagina estava seca?

$$
\text { sempre quase sempre algumas vezes quase nunca nunca }
$$

10. Com que freqüência você sentiu dor ou desconforto durante a relação sexual?

$$
\text { sempre quase sempre algumas vezes quase nunca nunca }
$$

Subtotal

11. Á medida que você ficava mais excitada sexualmente, até que ponto você percebia que estava transpirando, com a respiração ofegante e os batimentos cardíacos acelerados?

$$
\text { sempre quase sempre algumas vezes quase nunca nunca }
$$

12. À medida que a excitação sexual se tornava mais intensa, com que freqüência você estava ciente das sensações de contração vaginal?

$$
\text { sempre quase sempre algumas vezes nuase nunca nuta }
$$

13.

Com que freqüência você foi capaz de chegar ao clímax (gozar)?

$$
\text { sempre quase sempre algumas vezes quase nunca nunca }
$$

14. Até que ponto era importante para você chegar ao clímax (gozar)?

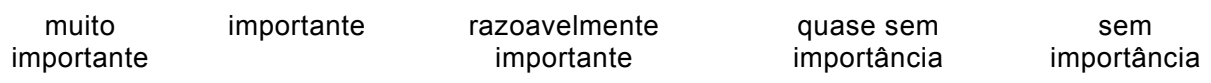

Subtotal 
15. Até que ponto você se sentiu satisfeita após a relação sexual? muito satisfeita satisfeita razoavelmente satisfeita pouco satisfeita não me satisfaço

16. Com que freqüência você ficou satisfeita com a freqüência de sua atividade sexual?

sempre quase sempre algumas vezes quase nunca nunca

17. Com que freqüência você se sentiu tensa ou nervosa após a relação sexual?

$\begin{array}{ccc}\text { sempre quase sempre } \quad \text { algumas vezes } & \text { quase nunca } \\ \text { Subtotal } & & \text { TOTAL }\end{array}$

18. Com que freqüência você teve relações sexuais nos últimos dois meses?

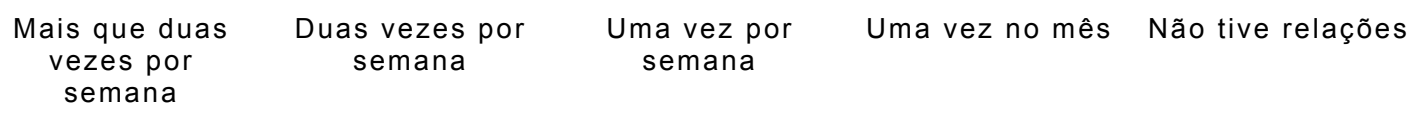




\section{ANEXO I \\ WSFQ GRUPO CIRÚRGICO - FASE DIAGNÓSTICA}

Este questionário tem como objetivo conhecer um pouco mais sobre sua sexualidade.

Você não precisa se identificar e todas as respostas dadas são sigilosas, e serão usadas em sua totalidade para fins únicos e exclusivos de pesquisa.

Desde já agradeço sua colaboração.

Data da aplicação: /2006

Fase diagnóstica

Número de identificação (RGHC)

Iniciais do nome:

Idade:

Estado civil:

Filhos: ( ) sim ( ) não

Quantos?

Naturalidade (estado de nascimento):

Religião:

\begin{tabular}{|l|l|l|}
\hline Profissão: & dona-de-casa & $($ ) \\
\hline & professor / magistério & $($ ) \\
\hline & funcionário público & $($ ) \\
\hline & profissional liberal & $($ ) \\
\hline & profissional de saúde & $(\quad$ ) \\
\hline & outros & \\
\hline
\end{tabular}
Escolaridade: ( Ensino fundamental (1 ${ }^{\circ}$ grau) ( ) Ensino médio ( $2^{\circ}$ grau) ( ) Ensino superior ) incompleto incompleto incompleto
( Ensino fundamental $\left(1^{\circ} \mathrm{grau}\right)\left(\mathrm{)}\right.$ Ensino médio $\left(2^{\circ}\right.$ grau $)(\mathrm{l})$ Ensino superior ) completo completo completo

Histórico pessoal:
Menopausa:
( ) não
( ) $\operatorname{sim}$
Idade:
Tem sintomas de menopausa, como
( ) não
( ) $\operatorname{sim}$
Quais
calores?
Faz terapia de reposição hormonal:
( ) não
( ) $\operatorname{sim}$
Medic.:
Doenças importantes:
( ) não ( ) sim
Quais:
Cirurgias anteriores:
( ) não
( ) $\operatorname{sim}$
Quais:
Medicações em uso:
( ) não ( ) sim
Quais:
Histórico de problemas sexuais
( ) não ( ) sim
Quais:
Histórico de disfunção sexual prévia:
( ) não
( ) $\operatorname{sim}$
Quais: 
Instruções: Leia atentamente cada questão. Circule a melhor resposta para cada questão que melhor descreva seus sentimentos e experiências sexuais durante o último mês.

1. Até que ponto "fazer sexo" é uma parte importante de sua vida? $\begin{array}{ccc}\text { muito importante importante } & \begin{array}{c}\text { razoavelmente } \\ \text { importante }\end{array} & \begin{array}{c}\text { quase sem } \\ \text { importância }\end{array}\end{array}$

sem importância

2. Com que freqüência você curtiu/gostou de suas relações sexuais?
sempre
quase sempre
algumas vezes
quase nunca
nunca

3. Com que freqüência você estava muito cansada para fazer sexo?

sempre quase sempre algumas vezes quase nunca

nunca

4. Com que freqüência você "sonhava acordada" ou tinha fantasias sexuais?

sempre quase sempre algumas vezes quase nunca nunca

5. Com que freqüência você sentiu desejo em fazer sexo com seu parceiro (s)?
sempre
quase sempre
algumas vezes
quase nunca
nunca

6. Até que ponto você quis mais sexo do que seu parceiro (s)?

sempre quase sempre algumas vezes quase nunca nunca

Subtotal

Código

7. Durante sua última experiência sexual, até que ponto você percebeu sua lubrificação vaginal quando você ficou sexualmente excitada?

$$
\text { sempre quase sempre algumas vezes quase nunca }
$$

nunca

8. Levava muito tempo para sua vagina começar a ficar molhada ou escorregadia, assim que você ficava sexualmente excitada?

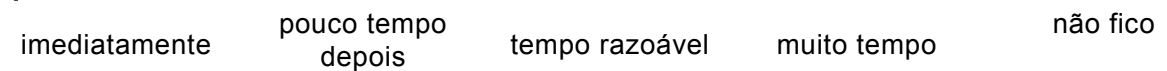

9. Durante a relação sexual, com que freqüência você sentiu que sua vagina estava seca?

$$
\text { sempre quase sempre algumas vezes quase nunca nunca }
$$

10. Com que freqüência você sentiu dor ou desconforto durante a relação sexual?

$$
\text { sempre quase sempre algumas vezes quase nunca nunca }
$$

Subtotal

11. Á medida que você ficava mais excitada sexualmente, até que ponto você percebia que estava transpirando, com a respiração ofegante e os batimentos cardíacos acelerados?

$$
\text { sempre quase sempre algumas vezes quase nunca nunca }
$$

12. À medida que a excitação sexual se tornava mais intensa, com que freqüência você estava ciente das sensações de contração vaginal?

$$
\text { sempre quase sempre algumas vezes quase nunca nunca }
$$

13. Com que freqüência você foi capaz de chegar ao clímax (gozar)?

$$
\text { sempre quase sempre algumas vezes quase nunca nunca }
$$

14. Até que ponto era importante para você chegar ao clímax (gozar)?

$\begin{array}{cccc}\text { muito } & \text { importante } & \text { razoavelmente } & \text { quase sem } \\ \text { importante } & \text { importante } & \begin{array}{c}\text { sem } \\ \text { importância }\end{array} & \end{array}$

\section{Subtotal}


15. Até que ponto você se sentiu satisfeita após a relação sexual? muito satisfeita satisfeita razoavelmente satisfeita pouco satisfeita não me satisfaço

16. Com que freqüência você ficou satisfeita com a freqüência de sua atividade sexual?

$$
\text { sempre quase sempre algumas vezes quase nunca nunca }
$$

17. Com que freqüência você se sentiu tensa ou nervosa após a relação sexual?

sempre quase sempre algumas vezes quase nunca nunca

Subtotal

TOTAL

18. Com que freqüência você teve relações sexuais nos últimos dois meses?

$\begin{array}{cccc}\begin{array}{c}\text { Mais que duas } \\ \text { vezes por }\end{array} & \begin{array}{c}\text { Duas vezes por } \\ \text { semana }\end{array} & \text { Uma vez por } & \text { Uma vez no mês } \\ \text { semano tive relações }\end{array}$
vezes por

semana

19. Como você se sentiu ao receber o diagnóstico de que tem um nódulo maligno na mama e que terá que ser operada?

\begin{tabular}{|l|c|l|}
\hline Muito mal & $(\quad)$ & \\
\hline $\begin{array}{l}\text { Mal e ainda estou } \\
\text { insegura }\end{array}$ & $(\quad)$ & \\
\hline Não tive reação & $(\quad)$ & \\
\hline Outros & $(\quad)$ & \\
\hline
\end{tabular}

20. Como você se sente em relação a seu atual (ou novo) parceiro?

21. Você teve (está tendo) apoio ( ) não tenho parceiro

de seu

parceiro em relação ao ( ) está sendo muito próximo

diagnóstico

de câncer de mama?

( ) está sendo muito afastado

( ) está menor do que o recebido por filhos, parentes e amigos

( ) não estou recebendo apoio

22. Como você se vê sabendo que ( ) mal

tem

( ) indiferente ao resultado

( ) como antes do diagnóstico

( ) outros

23. Você se sente uma mulher desejável? ( ) sim

( ) nunca pensei sobre isso

( ) não

24. Com que freqüência seu parceiro tem Ihe procurado?

( ) diariamente

( ) semanalmente

( ) quinzenalmente

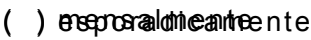


( ) não tem procurado

( ) sem parceiro

25. Você tem sido receptiva?
( ) $\operatorname{sim}$
( ) não
( ) sem parceiro
( ) não tem procurado

26. Você apresenta idéias de menos valia, desesperança, pensamentos sobre a temática de morte e auto-estima negativa? Comente.

27. Pensando num período de 2 semanas, você (é possível marcar mais de uma opção):

( ) Sente-se triste ou com uma sensação de vazio, chora muito

( ) Sente desinteresse ou prazer diminuído em fazer as tarefas do dia-a-dia

( ) Teve uma perda ou ganho peso significativo sem estar de dieta (regime), ou aumento ou diminuição do apetite, quase todos os dias

( ) Teve insônia ou estava com muito sono, quase todos os dias

( ) Estava muito agitada (inquieta) ou muito devagar (senti-se lenta), sendo isto percebido por você ou por outras pessoas

( ) Sentia-se cansada ou com perda de energia, quase todos os dias

( ) Sentiu-se inútil ou com excessiva culpa ou inadequada, quase todos os dias

( ) Estava com a capacidade de pensar ou concentra-se diminuídas ou indecisa, quase todos os dias

( ) Pensou várias vezes em morrer, quis várias vezes se suicidar (tendo ou não um plano específico para fazer isso)

28. Como você se sente em ( ) tenho uma boa auto-imagem e uma sexualidade relação a adequada

sua sexualidade e auto-imagem ( ) tenho uma boa auto-imagem porém não exerço minha sexualidade

(imagem que você tem de si ( ) nunca pensei sobre isso

mesma)?

( ) não tenho uma boa auto-imagem, mas exerço minha sexualidade

( ) não tenho uma boa auto-imagem e não exerço minha sexualidade

29. Qual (is) suas perspectivas com relação ao futuro? 


\section{ANEXO J \\ WSFQ GRUPO CIRÚRGICO - FASE PÓS-DIAGNÓSTICA}

Este questionário tem como objetivo conhecer um pouco mais sobre sua sexualidade.

Você não precisa se identificar e todas as respostas dadas são sigilosas, e serão usadas em sua totalidade para fins únicos e exclusivos de pesquisa.

Desde já agradeço sua colaboração.

Iniciais do nome:

Data da aplicação:

Fase pós-diagnóstica: 12006

Número de identificação (RGHC)

\begin{tabular}{|l|l|l|}
\hline Você tem realizado exames para seguimento? & $($ ) & não \\
\hline & $($ ) & sim \\
\hline
\end{tabular}

\begin{tabular}{|l|l|l|l|}
\hline Se sim, quais? & ( ) & mamografia & \\
\hline & ( ) & ultrassom & \\
\hline & ( ) & outros & \\
\hline
\end{tabular}

\begin{tabular}{|l|c|l|l|}
\hline Sabe resultado? & \multicolumn{2}{|l|}{} & \multicolumn{1}{|l|}{} \\
\hline Mamografia & $($ ) & sem alteração & \\
\hline & $($ ) & alteração & \\
\hline & $($ ) & não saiu o resultado \\
\hline & & & \\
\hline & $($ ) & sem alteração & \\
\hline & $($ ) & alteração & \\
\hline & $($ ) & não saiu o resultado \\
\hline Uutrassom & & & \\
\hline & $($ ) & sem alteração & \\
\hline & $($ ) & alteração & \\
\hline & $($ ) & não saiu o resultado \\
\hline
\end{tabular}

Instruções: Leia atentamente cada questão. Circule a melhor resposta para cada questão que melhor descreva seus sentimentos e experiências sexuais durante o último mês.

1. Até que ponto "fazer sexo" é uma parte importante de sua vida?

$$
\begin{array}{ccc}
\text { muito importante importante } & \begin{array}{c}
\text { razoavelmente } \\
\text { importante }
\end{array} & \begin{array}{c}
\text { quase sem } \\
\text { importância }
\end{array}
\end{array}
$$

2. Com que freqüência você curtiu/gostou de suas relações sexuais?

$$
\text { sempre quase sempre algumas vezes quase nunca nunca }
$$

3. Com que freqüência você estava muito cansada para fazer sexo?

sempre quase sempre algumas vezes quase nunca
4. Com que freqüência você "sonhava acordada" ou tinha fantasias sexuais?

nunca

$$
\text { sempre quase sempre algumas vezes quase nunca nunca }
$$

5. Com que freqüência você sentiu desejo em fazer sexo com seu parceiro (s)?

$$
\text { sempre quase sempre algumas vezes quase nunca nunca }
$$

6. Até que ponto você quis mais sexo do que seu parceiro (s)?

$$
\text { sempre quase sempre algumas vezes quase nunca nunca }
$$

Subtotal 
7. Durante sua última experiência sexual, até que ponto você percebeu sua lubrificação vaginal quando você ficou sexualmente excitada?

$$
\text { sempre quase sempre algumas vezes quase nunca nunca }
$$

8. Levava muito tempo para sua vagina começar a ficar molhada ou escorregadia, assim que você ficava sexualmente excitada?

imediatamente pouco tempo tempo razoável muito tempo não fico

9. Durante a relação sexual, com que freqüência você sentiu que sua vagina estava seca?

sempre quase sempre algumas vezes quase nunca
10. Com que freqüência você sentiu dor ou desconforto durante a relação sexual?

$$
\text { sempre quase sempre algumas vezes quase nunca nunca }
$$

Subtotal

11. Á medida que você ficava mais excitada sexualmente, até que ponto você percebia que estava transpirando, com a respiração ofegante e os batimentos cardíacos acelerados?

$$
\text { sempre quase sempre algumas vezes quase nunca }
$$

nunca

12. À medida que a excitação sexual se tornava mais intensa, com que freqüência você estava ciente das sensações de contração vaginal?

13.

$$
\text { sempre quase sempre algumas vezes quase nunca nunca }
$$

3. Com que freqüência você foi capaz de chegar ao clímax (gozar)?

sempre quase sempre algumas vezes quase nunca nunca

14. Até que ponto era importante para você chegar ao clímax (gozar)?
muito importante
importante
razoavelmente
quase sem
importância
sem importância

\section{Subtotal}

15. Até que ponto você se sentiu satisfeita após a relação sexual?
muito satisfeita
satisfeita
razoavelmente satisfeita
pouco satisfeita
não me satisfaço

16. Com que freqüência você ficou satisfeita com a freqüência de sua atividade sexual?

$$
\text { sempre quase sempre algumas vezes quase nunca }
$$

nunca

17. Com que freqüência você se sentiu tensa ou nervosa após a relação sexual?

$$
\begin{aligned}
& \text { sempre quase sempre algumas vezes quase nunca } \\
& \text { Subtotal }
\end{aligned}
$$

TOTAL

18. Com que freqüência você teve relações sexuais nos últimos dois meses?

$\begin{array}{ccccc}\text { Mais que duas } & \text { Duas vezes por } & \text { Uma vez por } & \text { Uma vez no mês } & \text { Não tive relações } \\ \text { vezes por semana } & \text { semana } & \text { semana } & \end{array}$

19. Como você se sente neste momento (fazendo reavaliações constantes de acompanhamento, meses depois da cirurgia)?

\begin{tabular}{|l|l|}
\hline Muito mal & $($ ) \\
\hline Mal e ainda estou insegura & $($ ) \\
\hline Não pensei sobre isso & $($ ) \\
\hline Bem & $($ ) \\
\hline Muito bem & $($ ) \\
\hline Outros & \\
\hline
\end{tabular}


20. Como você se sente em relação a seu atual (ou novo) parceiro?

21. Você teve (está tendo) apoio de seu parceiro

em relação ao acompanhamento periódico pós-cirúrgico (reavaliações)?
( ) não tenho parceiro

( ) está sendo muito próximo

( ) está sendo muito afastado

( ) está menor do que o recebido por filhos, parentes e amigos

( ) não estou recebendo apoio

22. Como você se vê após a cirurgia?
( ) mal
( ) indiferente ao resultado
( ) como antes do diagnóstico
( ) outros

23. Você se sente uma mulher desejável? (que desperta desejo)
( ) $\operatorname{sim}$

( ) nunca pensei sobre isso

( ) não

24. Com que freqüência seu parceiro tem lhe procurado?
( ) diariamente
( ) semanalmente
( ) quinzenalmente
( ) mensalmente
( ) esporadicamente
( ) não tem procurado
( ) sem parceiro

25. Você tem sido receptiva?
( ) $\operatorname{sim}$
( ) não
( ) sem parceiro
( ) não tem procurado

26. Você apresenta idéias de menos valia, desesperança, pensamentos sobre a temática de morte e auto-estima negativa? Comente. 
27. Pensando num período de 2 semanas, você (é possível marcar mais de uma opção):

( ) Sente-se triste ou com uma sensação de vazio, chora muito

( ) Sente desinteresse ou prazer diminuído em fazer as tarefas do dia-a-dia

( ) Teve uma perda ou ganho peso significativo sem estar de dieta (regime), ou aumento ou diminuição do apetite, quase todos os dias

( ) Teve insônia ou estava com muito sono, quase todos os dias

( ) Estava muito agitada (inquieta) ou muito devagar (senti-se lenta), sendo isto percebido por você ou por outras pessoas

( ) Sentia-se cansada ou com perda de energia, quase todos os dias

( ) Sentiu-se inútil ou com excessiva culpa ou inadequada, quase todos os dias

( ) Estava com a capacidade de pensar ou concentra-se diminuídas ou indecisa, quase todos os dias

( ) Pensou várias vezes em morrer, quis várias vezes se suicidar (tendo ou não um plano específico para fazer isso)

28. Como você se sente em relação a

( ) tenho uma boa auto-imagem e uma sexualidade adequada

sua sexualidade e auto-imagem

( ) tenho uma boa auto-imagem porém não exerço minha sexualidade

(imagem que você tem de você

( ) nunca pensei sobre isso

mesma)?

( ) não tenho uma boa auto-imagem, mas exerço minha sexualidade

( ) não tenho uma boa auto-imagem e não exerço minha sexualidade

29. Qual (is) suas perspectivas com relação ao futuro? 


\section{ANEXO L \\ WSFQ GRUPO CONTROLE - FASE DIAGNÓSTICA}

Este questionário tem como objetivo conhecer um pouco mais sobre sua sexualidade.

Você não precisa se identificar e todas as respostas dadas são sigilosas, e serão usadas em sua totalidade para fins únicos e exclusivos de pesquisa.

Desde já agradeço sua colaboração.

Data da aplicação: $\quad / \quad / 2006$

Fase diagnóstica

Número de identificação (RGHC)

Iniciais do nome:

Idade:

Estado civil:

Filhos: ( ) Sim ( ) Não Quantos?

Naturalidade (estado de nascimento):

Religião:

\begin{tabular}{|l|l|l|}
\hline Profissão: & dona-de-casa & $($ ) \\
\hline & professor / magistério & $($ ) \\
\hline & funcionário público & $(\quad$ ) \\
\hline & profissional liberal & $(\quad$ ) \\
\hline & profissional de saúde & $(\quad$ ) \\
\hline & outros & $(\quad$ ) \\
\hline
\end{tabular}

Escolaridade: ( ) Ensino fundamental ( $1^{\circ}$ grau) ( ) Ensino médio ( $2^{\circ}$ grau) ( ) Ensino superior incompleto incompleto incompleto
( ) Ensino fundamental ( $\left.1^{\circ} \mathrm{grau}\right)$ ( ) Ensino médio $\left(2^{\circ} \mathrm{grau}\right)$ ( ) Ensino superior completo completo completo

Histórico pessoal:
Menopausa:
( ) não ( ) sim idade:

Sente ondas de calor e/ou outros sintomas de menopausa ( ) não ( ) sim quais:

Faz terapia de reposição hormonal:

( ) não ( ) sim medic.

Doenças importantes:

( ) não ( ) sim quais:

Cirurgias anteriores:

( ) não ( ) sim quais:

Medicações em uso:

( ) não ( ) sim quais:

Histórico de problemas sexuais

( ) não ( ) sim quais:

Histórico de disfunção sexual prévia:

( ) não ( ) sim quais: 
Instruções: Leia atentamente cada questão. Nas questões abaixo (1 a 17) circule a melhor resposta que melhor descreva seus sentimentos e experiências sexuais durante o ÚLTIMO MÊS.

1. Até que ponto "fazer sexo" é uma parte importante de sua vida?

muito importante importante razoavelmente quase sem importante importância

muito importante importante $\begin{array}{cc}\text { razoavelmente } \\ \text { importante }\end{array} \quad \begin{gathered}\text { quase sem } \\ \text { importância }\end{gathered}$

sem importância

2. Com que freqüência você curtiu/gostou de suas relações sexuais?

$$
\text { sempre quase sempre algumas vezes quase nunca nunca }
$$

3. Com que freqüência você estava muito cansada para fazer sexo?

$$
\text { sempre quase sempre algumas vezes quase nunca nunca }
$$

4. Com que freqüência você "sonhava acordada" ou tinha fantasias sexuais?

$$
\text { sempre quase sempre algumas vezes quase nunca nunca }
$$

5. Com que freqüência você sentiu desejo em fazer sexo com seu parceiro (s)?

$$
\text { sempre quase sempre algumas vezes quase nunca nunca }
$$

6. Até que ponto você quis mais sexo do que seu parceiro (s)?

$$
\text { sempre quase sempre algumas vezes quase nunca nunca }
$$

Subtotal

7. Durante sua última experiência sexual, até que ponto você percebeu sua lubrificação vaginal quando você ficou sexualmente excitada?
sempre
quase sempre
algumas vezes
quase nunca
nunca

8. Levava muito tempo para sua vagina começar a ficar molhada ou escorregadia, assim que você ficava sexualmente excitada?

imediatamente pouco tempo tempo razoável muito tempo não fico

9. Durante a relação sexual, com que freqüência você sentiu que sua vagina estava seca?
sempre
quase sempre
algumas vezes
quase nunca
nunca

10. Com que freqüência você sentiu dor ou desconforto durante a relação sexual?
sempre
quase sempre
algumas vezes
quase nunca
nunca

Subtotal

11. Á medida que você ficava mais excitada sexualmente, até que ponto você percebia que estava transpirando, com a respiração ofegante $e$ os batimentos cardíacos acelerados?
sempre
quase sempre
algumas vezes
quase nunca
nunca

12. À medida que a excitação sexual se tornava mais intensa, com que freqüência você estava ciente das sensações de contração vaginal?
sempre
quase sempre
algumas vezes
quase nunca
nunca

13.

Com que freqüência você foi capaz de chegar ao clímax (gozar)?
sempre
quase sempre
algumas vezes
quase nunca
nunca

14. Até que ponto era importante para você chegar ao clímax (gozar)?

muito importante importante razoavelmente quase sem

sem importância

\section{Subtotal}


15. Até que ponto você se sentiu satisfeita após a relação sexual?
muito satisfeita
satisfeita
razoavelmente
pouco satisfeita
não me satisfaço

16. Com que freqüência você ficou satisfeita com a freqüência de sua atividade sexual?
sempre
quase sempre
algumas vezes
quase nunca
nunca

17. Com que freqüência você se sentiu tensa ou nervosa após a relação sexual?

$$
\text { sempre quase sempre algumas vezes quase nunca nunca }
$$

Subtotal

Total

18. Com que freqüência você teve relações sexuais nos ÚLTIMOS DOIS MESES?

\begin{tabular}{|c|c|c|c|}
\hline $\begin{array}{l}\text { Mais que duas } \\
\text { vezes por } \\
\text { semana }\end{array}$ & $\begin{array}{c}\text { Duas vezes por } \\
\text { semana }\end{array}$ & $\begin{array}{c}\text { Uma vez por } \\
\text { semana }\end{array}$ & Uma vez no mês Não tive relações \\
\hline
\end{tabular}

19. Como você se sentiu ao receber o diagnóstico de que tinha um nódulo benigno na mama?

\begin{tabular}{|l|c|l|}
\hline Muito mal & $($ ) & \\
\hline Mal e ainda estou insegura & $($ ) & \\
\hline Não tive reação & $($ ) & \\
\hline Aliviada, afinal não tenho câncer & $($ ) & \\
\hline Outros & $($ ) & \\
\hline
\end{tabular}

20. Como você se sente em relação a seu atual (ou novo) parceiro?

21. Você teve (está tendo) apoio de seu parceiro em relação a ter (não) nódulo benigno

na mama?
( ) não tenho parceiro
( ) está sendo muito próximo
( ) está sendo muito afastado
( ) está menor do que o recebido por filhos, parentes e amigos
( ) não estou recebendo apoio

22. Como você se vê sabendo que tem (não) um nódulo benigno na mama
( ) $\mathrm{mal}$
( ) indiferente ao resultado
( ) como antes do diagnóstico
( ) outros

23. Você se sente uma mulher desejável (que desperta desejo)?

\section{( ) $\operatorname{sim}$}

( ) nunca pensei sobre isso

( ) não 
24. Com que freqüência seu parceiro tem lhe ( ) sem parceiro procurado?
( ) não tem procurado
( ) diariamente
( ) semanalmente
( ) quinzenalmente
( ) mensalmente
( ) esporadicamente

\author{
25.Você tem sido receptiva? ( ) sim \\ ( ) não \\ ( ) sem parceiro \\ ( ) não tem procurado
}

26. Você apresenta idéias de menos valia, desesperança, pensamentos sobre a temática de morte e auto-estima negativa? Comente.

27. Pensando num período de 2 SEMANAS, você (é possível marcar mais de uma opção):

( ) sente-se triste ou com uma sensação de vazio, chora muito

( ) sente desinteresse ou prazer diminuído em fazer as tarefas do dia-a-dia

( ) teve uma perda ou ganho peso significativo sem estar de dieta (regime), ou aumento ou diminuição do apetite, quase todos os dias

( ) teve insônia ou estava com muito sono, quase todos os dias

( ) estava muito agitada (inquieta) ou muito devagar (senti-se lenta), sendo isto percebido por você ou por outras pessoas

( ) sentia-se cansada ou com perda de energia, quase todos os dias

( ) sentiu-se inútil ou com excessiva culpa ou inadequada, quase todos os dias

( ) estava com a capacidade de pensar ou concentra-se diminuídas ou indecisa, quase todos os dias

( ) pensou várias vezes em morrer, quis várias vezes se suicidar (tendo ou não um plano específico para fazer isso)

28. Como você se sente em ( ) tenho uma boa auto-imagem e exerço minha relação a sua sexualidade e auto- ( ) tenho uma boa auto-imagem porém não exerço minha imagem (imagem que você tem sexualidade de você mesma)

( ) nunca pensei sobre isso

( ) não tenho uma boa auto-imagem, mas exerço minha sexualidade

( ) não tenho uma boa auto-imagem e não exerço minha sexualidade

29. Qual (is) suas perspectivas com relação ao futuro? 


\section{ANEXO M \\ WSFQ GRUPO CONTROLE - FASE PÓS-DIAGNÓSTICA}

Este questionário tem como objetivo conhecer um pouco mais sobre sua sexualidade.

Você não precisa se identificar e todas as respostas dadas são sigilosas, e serão usadas em sua totalidade para fins únicos e exclusivos de pesquisa.

Desde já agradeço sua colaboração.

Data da aplicação: 12006

Fase pós-diagnóstica: mês

Número de identificação (RGHC)

Iniciais do nome:

\begin{tabular}{|l|l|l|l|}
\hline Você tem realizado exames para seguimento? & $($ ) & Não \\
\hline & $($ ) & Sim \\
\hline
\end{tabular}

\begin{tabular}{|l|l|l|l|}
\hline Se sim, quais? & $($ ) & Mamografia & \\
\hline & $($ ) & Ultrassom & \\
\hline & $($ ) & Outros & \\
\hline
\end{tabular}

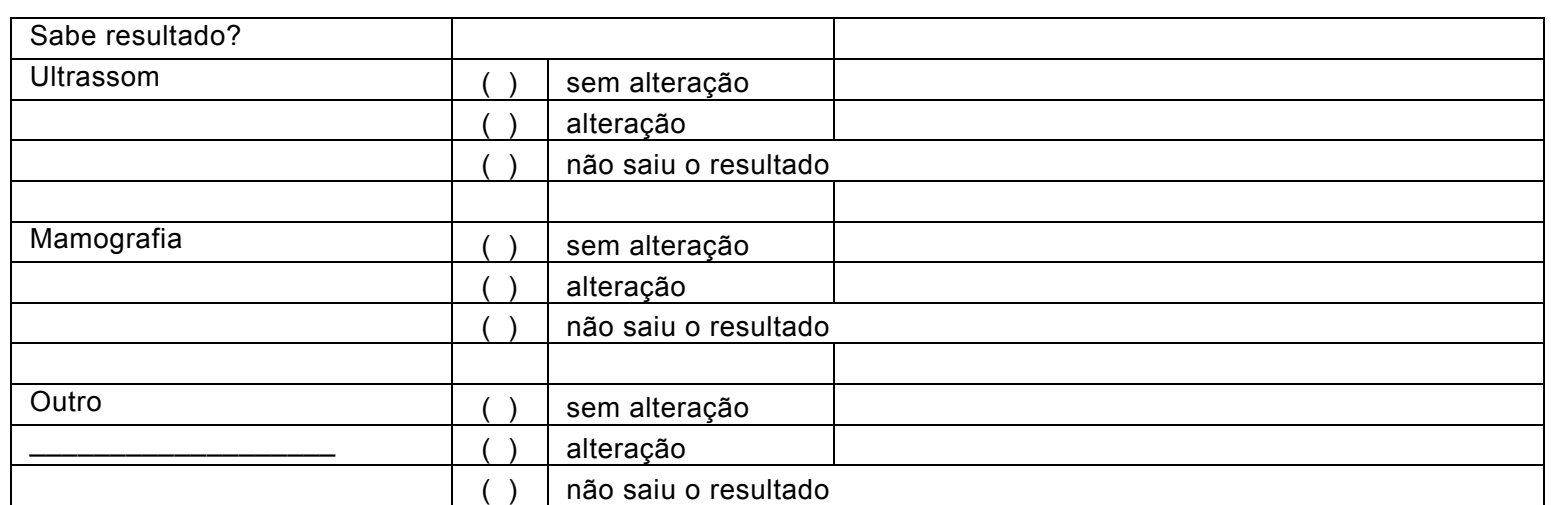

Instruções: Leia atentamente cada questão. Nas questões abaixo (1 a 17) circule a melhor resposta que melhor descreva seus sentimentos e experiências sexuais durante o ÚLTIMO MÊS.

1. Até que ponto "fazer sexo" é uma parte importante de sua vida? muito importante importante $\begin{array}{cc}\text { razoavelmente } \\ \text { importante }\end{array} \quad \begin{gathered}\text { quase sem } \\ \text { importância }\end{gathered}$

2. Com que freqüência você curtiu/gostou de suas relações sexuais?
sempre
quase sempre
algumas vezes
quase nunca
nunca

3. Com que freqüência você estava muito cansada para fazer sexo?
sempre
quase sempre
algumas vezes
quase nunca
nunca

4. Com que freqüência você "sonhava acordada" ou tinha fantasias sexuais?
sempre
quase sempre
algumas vezes
quase nunca
nunca

5. Com que freqüência você sentiu desejo em fazer sexo com seu parceiro (s)?
sempre
quase sempre
algumas vezes
quase nunca
nunca

6. Até que ponto você quis mais sexo do que seu parceiro (s)?
sempre
quase sempre
algumas vezes
quase nunca
nunca 
7. Durante sua última experiência sexual, até que ponto você percebeu sua lubrificação vaginal quando você ficou sexualmente excitada?
sempre
quase sempre
algumas vezes
quase nunca
nunca

8. Levava muito tempo para sua vagina começar a ficar molhada ou escorregadia, assim que você ficava sexualmente excitada?
imediatamente
pouco tempo
tempo razoável muito tempo
não fico depois

9. Durante a relação sexual, com que freqüência você sentiu que sua vagina estava seca?
sempre
quase sempre
algumas vezes
quase nunca
nunca

10. Com que freqüência você sentiu dor ou desconforto durante a relação sexual?
sempre
quase sempre
algumas vezes
quase nunca
nunca

Subtotal

Código

11. Á medida que você ficava mais excitada sexualmente, até que ponto você percebia que estava transpirando, com a respiração ofegante $e$ os batimentos cardíacos acelerados?
sempre
quase sempre
algumas vezes
quase nunca
nunca

12. À medida que a excitação sexual se tornava mais intensa, com que freqüência você estava ciente das sensações de contração vaginal?
sempre
quase sempre
algumas vezes
quase nunca
nunca

13. Com que freqüência você foi capaz de chegar ao clímax (gozar)?
sempre
quase sempre
algumas vezes
quase nunca
nunca

14. Até que ponto era importante para você chegar ao clímax (gozar)?

muito importante importante $\begin{gathered}\text { razoavelmente } \\ \text { importante }\end{gathered} \begin{gathered}\text { quase sem } \\ \text { importância }\end{gathered}$

sem importância

\section{Subtotal}

15. Até que ponto você se sentiu satisfeita após a relação sexual?
muito satisfeita
satisfeita
razoavelmente
pouco satisfeita
não me satisfaço satisfeita

16. Com que freqüência você ficou satisfeita com a freqüência de sua atividade sexual?

$$
\text { sempre quase sempre algumas vezes quase nunca nunca }
$$

17. Com que freqüência você se sentiu tensa ou nervosa após a relação sexual?
sempre
quase sempre
algumas vezes
quase nunca
nunca

Subtotal

TOTAL

18. Com que freqüência você teve relações sexuais nos últimos dois meses?

\begin{tabular}{|c|c|c|c|}
\hline $\begin{array}{c}\text { Mais que duas } \\
\text { vezes por } \\
\text { semana }\end{array}$ & $\begin{array}{c}\text { Duas vezes por } \\
\text { semana }\end{array}$ & $\begin{array}{c}\text { Uma vez por } \\
\text { semana }\end{array}$ & Uma vez no mês Não tive relações \\
\hline
\end{tabular}

19. Como você se sente neste momento (fazendo reavaliações constantes de acompanhamento, meses depois da confirmação de que você não tem câncer)?

$\begin{array}{ll}\text { Muito mal } & (\text { ) } \\ \text { Mal e ainda estou insegura } & (\text { ) } \\ \text { Não pensei sobre isso } & (\text { ) } \\ \text { Bem } & (\text { ( ) } \\ \text { Muito bem } & \text { ( ) }\end{array}$

Outros 
20. Como você se sente em relação a seu atual (ou novo) parceiro?

\begin{tabular}{|c|}
\hline 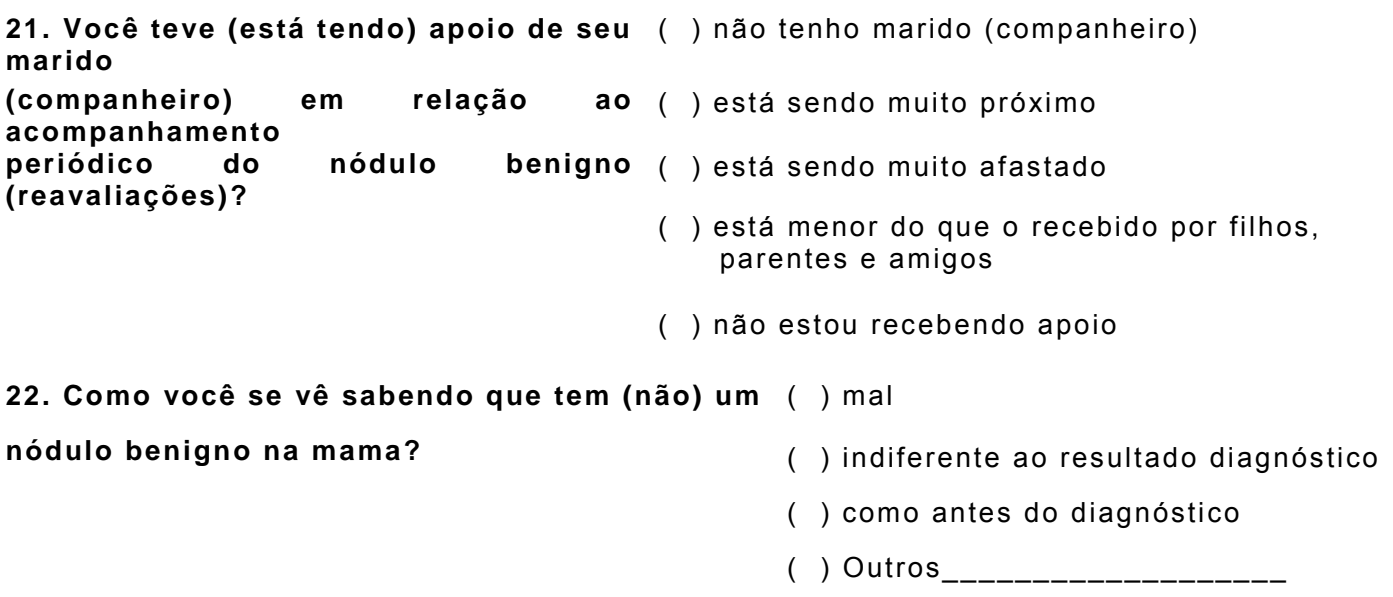 \\
\hline
\end{tabular}

23. Você se sente uma mulher desejável (que desperta desejo)?
( ) $\operatorname{sim}$
( ) nunca pensei sobre isso
( ) não

24. Com que freqüência seu parceiro tem the procurado?
( ) sem parceiro
( ) não tem procurado
( ) diariamente
( ) semanalmente
( ) quinzenalmente
( ) mensalmente
( ) esporadicamente

\author{
25.Você tem sido receptiva? ( ) sim \\ ( ) não \\ ( ) sem parceiro \\ ( ) não tem procurado
}

26. Você apresenta idéias de menos valia, desesperança, pensamentos sobre a temática de morte e auto-estima negativa? Comente.

27. Pensando num período de 2 SEMANAS, você (é possível marcar mais de uma opção):

( ) Sente-se triste ou com uma sensação de vazio, chora muito

( ) Sente desinteresse ou prazer diminuído em fazer as tarefas do dia-a-dia

( ) Teve uma perda ou ganho peso significativo sem estar de dieta (regime), ou aumento ou diminuição do apetite, quase todos os dias

( ) Teve insônia ou estava com muito sono, quase todos os dias

( ) Estava muito agitada (inquieta) ou muito devagar (senti-se lenta), sendo isto percebido por você ou por outras pessoas

( ) Sentia-se cansada ou com perda de energia, quase todos os dias 
( ) Sentiu-se inútil ou com excessiva culpa ou inadequada, quase todos os dias

( ) Estava com a capacidade de pensar ou concentra-se diminuídas ou indecisa, quase todos os dias

( ) Pensou várias vezes em morrer, quis várias vezes se suicidar (tendo ou não um plano específico para fazer isso)

28. Como você se sente em relação

( ) tenho uma boa auto-imagem e exerço minha sexualidade

a sua sexualidade e auto-imagem

( ) tenho uma boa auto-imagem porém não exerço minha sexualidade

(imagem que você tem de você)

( ) nunca pensei sobre isso

mesma

( ) não tenho uma boa auto-imagem, mas exerço minha sexualidade

( ) não tenho uma boa auto-imagem e não exerço minha sexualidade

29. Qual (is) suas perspectivas com relação ao futuro? 
ANEXO N

APROVAÇÃO MINISTÉRIO DA SAÚDE

\begin{tabular}{|c|c|c|c|c|c|c|}
\hline \multicolumn{7}{|c|}{ Andamento do projeto - CAAE - 0868.0.015.000-03] } \\
\hline \multicolumn{7}{|c|}{ O perfil da sexualidade em mulheres com câncer de mama } \\
\hline Aprovado no CEP & 27/04/2004 00:00:00 & 27/04/2004 00:00:00 & $27 / 04 / 2$ & & $27 / 0$ & 00 \\
\hline Descrição & & Data & Documento & № dc & & Origem \\
\hline 2 - Recebimento de Protocolo pelo CEP (Check-List) & & 08/12/2003 08:25:18 & Folha de Rosto & 0868. & & CEP \\
\hline 3 - Protocolo Pendente no CEP & & 04/02/2004 09:18:55 & Folha de Rosto & 1006/ & & CEP \\
\hline 4 - Protocolo Aprovado no CEP & & 27/04/2004 09:36:44 & Folha de Rosto & 1006/ & & CEP \\
\hline
\end{tabular}


ANEXO O

APROVAÇÃO DO COMITÊ DE ÉTICA E PESQUISA 


\section{ANEXO P \\ TERMO DE CONSENTIMENTO LIVRE E ESCLARECIDO GRUPO CIRÚRGICO \\ (Instruções para preenchimento no verso)}

\section{I - DADOS DE IDENTIFICAÇÃO DO SUJEITO DA PESQUISA OU RESPONSÁVEL LEGAL}

1.NOME DO PACIENTE

DOCUMENTO DE IDENTIDADE N ${ }^{\circ}$ : SEXO : $M \quad F$

DATA NASCIMENTO: ........................

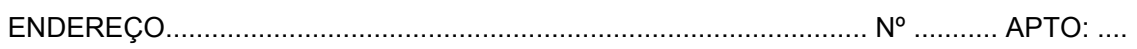

BAIRRO:

CIDADE

CEP:

TELEFONE: DDD (............)

2. RESPONSÁVEL LEGAL

NATUREZA (grau de parentesco, tutor, curador etc.)

DOCUMENTO DE IDENTIDADE $N^{\circ}$ : SEXO: .M F

DATA NASCIMENTO: .......................

ENDEREÇO

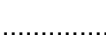

CIDADE

$\mathrm{N}^{\circ}$

APTO:

BAIRRO

.TELEFONE: DDD

...)

\section{II - DADOS SOBRE A PESQUISA CIENTÍFICA}

1. TÍTULO DO PROTOCOLO DE PESQUISA: O perfil da sexualidade em mulheres com câncer de mama PESQUISADOR: Maria Fernanda de Matos Maluf

CARGO/FUNÇÃO: aluna do curso de pós-graduação Strictu Sensu em Ginecologia e Obstetrícia da FMUSP INSCRIÇÃO CONSELHO REGIONAL Nº 06/60574-3

UNIDADE DO HCFMUSP:

3. AVALIAÇÃO DO RISCO DA PESQUISA:

$\begin{array}{lll}\text { SEM RISCO } & \text { RISCO MÍNIMO Q RISCO MÉDIO } \\ \text { RISCO BAIXO } & \text { RISCO MAIOR }\end{array}$

(probabilidade de que o indivíduo sofra algum dano como conseqüência imediata ou tardia do estudo)

4. DURAÇÃO DA PESQUISA: 2 anos

\section{III - REGISTRO DAS EXPLICAÇÕES DO PESQUISADOR AO PACIENTE OU SEU REPRESENTANTE LEGAL} SOBRE A PESQUISA CONSIGNANDO:

1. justificativa e os objetivos da pesquisa;

2. procedimentos que serão utilizados e propósitos, incluindo a identificação dos procedimentos que são experimentais;

3. desconfortos e riscos esperados;

4. benefícios que poderão ser obtidos;

5. procedimentos alternativos que possam ser vantajosos para o indivíduo

Meu nome é Maria Fernanda de Matos Maluf, sou psicóloga e gostaria de convidá-la a participar de uma pesquisa sobre a sexualidade das mulheres com câncer de mama.

Para tanto gostaria de vê-la cinco vezes para que possamos conversar um pouco sobre você. Nestes encontros, pedirei para que você responda a algumas perguntas sobre sua sexualidade. Gostaria também de estar conversando com seu marido (companheiro), caso você não se importe, para que ele responda ao mesmo questionário que você.

Não são esperados riscos à sua saúde devido ao procedimento que utilizarei. momento.

Você não é obrigada a participar da pesquisa e também pode solicitar o seu desligamento dela a qualquer

Desde já agradeço sua colaboração. 


\section{IV - ESCLARECIMENTOS DADOS PELO PESQUISADOR SOBRE GARANTIAS DO SUJEITO DA PESQUISA} CONSIGNANDO:

1. acesso, a qualquer tempo, às informações sobre procedimentos, riscos e benefícios relacionados à pesquisa, inclusive para dirimir eventuais dúvidas.

2. liberdade de retirar seu consentimento a qualquer momento e de deixar de participar do estudo, sem que isto traga prejuízo à continuidade da assistência.

3. salvaguarda da confidencialidade, sigilo e privacidade.

4. disponibilidade de assistência no HCFMUSP, por eventuais danos à saúde, decorrentes da pesquisa.

5. viabilidade de indenização por eventuais danos à saúde decorrentes da pesquisa.

V. INFORMAÇÕES DE NOMES, ENDEREÇOS E TELEFONES DOS RESPONSÁVEIS PELO ACOMPANHAMENTO DA PESQUISA, PARA CONTATO EM CASO DE INTERCORRÊNCIAS CLÍNICAS E REAÇÕES ADVERSAS.

Faculdade de Medicina da USP - Instituto de Ginecologia - Prof. Dra . Elsa Aida Gay Pereira

f. $3071-2331$

\section{OBSERVAÇÕES COMPLEMENTARES:}

\section{VII - CONSENTIMENTO PÓS-ESCLARECIDO}

Declaro que, após convenientemente esclarecido pelo pesquisador e ter entendido o que me foi explicado, consinto em participar do presente Protocolo de Pesquisa
São Paulo,
de
de 2006 . 


\section{ANEXO Q \\ TERMO DE CONSENTIMENTO LIVRE E ESCLARECIDO GRUPO CONTROLE}

(Instruções para preenchimento no verso)

Anexo I

\section{I - DADOS DE IDENTIFICAÇÃO DO SUJEITO DA PESQUISA OU RESPONSÁVEL LEGAL}

1. NOME DO PACIENTE DOCUMENTO DE IDENTIDADE No : SEXO : M F

DATA NASCIMENTO: .......................

ENDEREÇO. $\mathrm{N}^{\mathrm{o}}$ APTO:

BAIRRO CIDADE

CEP:

TELEFONE:.DDD (...............

3. RESPONSÁVEL LEGAL

NATUREZA (grau de parentesco, tutor, curador etc.) DOCUMENTO DE IDENTIDADE $\mathrm{N}^{\circ}$ : DATA NASCIMENTO: ........................ ENDEREÇO............ BAIRRO CIDADE SEXO : .M F

CEP:.

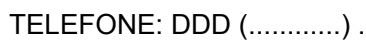
$\mathrm{N}^{\circ}$ APTO:.......

\section{II - DADOS SOBRE A PESQUISA CIENTÍFICA}

1. TÍTULO DO PROTOCOLO DE PESQUISA: O perfil da sexualidade em mulheres com câncer de mama PESQUISADOR: Maria Fernanda de Matos Maluf

CARGO/FUNÇÃO: aluna do curso de pós-graduação Strictu Sensu em Ginecologia e Obstetrícia da FMUSP INSCRIÇÃO CONSELHO REGIONAL Nº 06/60574-3

UNIDADE DO HCFMUSP:

3. AVALIAÇÃO DO RISCO DA PESQUISA:

$\begin{array}{lll}\text { SEM RISCO } & \text { RISCO MÍNIMO } \text { Q RISCO MÉDIO } \\ \text { RISCO BAIXO } & \text { RISCO MAIOR }\end{array}$

(probabilidade de que o indivíduo sofra algum dano como conseqüência imediata ou tardia do estudo)

4. DURAÇÃO DA PESQUISA: 2 anos

\section{III - REGISTRO DAS EXPLICAÇÕES DO PESQUISADOR AO PACIENTE OU SEU REPRESENTANTE LEGAL} SOBRE A PESQUISA CONSIGNANDO:

6. justificativa e os objetivos da pesquisa;

7. procedimentos que serão utilizados e propósitos, incluindo a identificação dos procedimentos que são experimentais;

8. desconfortos e riscos esperados;

9. benefícios que poderão ser obtidos;

10. procedimentos alternativos que possam ser vantajosos para o indivíduo

Meu nome é Maria Fernanda de Matos Maluf, sou psicóloga e gostaria de convidá-la a participar de uma pesquisa sobre a sexualidade feminina.

Para tanto gostaria de vê-la cinco vezes para que possamos conversar um pouco sobre você. Nestes encontros, pedirei para que você responda a algumas perguntas sobre sua sexualidade. Gostaria também de estar conversando com seu marido (companheiro), caso você não se importe, para que ele responda ao mesmo questionário que você.

Não são esperados riscos à sua saúde devido ao procedimento que utilizarei.

Você não é obrigada a participar da pesquisa e também pode solicitar o seu desligamento dela a qualquer momento.

Desde já agradeço sua colaboração. 


\section{IV - ESCLARECIMENTOS DADOS PELO PESQUISADOR SOBRE GARANTIAS DO SUJEITO DA PESQUISA CONSIGNANDO:}

6. acesso, a qualquer tempo, às informações sobre procedimentos, riscos e benefícios relacionados à pesquisa inclusive para dirimir eventuais dúvidas.

7. liberdade de retirar seu consentimento a qualquer momento e de deixar de participar do estudo, sem que isto traga prejuízo à continuidade da assistência.

8. salvaguarda da confidencialidade, sigilo e privacidade.

9. disponibilidade de assistência no HCFMUSP, por eventuais danos à saúde, decorrentes da pesquisa.

10. viabilidade de indenização por eventuais danos à saúde decorrentes da pesquisa.

V. INFORMAÇÕES DE NOMES, ENDEREÇOS E TELEFONES DOS RESPONSÁVEIS PELO ACOMPANHAMENTO DA PESQUISA, PARA CONTATO EM CASO DE INTERCORRÊNCIAS CLÍNICAS E REAÇÕES ADVERSAS.

Faculdade de Medicina da USP - Instituto de Ginecologia - Prof. Dr ${ }^{a}$ Elsa Aida Gay Pereyra

f. $3071-2331$

\section{OBSERVAÇÕES COMPLEMENTARES:}

\section{VII - CONSENTIMENTO PÓS-ESCLARECIDO}

Declaro que, após convenientemente esclarecido pelo pesquisador e ter entendido o que me foi explicado, consinto em participar do presente Protocolo de Pesquisa
São Paulo,
de
de 2006

assinatura do sujeito da pesquisa ou responsável legal

assinatura do pesquisador

(carimbo ou nome Legível) 
10. REFERÊNCIAS 
Abdo $\mathrm{CHN}$, organizadora. Sexualidade humana e seus transtornos. $2^{\mathrm{a}}$ ed. rev. e ampl. São Paulo: Lemos Editorial; 2000.

Abdo CHN, Guariglia Filho JEF. A mulher e sua sexualidade. In:Cordas TA, Salzano FT. Saúde mental da mulher. São Paulo: Atheneu; 2004.

Al-Ghazal SK, Sully L, Fallowfield L, Blamey RW. The psychological impact of immediate rather than delayed breast reconstruction. Eur J Surg Oncol. 2000; 36(1):17-9.

Ah-Ghazal SK, Sully L, Fallowfield L, Blamey RW. Comparison of psychological aspects and patient satisfaction following breast conserving surgery, simple mastectomy and breast reconstruction. Eur J Surg Oncol. 2000; 36(15): 1938-43.

American College of Radiology (ACR). Breast Imaging Reporting and Data System (BI-RADS). $3^{\mathrm{a}}$ ed. Virginia: American College of Radiology; 2001. [cited 15 aug 2003]. Available from: http://www.acr.org/departments/ stand_accered/birads/intro.html.

Amin S H, Kuhle CL, Fitzpatrick LA. Comprehensive evaluation of the older women. Mayo Clin Proc. 2003; 78: 1157-85. 
Associação Psiquiátrica Americana (APA) Manual diagnóstico e estatístico de transtornos mentais (DSM-IV-TR-TM). $4^{a}$ ed. Texto revisado. Tradução de Cláudia Dornelles. Porto Alegre: Artes Médicas; 2002.

Anzieu D. O eu - pele. Tradução de Zakie Yazigi, Rosali Mahfuz. São Paulo: Casa do Psicólogo; 1989.

Averill JR, Nunley EP. Grief as an emotion and a disease: a socioconstructionist perspective. In: Strebe W, Stroebe M, Hansson RO. Handbook of bereavement: theory, research and intervention. Cambridge: Cambridge University Press, 1993.

Backmann GA, Leiblum SR. The impact of hormones on menopausal sexuality: a literature review. Menopause. 2004; 11(1):120-30.

Backus VP. Psychiatric aspects of breast cancer. Harv Rev Psychiatry. 2002; 10(5):307-14.

Barni S, Mondin R. Sexual dysfunction in treated breast cancer patients. Ann Oncol. 1997; 8(2): 149-53. 
Barret-Connor E. Hormone replacement therapy. BMJ. 1998; $317(7156): 457-61$.

Basegio DL. Câncer de mama. Rio de Janeiro: Revinter, 1999.

Basson R. Female sexual response: the role of drugs in the management of sexual dysfunction [erratum Obstet Gynecol 2001; 98:522]. Obstet Gynecol 2001; 98:350-3.

Basson R. Women's sexual dysfunction: revised and expanded definitions. CMAJ. 2005; 172(10):1327-33.

Ben-Zur H, Gilbar O, Lev S. Coping with breast cancer: patient, spouse and dyad models. Psychom Med. 2001; 63(1):32-9.

Bland KI, Copeland EM. The breast: comprehensive management of benign and malignant diseases. USA: W. B. Sauders Company, 1991.

Boff RA. Repercussões psicossociais associadas à terapêutica cirúrgica de mulheres com câncer de mama. [dissertação]. São Paulo: Faculdade de Medicina, Universidade de São Paulo, 1999. 
Broeckel JA, Thors CL, Jacobsen PB, Small M, Cox CE. Sexual functioning in long-term cancer survivors treated with adjuvant chemotherapy. Cancer Res Treat. 2002; 75(3):241 - 8.

Bruner DW, Boyd CP. Assessing women's sexuality after cancer therapy: checking assumptions with the focus group technique. Cancer Nurs. 1999; 22(6), $438-47$.

Buković D, Fajdić J, Hrgović Z, Kaufmann M, Hojsak I. Sexual dysfunction in breast cancer survivors. Onkologie. 2005; 28:29-34.

Caliri MHL, Almeida AM, Silva CA. Câncer de mama: a experiência de um grupo de mulheres. Rev. Bras. Cancerol. 1998; 44(3):239-47.

Campos TCP. Psicologia Hospitalar: a atuação do psicólogo em hospitais. São Paulo: E.P.U.; 1995.

Carrasco MJ. Disfunciones sexuales femeninas. Madri: Editorial Síntesis, 2001.

Cawood EH, Bancroft J. Steroid hormones, the menopause, sexuality and well-being women. Psychol Med. 1996; 26: 925-36. 
Chessear ES, Anderson JL. Treatment of breast cancer: doctor / patient communication and psychological implications. Proc R Soc Med. 1975; 68(12): 793-5.

Chevalier J, Gheerbrant A. Dicionário de símbolos: mitos, sonhos, costumes, gestos, formas, figuras, cores, números. Tradução de Vera da Costa e Silva. $10^{\text {a }}$ ed. Rio de Janeiro: José Olympio, 1996. p. 153-6, 628, 809.

Cohen L, Hack TF, De Moor C, Katz J, Goss PE. The effects of type of surgery and time on psychological adjustment in women after breast cancer treatment. Ann Surg Oncol. 2000; 7(6):427-34.

Cunha AG. Dicionário etimológico Nova Fronteira da língua portuguesa. $2^{\mathrm{a}}$ ed. rev. e ampl. Rio de Janeiro: Nova Fronteira, 1998, p.146.

Cyran EM, Crame LA, Palmer L. Physician sex and other factors associated with type of breast cancer surgery in older women. Arch Surg. 2001; 136: $185-91$.

Dali S. Space Eve. In: Descharnes R. Dali a obra pintada. Köln: Taschen; 1997. p.603 
Dali S. Estudos anatômicos. In: Descharnes R. Dali a obra pintada. Köln: Taschen; 1997. p.81

Daune F. Psychological aspects of breast cancer. Rev Med Brux. 1995; 16(4):245-7.

De Lorenzi DRS, Saciloto B. Freqüência da atividade sexual em mulheres menopausadas. Rev Assoc Med Bras. 2006. 52(4):256-60.

Deutsch H. La psicologia de la mujer. Tradução de Felipe Jiménez de Asúa. $2^{\mathrm{a}}$ ed., Buenos Aires: Losada, 1960; v. 2.

Deutsch H. Some Psychoanalytic observations in surgery. Psychosom Med. 1942; 4: 105-15.

Dias E N, Caleffi M. Mastologia atual. Rio de Janeiro: Revinter, 1994.

Dolto F. No jogo do desejo: ensaios clínicos. Tradução de Vera Ribeiro. $2^{\mathrm{a}}$ ed. São Paulo: Ática, 1996 a.

Dolto F. Sexualidade feminina: libido, erotismo, frigidez. Tradução de Roberto Cortes de Lacerda. $3^{\mathrm{a}}$ ed. São Paulo: Martins Fontes, 1996 b. 
Donegan WL, Spratt JS. Cancer of the breast. $4^{\text {th }}$ ed. Philadelphia: W B Saunders; 1995.

Dorval M, Maunsell E, Deschênes L, Brisson J. Type of mastectomy and quality of life for long term breast carcinoma survivors. Cancer. 1998; 83(10), 2130-8.

Dorval M, Maunsell E, Taylor-Brown J, Kilpatrick M. Marital stability after breast cancer. J Natl Cancer Inst. 1999; 91(1):54-9.

Fallowfield LJ. Psychosocial adjustment after treatment for early breast cancer. Oncology (Huntingt). 1990; 4(4):87-97.

Fallowfield LJ, Hall A. Psychosocial and sexual impact of diagnosis and treatment of breast cancer. Br Med Bull. 1991; 47(2):388-99.

Falzoni R. Câncer de mama: história natural e anatomia patológica. In: Halbe HW. Tratado de ginecologia. $3^{a}$ ed. São Paulo: Roca; 2000. p. 2027-41

Fenlon D. Menopause: a problem for breast cancer patients. Eur J Cancer Care. 1995; 4(4): 166-72. 
Fernandes CE, Melo NR, Webha S. editores. Climatério feminino: fisiopatologia, diagnóstico e tratamento. São Paulo: Lemos editorial, 1999.

Fischer RB, Anderson S, Bryant J, Margolese RG, Deutsch M, Fischer ER, Jeong $\mathrm{JH}$, Wolmark N. Twenty year follow-up of a randomized trial comparing total mastectomy, lumpectomy, and lumpectomy plus irradiation for the treatment of invasive breast cancer. N Engl J Med. 2002; 347(16):1233-41.

Foltz AT. The influence of cancer on self concept and life quality. Sem Oncol Nurs. $1987 ; 3(4): 303-12$.

Franco MHP. organizadora. Estudos avançados sobre o luto. Campinas: Livro Pleno; 2002.

Freud S. Três ensaios sobre a teoria da sexualidade. Edição Standard das obras psicológicas completas. Rio de Janeiro: Imago; 1996a. v.7.

Freud S. Luto e melancolia. In: A história do movimento psicanalítico. (1914 - 1916). Edição Standard das obras psicológicas completas. Rio de Janeiro: Imago; 1996b. v.14. p 243 - 66. 
Freud S. Conferência XX: a vida sexual dos seres humanos. A dissolução do complexo de Édipo. In: Conferências introdutórias sobre psicanálise, parte III (1916 - 1917). Edição standard das obras psicológicas completas. Rio de Janeiro, Imago, 1996c. v.16. p. $309-24$.

Freud S. Conferência XXI: o desenvolvimento da libido e as organizações sexuais. In: Conferências introdutórias sobre psicanálise, parte III (1916 1917). Edição Standard das obras psicológicas completas. Rio de Janeiro, Imago, 1996d. v.16. p. $325-42$.

Freud S. A dissolução do complexo de Édipo. In: O ego e o id e outros trabalhos. Edição standard das obras psicológicas completas. Rio de Janeiro: Imago; 1996e. v.19. p. 191 - 9.

Frischenschlarger O, Balogh B, Predovic M. Psychosocial effects of plastic surgery reconstruction of the female breast following amputation for malignant / benign tumor. Psychother Psychosom Med Psychol. 1990; 40(11):441-7.

Frost MH, Schaid DJ, Sellers TA, Slezak JM, Arnold PG, Woods JE, Petty PM, Johnson JL, Sitta DL, McDonnelL SK, Rummans TA, Jenkins RB, Sloan JA, Hartmann LC. Long-term satisfaction and psychological and 
social function following bilateral prophylactic mastectomy. JAMA. 2000a; 284(3):319-24.

Frost MH, Suman VJ, Rummans TA, Dose AM, Taylor M, Novotny P, Johnson R, Evans RE. Physical, psychological and social well-being of women with breast cancer: the influence of disease phase. PsychoOncology. 2000b; 9(3):221-31.

Fung KW, Lau Y, Fielding R, Or A, YIP AW. The impact of mastectomy, breast conserving treatment and the immediate breast reconstruction on the quality of life of Chinese women. ANZ J Surg. 2001; 71(4):202-6.

Ganz PA, Schag AC, Lee JJ, Polinsky ML, Tan SL. Breast conservation versus mastectomy Is there a difference in psychological adjustment or quality of life in the year after surgery? Cancer 1992; 69(7):1729-38.

Ganz PA, Rowland JH, Desmond K, Meyerowitz BE, Wyatt GE. Life after breast cancer: understanding women's health related quality of life and sexual functioning. J Clin Oncol 1998; 16(2):501-14.

Ganz PA, Rowland JH, Desmond KA, Meyerowitz BE, Belin TR, Wyatt GE. Predictors of sexual health in women after a breast cancer diagnosis. $J$ Clin Oncol. 1999; 17(8):2371-80. 
Ganz PA, Greendale GA, Petersen L, Zibecchi L, Kahn B, Belin TR. Managing menopausal symptoms in breast cancer survivors: results of a randomized controlled trial. J Natl Cancer Inst. 2000; 92(13): 1054-64.

Ganz PA, Gail AG, Petersen L, Kahn B, Bower J E. Breast cancer in older women: quality of life and psychosocial adjustment in the 15 months after diagnosis. J Clin Oncol. 2003; 21(21):4027-33.

Ganz PA, Gail AG, Petersen L, Kahn B, Bower JE. Breast cancer in younger women: reproductive and late health effects of treatment. J Clin Oncol. $2003 ; 21(22): 4184-93$.

Ganz PA, Kwan L, Stanton A L, Rowland JH, Meyerowitz BE, Bower JE, Belin T R. Quality of life at the end of primary treatment of breast cancer: first results from the moving beyond cancer randomized trial. J Natl Cancer Inst. 2004; 96(5):376-87.

Garcia-Roza LA. Freud e o inconsciente. $15^{\mathrm{a}}$ ed. Rio de Janeiro: Jorge Zahar, 1998.

Góes JCS. Mastectomy by periareolar approach with immediate breast reconstruction. Rev Soc Bras Cir Plast Estet Reconstr 1995; 10(3):44-55. 
Góes JCS, Garcia EB. Immediate reconstruction with tissue expander after mastectomy by periareolar approach. The Breast Journal. 1996; 2(1): 716.

Goin MK, Goin JM. Midlife reactions to mastectomy and subsequent breast reconstruction. Arch Gen Psychiatry. 1981; 38(2):225-7.

Greendale G, Petersen L, Zibecchi L, Ganz PA. Factors related to sexual function in postmenopausal women with a history of breast cancer. Menopause. 2001; 8(2):111-9.

Greene FI, Page D, Morrow M, Balch CM, Haller DG, Frintz A, Fleming ID. editors. AJCC Cancer Staging Manual. $6^{\text {th }}$ ed. New York: Springer; 2002.

Greer G. Mulher: maturidade e mudança. Tradução de Analaura Faria de Antezana. São Paulo: Augustus; 1994.

Gupta P, Sturdee DW, Palin SL, Majumder K, Fear R, Marshall T, Paterson I. Menopausal symptoms in women treated for breast cancer: the prevalence and severity of symptoms and their perceived effects on quality of life.Climacteric. 2006; 9(1):49-58. 
Harcourt DM, Rumsey NJ, Ambler NR, Cawthorn SJ, Reid CD, Maddox PR, Kenealy JM, Rainsbury RM, Umpleby HC. The psychological effect of mastectomy with or without breast reconstruction: a prospective, multicenter study. Plast Reconstr Surg 2003; 111(3):1060-8.

Hartcher MB, Fallowfield L, A'herm R. The psychosocial impact of bilateral prophylactic mastectomy: prospective study using questionnaires and semistructured interviews. BMJ. 2001; 322(7278): 76.

Hermann RE, Esselsty CB Jr; Grundefest-Broniatowski S, Steiger E, Vogt DP, Brouglian TA, Dpwden RV, Hardesty, I Medendorp SV, Boyett JM. Partial mastectomy without radiation is adequate treatment for patients with stage 0 and 1 carcinoma of the breast. Surg Gynecol Obstet. 1993; 177(3): 247-53.

Holmberg SK, Scott LL, Alexy W, Fife B L. Relationship issues of women with breast cancer. Cancer Nurs. 2001; 24(1): 53-60.

Hopwood P, Lee A, Shenton A, Brain A, Lalloo F, Evans G, Howell A. Clinical follow-up after bilateral risk reducing ('prophylatic') mastectomy: mental health and body image. Psychooncology. 2000; 9(6): 462-72. 
Hordern A. Intimancy and sexuality for women with breast cancer. Cancer Nurs. 2000; 23(3):230-6.

Horney K. Psicologia feminina. Tradução de Talita M. Rodrigues. Rio de Janeiro: Bertrand Brasil; 1991.

Howell JR, Reynolds $3^{\text {rd }}$ CF, Thase ME, Frank E, Jennings JR, Houck PR, Berman S, Jacobs E, Kupfer DJ. Assessment of sexual function, interest and activity in depressed men. J Affect Disord. 1987; 13(1): 61-6.

Hughes MK. Sexuality and the cancer survivor: a silent coexistence. Cancer Nurs. 2000; 23(6): 477-82.

Instituto Nacional do Câncer (INCA). Ministério da Saúde. Estimativa de incidência de mortalidade por câncer de mama no Brasil (2003). [citado 20 mai 2003]. Disponível em http://wwwincagovbr/estimativas /2003/indexasp?link=tabelaestadosasp\&UF=BR

Instituto Nacional do Câncer (INCA). Ministério da Saúde. Estimativa de incidência de mortalidade por câncer de mama no Brasil (2005). [citado 16 dez 2004]. Disponível em http://www.inca.gov.br/estimativa/2005. 
Instituto Nacional do Câncer (INCA). Ministério da Saúde. Estimativa de incidência de mortalidade por câncer de mama no Brasil (2006). [citado 18 jan 2006]. Disponível em http://www.inca.gov.br/estimativa/2006.

Instituto Nacional do Câncer (INCA). Ministério da Saúde. Estimativa de incidência de mortalidade por câncer de mama no Brasil (2008). [citado 15 dez 2007]. Disponível em http://www.inca.gov.br/estimativa/2008.

Irwing L, Bennetts A. Quality of life after breast conservation mastectomy or mastectomy: a systematic review. Aust N Z J Surg. 1997; 67(11):750-4.

Jahkola T. Self-perception of women after early breast cancer surgery. Eur J Surg Oncol. 1998; 24(1):9-14.

Janni W, Rjosk D, Dimpfl Th, Haertl K, Strobl B, Hepp F, Hanke A, Bergauer F, Sommer H. Quality of life influenced by primary surgical treatment for stage I-III breast cancer long-term follow-up of a matched-pair analysis. Ann Surg Oncol. 2001; 8(6):542-8.

Jung CG. O homem e seus símbolos. Tradução de Maria Lúcia Pinho. Rio de Janeiro: Nova Fronteira; 1996. 
Jung CG. O significado da constituição e da herança para a psicologia. In: A Dinâmica do Inconsciente. Tradução de Pe Dom Mateus Ramalho Rocha. $3^{\text {a }}$ ed. Petrópolis: Vozes; 1998. v. VIII.

Kaiser FE. Sexual function and older cancer patient Oncology (Huntingt). $1992 ; 6(2): 112-8$

Kaplan HI, Sadock B J, Grebb J A. Compêndio de psiquiatria: ciências do comportamento e psiquiatria clínica. Tradução de Dayse Batista. $7^{\mathrm{a}}$ ed Porto Alegre: Artes Médicas; 1997.

Kaplan HS. O desejo sexual e novos conceitos e técnicas da terapia do sexo. Rio de Janeiro: Nova Fronteira; 1979.

Kaplan HS. A neglected issue: the sexual side effects of current treatments for breast cancer. J Sex Mar Ther. 1992; 18(1):3-19.

Kaplan HS. Transtornos do desejo sexual: regulação disfuncional da motivação sexual. Tradução de Jussara N. Burnier. Porto Alegre: Artes Médicas; 1999. 
Kennedy SH, Dickens SE, Eisfeld BS, Bagby RM. Sexual Dysfunction before antidepressant therapy in major depression J Affect Disord. 1999; 56(2-3): 201-8.

Kennedy SH, Dickens SE, Eisfeld BS, Bagby RM. Antidepressant induced sexual dysfunction during treatment with moclobemide, paroxetine, sertaline and venlafaxine. J Clin Psychiatry. 2000; 61(4): 276-81.

Knobf MT. Natural menopause and ovarian toxicity associated with breast cancer therapy. Oncol Nurs Forum. 1998; 25(9):1519-30.

Kornblith AB, Ligibel J. Psychosocial and sexual functioning of survivors of breast cancer. Semin Oncol. 2003; 30(6):799-813.

Kovalevsky G. Female sexual dysfunction and use of hormone therapy in post menopausal women. Semin. Reprod. Med. 2005; 23(2): 180-7.

Kübler-Ross E. Sobre a morte e o morrer: o que os doentes têm a ensinar a médicos, enfermeiras, religiosos e aos seus próprios parentes. Tradução de Paulo Menezes. $7^{a}$ ed. São Paulo: Martins Fontes; 1996. 
Laplance J. Problemáticas II: Castração simbolizações. Tradução de Álvaro Cabral $1^{\mathrm{a}}$ ed, São Paulo: Martins Fontes; 1988.

LeMone P. Analysis of a human phenomenon: self-concept. Nursing Diagnosis. 1991; 2:126-30.

Le Shan L. O câncer como ponto de mutação: um manual para pessoas com câncer, seus familiares e profissionais de saúde. Tradução de Denise Bolanho. São Paulo: Summus; 1992.

Lim J, Hoe AL, Wong CY, Soo KC. Sexuality of women after mastectomy. Ann Acad Med Singapore. 1995; 24(5):659 - 63.

Lima CP. Genética Humana. 2a ed. São Paulo: Harper \& Row do Brasil; 1984.

Lobo RA. Hormone replacement therapy: oestrogen replacement after treatment for breast cancer? Lancet. 1993; 341(8856): 1313-4.

Maguire P. Late adverse psychological sequelae of breast cancer and its treatment. Eur J Surg Oncol. 1999; 25(3): 317-20. 
Mahoney JM, Carroll RA. The impact of breast cancer and its treatment on marital functioning. J Clin Psychol Med Settings. 1997; 4: 397-415.

Malata CM, Mcintosh SA, Puruschotham AD. Immediate breast reconstruction after mastectomy for cancer British Journal of Surgery. $2000 ; 87(11): 1455-72$.

Maluf MFM, Mori LJ, Barros ACSD. O Impacto psicológico do câncer de mama. Rev Bras. Cancol. 2005; 51(2): 149-54.

Maluf MFM. A sexualidade das pacientes submetidas à mastectomia radical [monografia] São Paulo: Curso de Sexualidade Humana, Faculdade de Medicina, Universidade de São Paulo, 2004.

Maluf MFM, Scanavino MT, Barros ACSD. A sexualidade das pacientes submetidas à mastectomia radical. Rev Bras Mastol. 2006a; 1: p.27 - 54 .

Maluf MFM. Mastectomia radical e sexualidade feminina. São Paulo: Livraria Médica Paulista Editora; 2006b.

Maluf MFM. O luto no câncer de mama. In: Piato S, Piato J R M. Doenças da mama. Rio de Janeiro: Revinter; 2006c, p.235-9. 
Maluf MFM, Barros ACSD. Sexualidade feminina em condições especiais: câncer de mama In: Disfunções sexuais femininas: a fisioterapia como recurso terapêutico. 1 ed. São Paulo: Livraria Médica Paulista Editora; 2006d, p. 115-123.

Margolis G, Goodman RL, Rubin A. Psychological effects of breastconserving cancer treatment and mastectomy. Psychosomatics. 1990; 31(1): 33-9.

Master WH, Johnson V E. A conduta sexual humana. $2^{\mathrm{a}}$ ed. Rio de Janeiro: Civilização Brasilera; 1976.

Mckee JR AL, Schover LR. Sexuality rehabilitation. Cancer. 2001; 92 (Suppl 4): 1008-12.

McPhail G, Wilson S. Women's experience of breast conserving treatment fro breast cancer. Eur J Caner Care. 2000; 9:144-50.

Meechan G, Collins J, Petrie KJ. The relationship of symptoms and psychological factors to delay seeking medical care for breast symptoms. Prev Med. 2003; 36(3):374-8. 
Meyerowitz BE, Desmond KA, Rowland JH, Wyatt GE, Ganz PA. Sexuality following breast cancer. J Sex Marital Ther. 1999; 25(3):237-50.

Miller SH, Graham WP. Breast reconstruction after radical mastectomy. Am Farm Physican. 1975; 11(5):97-101.

Mock V. Body image in women treated for breast cancer. Nurs Res. 1993; 42(3):153-7.

Mooradian AD, Greiff V. Sexuality in older women. Arch Intern Med. 1990; 150: 1033-8.

Moorey S, Greer S. Psychological therapy for patients with cancer. A new approach. Oxford: Heinemann; 1989.

Moyer A. Psychological outcomes of breast conserving surgery versus mastectomy: a meta-analytic review. Health Psychol. 1997; 16(3):284-98.

Nagera H. A. sexualidade feminina e o complexo de Édipo. Tradução de Joseti Marques Xisto Rio de Janeiro: Imago; 1983.

Nissen MJ, Swenson KK, Ritz LJ, Farrell JB, Sladek ML, Lally RM. Quality of life after breast carcinoma surgery: a comparison of three surgical procedures. Cancer. 2001; 91 (7): 1238-46. 
Northouse LL, Dorris G, Charron-Moore C. Factors affecting couples' adjustment to recurrent breast cancer. Soc Sci Med. 1995; 41(1):69-76.

Okamura H, Watanabe T, Narabayashi M, Katsumata N, Ando M, Adachi I, Akechi T, Uchitomi Y. Psychological distress following first recurrence of disease in patients with breast cancer: prevalence and risk factors. Breast Cancer Res Treat. 2000; 61(2):131-7.

Oktay JS. Phychological aspects of breast cancer. Lippincotts Prim Care Pract. 1998; 2(2): 149-59.

Organización Mundial de la Salud (OMS). Investigaciones sobre la menopausia. Informe de un grupo científico de la OMS. Serie de informes técnicos-670. Ginebra: OMS; 1981. p.8.

Organização Mundial da Saúde (OMS). Classificação internacional de doenças e problemas relacionados à saúde (CID-10). 10ª ed. São Paulo: EDUSP; 1995. v.1.

Organização Mundial da Saúde (OMS). Classificação internacional de doenças para oncologia (CID-0). $2^{\mathrm{a}}$ ed. São Paulo: Edusp; 1996. p. 12.

Parkers C M. Luto: estudo sobre a perda na idade adulta. Tradução de Maria Helena Franco Bromberg. São Paulo: Summus; 1998. 
Parvanova VM, Pandova VV, Garanina ZM. Conservative therapy of I and II stage breast cancer: successful alternative to modified radical mastectomy. Vopr Onkol. 2001; 47(1): 45-8.

Pelusi J. Sexuality and body image. Am J Nurs. 2006; 106 (3 suppl) :32-8.

Phillips NA. Female sexual dysfunction: evaluation and treatment. Am Fam Physician. 2000; 62(1):127-36, 141-2.

Pinto-Neto AM, Paiva LHSC, Fonsechi-Carvanan GA. Climatério: epidemiologia. In: Fernandes CE. Editor. Menopausa: diagnóstico e tratamento. São Paulo: Segmento; 2003. p 21-9.

Potts A, Short R. Historia de la sexualidad desde Adán e Eva. Tradução de Carmen Martínez Gimeno. Madrid: Cambridge University Press; 2001.

Poulsen B, Graversen HP, Beckmann J, Blichert-Toft M A. comparative study of post-operative psychosocial function in women with primary operable breast cancer randomized to breast conservation therapy or mastectomy. Eur J Surg Oncol. 1997; 23(4): 327-34. 
Pozo C, Carver CS, Noriega V, Harris SD, Robinson DS, Ketcham AS, Legaspi A, Moffat FL, Clark KC. Effects of mastectomy versus lumpectomy on emotional adjustment to breast cancer: a prospective study of the first year postsurgery. J Clin Oncol. 1992; 10(8):1292-8.

Rabinowitz B. Understanding and intervening in breast cancer's emotional and sexual effects. Curr Women's Health Reports. 2002; 2(2):140-7.

Reichman B, Green K. Breast cancer in young women: effects of chemotherapy on ovarian function, fertility, and birth defects. J Natl Cancer Instit Monogr. 1994; 16: 125-9.

Rennó Junior J, Guimarães DBS, Sant'anna Santos AD, Fernandes CE, Mello NR. Climatério e Menopausa. In: Cordas TA, Salzano FT, editores. Saúde mental da mulher. São Paulo: Atheneu; 2004. p. 49-71.

Resnick B, Belcher AE. Breast reconstruction: options, answers and support for patients making a difficult personal decision. Am J Nurs. 2002; 102(4):26-33. 
Rodrigues DP, Melo EM, Sila RM, Mamede MV. O suporte social para atender as necessidades de mulheres mastectomizadas. Rev Bras Cancerol. 1998; 44(3):231-8.

Rogers M, Kristjanson LK. The impact on sexual functioning of chemotherapy induced menopause in women with breast cancer. Cancer Nursing. 2002; 25(1):57-65.

Rowland JH, Desmond KA, Meyerowitz BE, Belin TR, Wyatt GE, Ganz PA. Role of breast reconstructive surgery in physical and emotional outcomes among breast cancer survivors. J Natl Cancer Inst. 2000; 92(17):1422-9.

Schain WS, D'angelo TM, Dunn ME, Lichter AS, Pierce LJ. Mastectomy versus conservative surgery and radiation therapy psychosocial consequences. Cancer. 1994; 73(4):1221-8.

Schávelzon J. Sobre psicossomática e câncer. In: Mello Filho J e col Psicossomática hoje. Porto Alegre: Artes Médicas; 1992. p 215-26.

Schover LR. The impact of breast cancer on sexuality, body image and intimate relationships. Ca Cancer J Clin. 1991; 41(2):112-20. 
Schover LR. Sexuality and body image in younger women with breast cancer. J Natl Cancer Inst Monogr. 1994; 16: 177-82.

Schover LR, Yetman RJ, Tuason LJ, Meisler E, Esselstyn CB, Hermann RE, Grundfest-Broniatowski S, Dowden RV. Partial mastectomy and breast reconstruction A comparison of their effects on psychosocial adjustment, body image and sexuality. Cancer 1995; 75(1): 54-65.

Scott JL, Halford WK, Ward BG. United we stand? The effects of a couplecoping intervention on adjustment to early stage breast cancer or gynecological cancer. J Consult Clin Pstchol. 2004; 72(6):1122-35.

Shimozuma K, Ganz PA, Petersen L, Hirji K. Quality of life in first year after breast cancer surgery: rehabilitation needs and patterns of recovery. Breast Cancer Res Treat. 1999; 56(1):45-57.

Simanke R T. Formação da teoria freudiana das psicoses. Rio de Janeiro : 34; 1994.

Silva HMS, Coelho Júnior JL, Vianna WJA, Avelar JTC, Reis JHP, Ferrari BL. Patologias malignas da mama. In: Vianna LC, Martins M, Geber S. Ginecologia. 2a ed. São Paulo: Medsi; 2001. p. 808-34. 
Soules MR, Sherman S, Parrott E, Rebar R, Santoro N, Utian W, Woods N. Executive summary: Stages of Reproductive Aging Workshop (STRAW). Fertility \& Sterility. 2001; 76(5):874-8.

Souza AZ, Aguiar LF, Hegg R. Câncer de mama: tratamento radical e prognóstico. In: Halbe HW. Tratado de ginecologia. $3^{a}$ ed. São Paulo: Roca; 2000. p. 2065-7.

Sundquist K, Yee L. Sexuality and body image after cancer. Aust Fam Physician. 2003; 32(1-2):19-23.

Taylor SE, Lichtman RR, Wood J V, Bluming AZ, Dosik GM, Leibowitz RL. Illness-related factors in psychological adjustment to breast cancer. Cancer. 1985; 55(10): 2506-13.

Taylor KL, Lamdn RM, Siegel JE, Shelby R, Hrywna M, Moran-Klimi K. Treatment regimen, sexual attractiveness concerns and psychological adjustment among African American breast cancer patients. Psycooncology. 2002; 11(6): 505-17.

Thors CL, Broeckel JA, Jacobsen PB. Sexual functioning in breast cancer survivors. Cancer Control. 2001; 8(5):442-8. 
Yilmazer N, Aydiner A, Ozkan S, Asley I, Bilge NA. Comparison of body image, self-esteem and social support in to total mastectomy and breastconserving therapy in Turkish women. Support Care Cancer. 1994; 2(4): 238-41.

Young-McCaughan SRN. Sexual functioning in women with breast cancer after treatment with adjuvant therapy. Cancer Nurs. 1996; 19(4):308-19.

Yurek D, Farrar W, Andersen BL. Breast cancer surgery: comparing surgical groups and determining individual differences in postoperative sexuality and body change stress. J Consult Clin Psychol. 2000; 68(4): 697-709.

Urbánek V, Weiss $P$, Kofránek J, Albl M. Sexuality in women after treatment of malignant breast tumors. Ceska Gynekol. 1992; 57(7):353-65.

Urbánek V, Weiss $\mathrm{P}$, Kofránek J, Albl M. Psychosexual reactions in women after treatment of breast carcinoma. Ceska Gynekol 1994a, 59(5):262-4.

Urbánek V, Weiss $\mathrm{P}$, Kofránek J, Albl M. Sexual function in women with breast carcinoma en relation to the time interval after mastectomy Ceska Gynekol. 1994b; 59(6):309-13.

Valle ERM. Câncer infantil: compreender e agir Campinas: Editorial Psy; 1997. 
Van't Spijker A, Trijburg RW, Duivenvoorden HJ. Psychological sequelae of cancer diagnosis: a meta-analytical review of 58 studies after 1980. Psychossom Med. 1997; 59(3):280-93.

Veronesi U, Banfi A, Vecchio M Del, Saccozzi R, Clemente C, Greco M, Luini A, Marubini E, Muscolino G, Rilke F, Sacchini V, Salvatori B, Zecchini A, Zucali R. Comparison of Halsted mastectomy with quadrantectomy axillary dissection, and radiotherapy in early breast cancer: long term results. Eur J Cancer Clin Oncol. 1986; 22(9):1085-9.

Veronesi U, Cascinelli N, Mariani L, Greco M, Saccozzi R, Luini A, Aguilar M, Marubini E. Twenty year follow-up of a randomized study comparing breast conserving surgery with radical mastectomy for early breast cancer. N Engl J Med. 2002; 347(16):1227-32.

Vos P, Garssen B, Visser AP, Duivenvoorden HJ, Haes da HCJ. Early stage breast cancer: explaining level of psychosocial adjustment using structural equation modeling. J Behav Med. 20004; 27(6):557-80.

Wapnir IL, Cody RP, Greco RS. Subtle differences in quality of life after breast cancer surgery. Ann Surg Oncol. 1999; 6(4):359-66.

Watts RJ. Sexual functioning, health beliefs and compliance with high blood pressure medications. Nurs Res. 1982; 31(5):278-83. 
Watts RJ. Sexual function of diabetic and non diabetic African American women: a pilot study. J Natl Black Nurses Assoc. 1994; 7(1):50-9.

Wilmoth MC, Townsend JA. A comparison of the effects of lumpectomy versus mastectomy on sexual behaviours. Cancer Pract. 1995; 3(5):27985.

Wilmoth MC, Ross JA. Women's perception breast cancer treatment and sexuality. Cancer Pract. 1997; 5(6):353-9.

Wilmoth M C. The aftermath of breast cancer: an altered sexual self Cancer Nurs $2001 ; 24(4): 278-86$.

Wilmoth MC. Sexuality. [cited 20 may 2003]. Available from: http://wwwonsorg/images/library/ons publications/pdfs/books/dimensions5 pdf.

Wyatt GE, Desmond K, Ganz PA, Rowland JH, Ashing-Giwa K, Meyerowitz BE. Sexual functioning and intimacy in African American and white breast cancer survivors: a descriptive study. Womens Health. 1998; 4(4): 385405. 


\section{APÊNDICE 1}

CLASSIFICAÇÃO DAS NEOPLASIAS MAMÁRIAS SEGUNDO O CID 10 (1995)

\begin{tabular}{ll}
\hline $\begin{array}{c}\text { Código CID } \\
\text { (C.50) }\end{array}$ & \multicolumn{1}{c}{ Sub-localização } \\
\hline C 50.0 & mamilo e auréola \\
C 50.1 & porção central \\
C 50.2 & quadrante superior interno \\
C 50.3 & quadrante inferior interno \\
C 50.4 & quadrante superior externo \\
C 50.5 & quadrante inferior externo \\
C 50.6 & prolongamento axilar \\
C 50.8 & neoplasia maligna da mama com lesão invasiva \\
C 50.9 & neoplasia maligna da mama, não especificada \\
\hline
\end{tabular}

FONTE: OMS, 199 


\section{APÊNDI CE 2}

\section{ESTADI AMENTO TMN DO CÂNCER DE MAMA}

\begin{tabular}{|c|c|c|c|}
\hline Estadiamento & $\begin{array}{l}\text { Tumor primário } \\
\text { (T) }\end{array}$ & $\begin{array}{l}\text { Linfonodos } \\
\text { regionais }(\mathrm{N})\end{array}$ & $\begin{array}{l}\text { Metástases à } \\
\text { distância (M) }\end{array}$ \\
\hline $\begin{array}{l}\text { Estádio } 0 \\
\text { (carcinoma de mama in } \\
\text { situ) }\end{array}$ & Tis & No & MO \\
\hline Estádio I & $\mathrm{T} 1^{*}$ & No & MO \\
\hline \multicolumn{4}{|l|}{ Estádio II } \\
\hline Estádio II A & TO & N1 & MO \\
\hline & $\mathrm{T} 1^{*}$ & N1 & MO \\
\hline & T2 & No & MO \\
\hline Estádio II B & T2 & N1 & MO \\
\hline & T3 & No & MO \\
\hline \multicolumn{4}{|l|}{ Estádio III } \\
\hline Estádio III A & T0 & N2 & MO \\
\hline & $\mathrm{T} 1^{*}$ & N2 & M0 \\
\hline & $\mathrm{T} 2$ & N2 & MO \\
\hline & T3 & N1, N2 & MO \\
\hline Estádio III B & T4 & N0, N1, N2 & M0 \\
\hline Estádio III C & Qualquer T & N3 & MO \\
\hline Estádio IV & Qualquer T & Qualquer N & M1 \\
\hline
\end{tabular}

FONTE:Greene et al, 2002

NOTA: *T1 inclui o T1mic 


\section{APÊNDICE 3 \\ TNM CLASSIFICAÇÃO CLÍNICA}

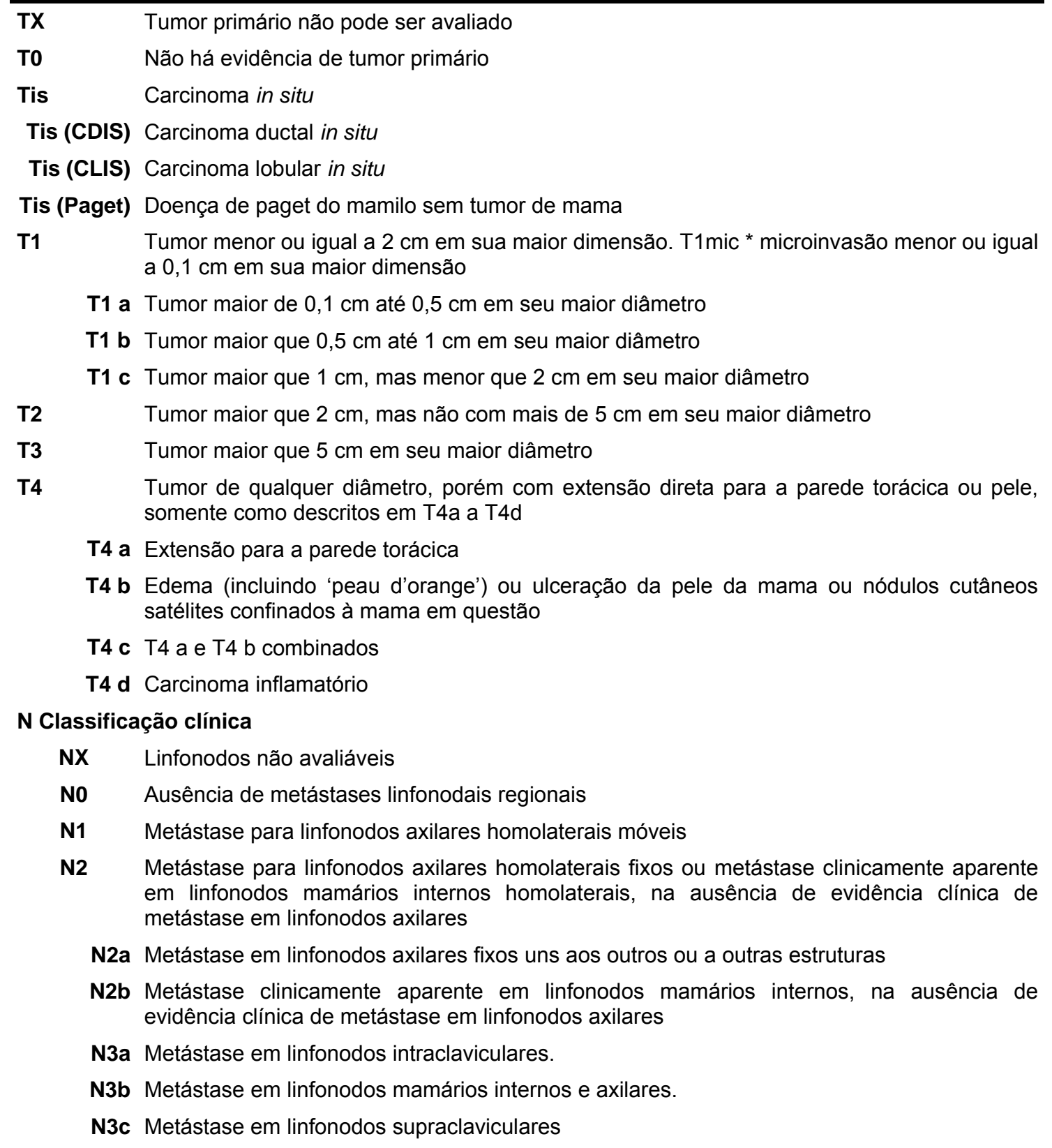

\section{Classificação clínica}

MX A presença de metástase à distância não pode ser avaliada

Mo Ausência de metástases à distância

M1 Metástases à distância

FONTE:Greene et al, 2002

NOTA: * quando há focos múltiplos de microinvasão, somente o tamanho maior é utilizado para a classificação da microinvasão. A presença de múltiplos focos de microinvasão deve ser anotada como se faz com os carcinomas invasores extensos múltiplos 


\title{
APÊNDICE 4
}

\section{pTNM - CLASSIFICAÇÃO PATOLÓGICA}

\author{
Linfonodos regionais $(\mathrm{pN})$ \\ pNX Linfonodos regionais não podem ser avaliados para estudo (não removidos para estudo ou \\ previamente removidos) \\ pNo Ausência de metástase em linfonodos regionais \\ pN1mi Micrometástases (maior que 0,2mm porém não maior que $2 \mathrm{~mm}$ em sua maior dimensão) \\ pN1 Metástase em 1-3 linfonodos axilares homolaterais, e/ou linfonodos mamários internos \\ homolaterais com metástase microscópica detectada por dissecção de linfonodo sentinela, \\ porém não clinicamente aparente.
}

pN1a Metástase em 1-3 linfonodos axilares incluindo pelo menos um maior que $2 \mathrm{~mm}$ em sua maior dimensão.

pN1b Metástase microscópica em linfonodos mamários internos detectada por dissecção de linfonodo sentinela, porém não clinicamente aparente.

pN1c Metástase em 1-3 linfonodos axilares e metástase em linfonodos mamários internos detectada por dissecção de linfonodo sentinela, porém não clinicamente aparente.

pN2 Metástase em 4-9 linfonodos axilares homolaterais ou em linfonodos mamários internos homolaterais, clinicamente aparente, na ausência de metástase em linfonodos axilares.

pN2a Metástase em 4-9 linfonodos axilares incluindo pelo menos um maior que $2 \mathrm{~mm}$.

pN2b Metástase em linfonodos mamários internos, clinicamente aparentes, na ausência de metástase em linfonodos axilares.

pN21c Metástase em 1-3 linfonodos axilares e metástase em linfonodos mamários internos detectada por dissecção de linfonodo sentinela, porém não clinicamente aparente.

pN3 Metástase em 10 ou mais linfonodos axilares homolaterais; ou em linfonodos intraclaviculares homolaterais; ou metástase clinicamente aparente em linfonodos mamários internos homolaterais, na presença de um ou mais linfonodos axilares positivos; ou em mais de 3 linfonodos axilares clinicamente negativos, metástase microscópica em linfonodos mamários internos; ou em linfonodo supraclaviculares homolaterais.

pN3a Metástase em 10 ou mais linfonodos axilares (pelo menos um maior que $2 \mathrm{~mm}$ ) ou metástase em linfonodos intraclaviculares.

pN3b Metástase clinicamente aparente em linfonodos mamários internos, na presença de linfonodos axilares positivos; ou metástase em mais de 3 linfonodos axilares e em linfonodos mamários internos com metástase microscópica detectada por dissecção de linfonodo sentinela, porém não clinicamente aparente.

pN3c Metástase em linfonodos supraclaviculares

pN3 Metástase para linfonodos da cadeia mamária homolateral.

PM As categorias $\mathrm{pM}$ correspondem às categorias $\mathrm{M}$

FONTE:Greene et al, 2002 


\section{APÊNDICE 5 \\ CATEGORIAS DE AVALIAÇÃO BI-RADS (2003)}

\begin{tabular}{|c|c|}
\hline Categorias & Avaliação \\
\hline BI-RADS 0 & Necessita de uma avaliação adicional da imagem latente \\
\hline BI-RADS 1 & Negativo \\
\hline BI-RADS 2 & Achado benigno \\
\hline BI-RADS 3 & Provável achado benigno - pequeno intervalo de seguimento \\
\hline BI-RADS 4 & Suspeita de anormalidade - considerar a possibilidade de biópsia \\
\hline BI-RADS 4A & Baixa suspeita de malignidade \\
\hline BI-RADS 4B & Média suspeita de malignidade \\
\hline BI-RADS 4C & Moderada suspeita de malignidade \\
\hline BI-RADS 5 & Alto indício de malignidade - tomada de ação apropriada \\
\hline BI-RADS 6 & $\begin{array}{l}\text { Confirmação de achados malignos por biópsia mas antes de terapias } \\
\text { definitivas como ressecção cirúrgica, radioterapia, quimioterapia ou } \\
\text { mastectomia. }\end{array}$ \\
\hline
\end{tabular}

